University of Louisville

ThinkIR: The University of Louisville's Institutional Repository

Electronic Theses and Dissertations

$5-2017$

\title{
The military meets the university : mapping issues of literacy sponsorship across military and academic settings.
}

Ashley Ludewig

University of Louisville

Follow this and additional works at: https://ir.library.louisville.edu/etd

Part of the Rhetoric and Composition Commons

\section{Recommended Citation}

Ludewig, Ashley, "The military meets the university : mapping issues of literacy sponsorship across military and academic settings." (2017). Electronic Theses and Dissertations. Paper 2629.

https://doi.org/10.18297/etd/2629

This Doctoral Dissertation is brought to you for free and open access by ThinkIR: The University of Louisville's Institutional Repository. It has been accepted for inclusion in Electronic Theses and Dissertations by an authorized administrator of ThinkIR: The University of Louisville's Institutional Repository. This title appears here courtesy of the author, who has retained all other copyrights. For more information, please contact thinkir@louisville.edu. 


\title{
THE MILITARY MEETS THE UNIVERSITY: MAPPING ISSUES OF LITERACY SPONSORSHIP ACROSS MILITARY AND ACADEMIC SETTINGS
}

\author{
By Ashley Ludewig \\ B.A., South Dakota State University, 2010 \\ M.A., Southern Illinois University - Carbondale, 2012
}

A Dissertation Submitted to the Faculty of the College of Arts and Sciences of the University of Louisville in Partial Fulfillment of the Requirements for the Degree of

Doctor of Philosophy in English/Rhetoric and Composition

Department of English

University of Louisville

Louisville, Kentucky

May 2016 

THE MILITARY MEETS THE UNIVERSITY: MAPPING ISSUES OF LITERACY SPONSORSHIP ACROSS MILITARY AND ACADEMIC SETTINGS

\author{
By Ashley Ludewig \\ B.A., South Dakota State University, 2010 \\ M.A., Southern Illinois University - Carbondale, 2012
}

A Dissertation Approved on

April 20, 2017

by the following Dissertation Committee:

Bronwyn T. Williams, Director

Stephen Schneider

Susan Ryan

D. Alexis Hart 


\section{DEDICATION}

This dissertation is dedicated to my family, to the student veterans who participated in this study, and to the men and women of the United States Armed Forces. 


\section{ACKNOWLEDGEMENTS}

I want to thank Dr. Bronwyn T. Williams for his steadfast support and mentorship — not just during the completion of this project, but since I first became a student at the University of Louisville. His willingness to share his time and his thoughtful responses my work have been invaluable to me. I am also grateful for the support of Dr. Stephen Schneider and Dr. Susan Ryan, both of whom offered distinct perspectives on this project that made its goals clearer and its arguments stronger. Additionally, I want to thank Dr. D. Alexis Hart, who graciously took me under her wing and welcomed me into the world of Veterans Studies. Her generosity and encouragement are what finally helped me believe this project was both timely and useful to student veterans and our field.

I also owe a huge debt of gratitude to my friends and colleagues at the University of Louisville. Every step of the way, I knew I had mentors I could rely on and fellow students I could lean on. We held each other up through the hardest phases of this program and celebrated all of our victories together. I am endlessly proud of what we have been able to accomplish together.

And, finally, I wish to thank my family and friends who cheered me on from afar as I completed this degree and this dissertation. They have never failed to welcome me with love and enthusiasm when I had time to visit or to make sure I felt their support from across state lines when I could not. I know I always have a home wherever they are, and that means the world to me. 


\section{ABSTRACT \\ THE MILITARY MEETS THE UNIVERSITY: MAPPING ISSUES OF LITERACY SPONSORSHIP ACROSS MILITARY AND ACADEMIC SETTINGS}

Ashley Ludewig

April 20, 2017

This dissertation is grounded in scholarship on communities of practice and literacy sponsorship and aims to contribute to a growing body of research about the literacy practices of student veterans. Rather than focusing on the impact of trauma or service-related injuries, this study demonstrates the influence that a military learning environment can have on a veteran's subsequent experiences with college writing. Chapter 1 includes a brief history of the military's impact on higher education and an overview of the existing scholarship on student veterans' academic writing. I also review scholarship on communities of practice in literacy studies and literacy sponsorship in order to establish the critical lens through which I analyzed my participants' experiences. Chapter 2 describes the procedures I followed for recruiting participants, structuring interviews, and analyzing data.

In Chapter 3, I demonstrate how the form of literacy sponsorship my participants experienced in the military is both collaborative and modeled after a master-apprentice relationship. Moreover, I contend that this structure reinforces values such as shared authorship, shared labor, and collective responsibility. In Chapter 4, I share participants' concerns about authority, institutional structure and resources, and disability in higher 
education settings. I argue that although universities are highly-structured institutions, their organization and the power dynamics embedded in them can be difficult for student veterans to navigate. In Chapter 5, I conclude by arguing that a more nuanced representation of military writing and its associated instructional practices can help student veterans transfer existing literacy skills toward new opportunities for application. 


\section{TABLE OF CONTENTS}

PAGE

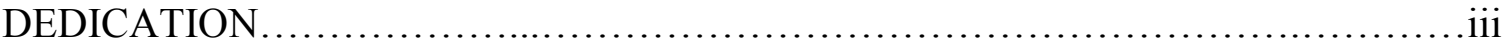

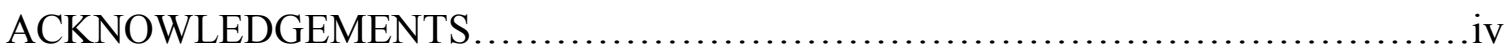

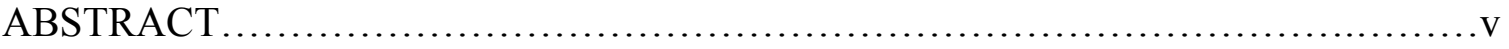

CHAPTER ONE: Introduction and Literature Review................................

CHAPTER TWO: Methods...........................................................

CHAPTER THREE: Literacy Sponsorship as Collaborative Apprenticeship in the

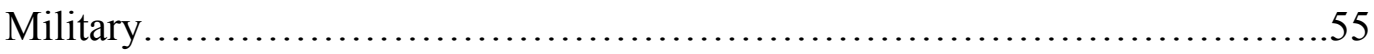

CHAPTER FOUR: Anxieties over Authority and Support in the Transition from

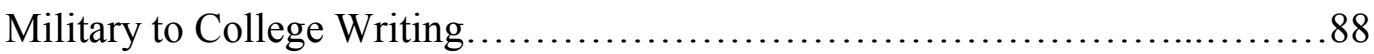

CHAPTER FIVE: Conclusion.................................................. 126

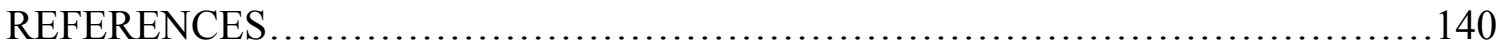

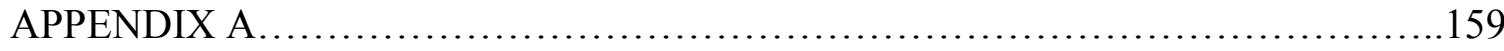

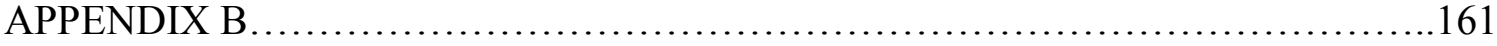

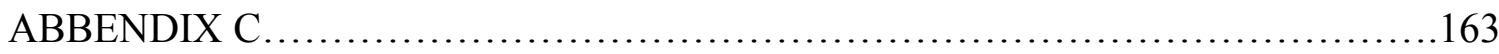

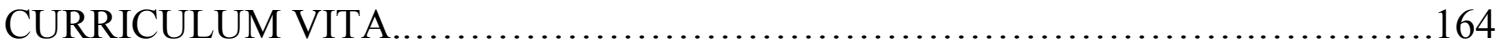




\section{CHAPTER ONE: INTRODUCTION AND LITERATURE REVIEW}

In November 2014, The Louisville Cardinal, the University of Louisville's independent student newspaper, published an article titled " $U$ of L Shows Support for Veterans." According to the article, $\mathrm{U}$ of $\mathrm{L}$ was ranked 78th on a list of best schools for veterans by Military Times $^{l}$. The tone of the article suggested this was a significant accomplishment; however, it went on to say that $\mathrm{U}$ of $\mathrm{L}$ ranked 5th among the schools in Kentucky and that "According to the data compiled by Military Times, $\mathrm{U}$ of $\mathrm{L}$ earned only half a star, out of four, in the categories labeled staff support and academic support" (Lewis). Despite the school's relatively high national ranking, there were clearly concerns about the quality of staff and academic support being offered to student veterans on campus, but the article addressed none of them.

By this point I was in my third year of teaching at $\mathrm{U}$ of $\mathrm{L}$ and $\mathrm{I}$ had taught for two years before that at Southern Illinois University, where I earned my master's degree.

Over the course of those five years, I had several self-identified student veterans in my first-year writing courses and had begun to notice the wide range of attitudes they brought to in my classroom. Disclosure of military affiliations happened in a variety of ways; while some would share their military experiences as part of class discussions,

\footnotetext{
${ }^{1}$ Military Times determines "Best for Vets" rankings via an extensive survey distributed to schools across the country. From their own website: "To create the rankings, we evaluated colleges' survey responses based on what veterans have told us is important to them, as well as on our own editorial judgment. [...] Broadly speaking, institutions were evaluated in five categories: university culture, academic outcomes/quality, student support, academic policies, and cost and financial aid. [...]Many factors other than those listed in the chart were considered when developing the rankings." For more detail into their methodology, see: www.militarytimes.com/colleges2017-methodology.
} 
others wore their affiliations in the form of uniforms, hats, and backpacks. Some were the "Type A," overachieving students who arrived to class early, sat in the front row, actively participated in class discussions, and submitted their work ahead of the due date. Others were withdrawn in class, missed major deadlines, and stopped attending class by midterm. Still others, of course, were nowhere near either of these extremes, operating in some middle ground where their performance was neither outstanding nor troubling.

I found these students' seeming unpredictability curious, sometimes comparing them to personal friends who had either excelled or struggled in college after leaving the military, trying to make sense of what might account for the differences in their selfpresentations and academic performances. Even more concerning to me was an awareness that there were almost certainly other student veterans in my courses who chose not to self-identify in any way — a type of student since dubbed the "stealth veteran" (Corley; Handley). I often wondered how many student veterans withheld that piece of their lives, for what reasons, and what might be gained or lost in that decision. I realized that I desired to be the kind of instructor that made student veterans feel comfortable talking about their military experiences (either privately or in class), but I felt unsure how to convey that interest and support in gentle, considerate ways. Ultimately, I was not sure how to instigate that kind of dialogue with student veteransnot necessarily for fear of "triggering" them, but due to an assumption that they did not want to be prodded and would share more information with me or the class when they felt it was relevant or just felt comfortable.

As I began my research, I discovered that the influx of student veterans using the Post-9/11 GI bill was already a growing concern in the field of Rhetoric and 
Composition. Marilyn Valentino's keynote address for the 2010 Conference on College Composition and Communication was a key moment for the uptake of concerns about/for student veterans in composition. In it, she calls for more open communication between writing instructors and their students. She further argues that university demographics are becoming increasingly diverse in terms of ethnicity, age, professional experience, and preparedness and as a result, many students are facing unprecedented challenges that if left unaddressed, may hinder their ability to do well in their classes or complete a degree (366-7). Ultimately, she claims that veterans in particular warrant our increased attention because, in the fall of 2009, "our institutions welcomed nearly five hundred thousand veterans, back from one or two or three tours of duty. That's an increase of 30 percent in just one year" (368).

Indeed, since the Post-9/11 GI Bill passed, well over one million veterans have used its benefits to enroll in American colleges and universities (Hart and Thompson, “An Ethical Obligation") ${ }^{2}$. Currently, more than 900 student veterans are enrolled at the University of Louisville and drawing on GI Bill benefits ("How Accommodating"; Military Times) ${ }^{3}$. It is worth noting that neither this number nor most national figures includes other active or separated military personnel who are enrolled using other forms of tuition assistance or without drawing on any sort of military-related education benefits

\footnotetext{
${ }^{2} \mathrm{~A}$ joint study published by Student Veterans of America and the National Student Clearinghouse in March 2017-the National Veteran Education Success Tracker (NVEST) - revealed that in its first six years, the Post-9/11 GI Bill helped 347,564 student veterans complete 453,508 degrees and certificates ("Fact Sheets" 7).

${ }^{3}$ It is unclear from these sources whether all of the individuals drawing on GI Bill benefits in these figures are in fact student veterans. College Factual states that these "are Post-9/11 G.I. Bill recipients as reported by the VA, which we use to determine the number of veterans at the college. Note, this figure does not include any active duty military personnel that are attending this college via Tuition Assistance, so the total military population is likely larger than this." Military Times explains that "Military enrollment figures are measured similarly and apply to service members and veterans actually tracked by a school, not just students using military-related benefits, except where otherwise indicated."
} 
("How Accommodating"). With a student population of about 22,000, 16,000 of whom are undergraduates, student veterans account for about $4.5 \%$ of our campus. This may seem small, but actually constitutes "a significant minority population" (Bonar and Domenici 205). Though student veteran populations necessarily vary from campus to campus, their overall numbers nationwide have drawn increasing attention. As such, Valentino's 2010 call to action has since proven to be an important moment of foreshadowing for both student veteran enrollments and subsequent research within Rhetoric and Composition. Her address also calls attention to the myriad ways that a better understanding of student veterans and their experiences and needs could benefit other students; for instance, while student veterans share a set of experiences that unite them as veterans, some of them also share characteristics with other adult learners who enter higher education settings with well-established community and workplace literacies that shape their learning and communication styles. Moreover, because some student veterans also deal with the lasting effects of physical and emotional trauma, they can offer insights about how a disability can impact a student's experiences and how universities can better serve students with disabilities both programmatically and in the classroom

The Louisville Cardinal article—in its vague brevity—appeared just in time to help me crystalize a set of questions that had already been lurking in the back of my mind for some time. What are the factors that lead to success for student veterans? What factors might inhibit success? What role do "staff and academic support" play in student veterans' experiences? What role does first-year writing play? It was from this initial set of questions that the study presented in this dissertation was formed. 


\section{Overview of the Dissertation}

In this dissertation, I describe the themes that emerged from nine participants' reflections on how they learned to write in and for the military and how they were learning to write in and for the university. In doing so, I demonstrate the impact that a military learning environment had on participants' subsequent experiences with college writing. In the chapters that follow, I forward several central findings of this study. Chief among them are:

1) The primary form of writing instruction reported by participants took place via informal workplace interactions (i.e., not in formal classroom spaces). These interactions involved intensive one-on-one instruction and task modeling and focused on correctness and mastery as their primary objectives. Using participants' descriptions of these interactions, I argue that this form of literacy sponsorship is collaborative and modeled after a master-apprentice relationship. Moreover, I contend that this structure reflects the hierarchical nature of the military and reinforces values such as shared authorship, shared labor, and collective responsibility.

2) Participants' descriptions of their experiences in college featured concerns about authority, institutional structure and resources, and disability. Drawing from those themes, I argue that although universities are highly-structured institutions, their organization and the power dynamics embedded in them can be difficult to understand or navigate for inexperienced students. Consequently, some student veterans may perceive a lack of structure when, in reality, it is just implicit rather than explicit. This shift away from the explicitly- and rigidly-structured nature of the military (of which the collaborative apprenticeship model of writing instruction described above is a result) can 
cause frustration and difficulty in everything from writing assignments to accessing campus resources to making decisions about self-disclosure of ones veteran or disability status.

These findings provide new insights into the role of structure and authority in both military and academic literacy practices, particularly as they relate to the experiences of student veterans. I discuss the implications of these findings for student veterans at $\mathrm{U}$ of $\mathrm{L}$, for Veterans Studies research in Rhetoric and Composition, and for the field more broadly in Chapter Five.

\section{Overview of the Literature Review}

In the following literature review, I provide the historical context and theoretical framework that shaped this study. First, I offer a brief history of veterans' impact on higher education in the United States, including the role of the GI Bill in providing veterans with access to higher education. Next, I discuss trends in the research on post9/11 veterans in Rhetoric and Composition more specifically, with particular emphasis on research that addresses student veterans' literacy practices and their learning in writing classrooms. Finally, I outline two major areas of research that are central to this study: Situated Literacies and Literacy Sponsorship. Within that discussion, I describe the ways I employ key terms and theories such as literacy practices, literacy events, communities of practice, Actor Network Theory, and sponsorship. 


\section{Student Veterans in Rhetoric and Composition}

\section{Historical Perspectives}

The influx of post-9/11 veterans into colleges and universities is hardly the first time that student veterans have given teachers and researchers pause. Before the Post9/11 GI bill, veterans were able to use a series of benefits programs that were created after our involvements in WWII, the Korean War, and the Vietnam War to go to college (Cate et. al. 8-10). The original GI Bill—first known as the World War II Servicemen's Readjustment Act — was not only a crucial step in opening pathways to secondary education for people who had historically been excluded from it, but was also part of an effort to avoid the unemployment and outrage over unpaid benefits that characterized the experiences of veterans after WWI (Mettler). The bill 'replaced the traditional veterans' bonus — an award of cash or land — with benefits," including government-secured loans for homes and businesses, funding for education and job training, financial support for the unemployed, and health care (Frydll 1-2). Historically, the GI Bill can be understood as an avenue for upward mobility for those willing and able to serve in the military, with the basic premise being that through continued educational training veterans would be able to secure more profitable careers than they would have otherwise. However, as Doe and Langstraat point out, the cultural undertones of the GI Bill have evolved over time; while its original purpose was to cultivate a "sense of citizenship, national pride, and optimism about social mobility" by "explicitly telling veterans that they mattered to the state," the Post-9/11 GI Bill functions more as a form of repayment "for what they have sacrificed" (10). 
Despite this shift in its underlying message, the GI Bill's overarching goal of providing financial assistance for veterans to attend college has remained consistent and each subsequent generation of veterans has brought with them their own assets and challenges, garnering a variety of responses from those involved in higher education. Among educators' chief concerns have been student veterans' perceived lack of preparedness for the rigors of college-level coursework, their resistance to the social norms of academic spaces, and the potential impact of physical and cognitive disabilities. After WWII, for instance, "record numbers of war veterans enrolled in colleges and universities using educational benefits... The impact that millions of new college students had on American higher education was unprecedented, and postsecondary education grew tremendously during that era" (DiRamio and Jarvis 2). Before long, educators started airing their concerns about the potential demands of a growing student veteran population. Edward McDonagh's famous article, which was published in the Journal of Higher Education in March 1947, has some hopeful threads to it, but much of it is alarmist in nature. Even the title, "Veterans Challenge Higher Education: Not Insurmountable if Recognized" is a bit foreboding.

In the article, McDonagh outlines what he sees as the key considerations colleges and their faculty will have to make. In the first paragraph, he warns that

Colleges and universities are facing perhaps the greatest challenge in their history as a million veterans seek the ways of higher education in America. These deserving students of the sophisticating experience of war and military service will certainly challenge many of the sacred and accepted practices of college training. (149).

Worried about the probability that some veterans might just use various types of education benefits to continue going to school indefinitely, he suggests that "Colleges 
and universities can discover these students by their complete lack of interest in anything but more schooling. Colleges and universities must not become substitutes for Civilian Conservation Corps or public works" (150). And lastly, he worries that instructors may not be able to "fail" veterans who do not have the "mentality or drive to succeed in college" and writes

Regardless of tests and eagerness to achieve, it will be a challenge to an instructor to fail a veteran-student who has earned a Purple Heart and Bronze Star Medal. Common sense cautions us to perceive the probable bitterness of this former combat soldier [in response to a failing grade] (150).

McDonagh's anxieties were not an isolated occurrence; instructors worried about student veterans being unprepared for college-level coursework (including writing), how other students would respond to their potential disabilities, and their "attitudes" in the classroom ("English"; Miller; "Report"; Watts).

Deborah Brandt's "Drafting U.S. Literacy" reflects on this time in our field and takes a historiographic approach to the ways the demand for an increasingly educated military force has shaped understandings of literacy and literacy instruction in higher education. Brandt argues that

World War II changed the rationale for mass literacy. Literacy was irrevocably transformed from a nineteenth-century moral imperative to a twentieth-century production imperative - transformed from an attribute of a 'good' individual to an individual 'good,' a resource or raw material vital to national security and global competition. (485).

In other words, wars, military and veterans have encouraged changes over time both because of the need to prepare soldiers for military employment and the need to offer them quality instruction after their return. And yet, despite the increasing importance of literacy and the apparent anxieties of writing instructors in higher education, it appears that little (if anything) was done in the way of strategic academic support (e.g., tutoring, 
specially-designed courses, veteran-focused pedagogical practices) for veterans during this time. This lack suggests that while educators were increasingly aware of their presence on campuses, they were not yet prepared to adjust their teaching to accommodate student veterans.

The new value of literacy and necessity of "functional literacy" continued to grow as the Korean and Vietnam Wars increased the demand for educated military personnel. Greater proportions of veterans drew on GI Bill benefits after those conflicts, in spite of reductions in their education assistance. As Altschuler and Blumin (2009) posit in their analysis, the Korean War followed closely after the end of WWII and due to the economic strains of multiple conflicts, the government began limiting the Bill's breadth. This move was also due to "the effects of the continuing concern on the part of congressional conservatives that the original GI Bill might be paving the road toward more general social welfare policies" (207). According to Altschuler and Blumin, a key reason for the continuing growth of student veteran populations was that more veterans of the Korean and Vietnam Wars were high school graduates. Thus, even though they were not eligible for the same levels of financial support as their WWII counterparts, they nevertheless persisted in their studies after serving (209). As a result, the relationship between the military and higher education continued to evolve, prompting educators to continually reconsider their work and their mission (DeMott; Drew and Creager).

Despite student veterans' influence on education policy and classroom practices, veterans themselves were, historically, rarely the focus of intensive research in Rhetoric and Composition (Doe and Langstraat, "Introduction" 6). They were, however, operating on the periphery of much significant and early work in Rhetoric and Composition. We 
know, for instance, that Don Murray and Victor Villanueva are veterans whose military experience shaped their perspectives on writing and instruction. Vietnam-era veterans in the 1960s and 1970s were also among the many "types" of students who took advantage of new open-admissions policies across the country and became part of an emergent understanding of "basic writers." Mike Rose recounts his experiences working with veterans and providing them with "opportunities to exercise critical thinking in rhetorically grounded writing contexts" in a 1983 article about remedial writing ("Introduction" 7). It was in another such program at the City University of New York (CUNY) where Mina Shaughnessy and her colleagues were reimagining the role of writing instruction in higher education in response to changing student demographics and needs. Shaughnessy's Errors and Expectations (1977), a thorough examination of her students' writing and the cognitive, socioeconomic and political circumstances that influenced their composing skills, built a descriptive theory of basic writing that both addressed traits specific to basic writers and offered an intuitive explanation of the logic behind their errors. Though she does not mention veterans specifically in her work, she does position herself as an instructor responding to concerns much like Rose's and makes a case for working harder to meet underprepared writers' needs.

While Errors and Expectations has been the subject of many thorough critiques over the years, perhaps most famously by Min-Zhan Lu with her analysis of the book's "politics of linguistic innocence," it nevertheless marks another moment in literacy research where instructors were working in earnest to understand more about their seemingly "new," "more diverse" students and to design instruction that would meet their needs. Shaughnessy also spoke out elsewhere against a tendency she saw for knee-jerk 
reactions to student diversity and perceived under-preparedness. In her 1976 article, “Diving In: An Introduction to Basic Writing," (1976) for example, she warns against two preliminary stages she believed instructors tended to go through when grappling with shifting student demographics — "Guarding the Tower" and "Converting the Natives." She implored instructors to instead "Sound the Depths" of their students' experiences and design a responsive curricula and then to "Dive In." Shaughnessy's recommendations are certainly applicable to approaching student veterans as basic writers, but neither her work nor the work of Rhetoric and Composition scholars at large truly "sounded the depths" of veterans' literacy practices during this era. Once again, educators indicated they were aware of student veterans and that their needs might be unique, but they ultimately failed to study and articulate them in explicit and nuanced ways. Rhetoric and Composition scholars have only recently begun to address this gap in our understanding of student veterans' experiences with writing in military and academic settings.

\section{Early Trends in Post-9/11 Veterans Studies Research}

Generally speaking, research about student veterans in the last decade has been somewhat limited (and limiting) in scope. In the years leading up to Valentino's call to action, research about post-9/11 military students and student veterans was only starting to take shape. The vast majority of research relied on teachers' anecdotes about veterans they had in their classes. Many of those accounts focus on resistance, conflict, and underpreparedness - describing student veterans who were reluctant to participate in personal writing assignments, who struggled with the transition to higher education and with conditions like PTSD, and who were in need of some kind of intervention (Hart and 
Thompson, “An Ethical Obligation"; Doe and Langstraat "Development Workshops"). A similar reliance on the deficit model can be seen in research on student veterans and military students more broadly in higher education, which is often devoted to outlining disadvantages the student veteran might face (Bonar and Domenici; Elliott, Gonzalez, and Martin; Madaus, Miller, and Vance). The emphasis of this early work seems to be on issues of administrative and staff support like advising, student services/affairs, and disability resources rather than on strategies for academic support. This research often makes recommendations about what university communities can do to raise and then sustain student veteran retention rates, but considers little else about how student veterans learn or write. ${ }^{4}$

One example of this trend in Rhetoric and Composition is in the 2009 Teaching English in the Two-Year College special issue titled "Teaching English in a Time of War." While I do not want to discount the significance of this scholarly moment in drawing much-needed attention to the realities of teaching student veterans, it is worth noting the themes of trauma, emotional strain, and conversion running through many of the issue's articles. For example, Galen Leonhardy's “Transformations: Working with Veterans in the Composition Classroom," discusses how to help student veterans transform their narratives about war and trauma into effective academic compositions and offers suggestions for responding to assignments where veterans disclose some of their troubling experiences. Melanie Burdick’s “Grading the War Story” and Sylvia A. Holliday’s "Gladly Teach and Gladly Learn" both take up similar concerns about

\footnotetext{
${ }^{4}$ This body of research is also distinct from Veterans Studies writ large, which has a much broader scope and includes research in the social sciences, medicine, history, literature, and cultural studies. This study is positioned at the intersection of the Rhetoric and Composition subset of Veterans Studies and the Veterans Studies subfield within Rhetoric and Composition.
} 
responding to student writing with distressing themes. Meanwhile, Denis Kiely and Lisa Swift's "Casualties of War: Combat Trauma and the Return of the Combat Veteran" and Robert Wallace’s “Twenty-Two Anti-Tank Mines Linked Together: The Effect of Student Stories on Classroom Dynamics" both reflect on the impact that student veterans and their stories can have on other students.

Virtually every piece in the issue advocated for empathy for student veterans and a more careful consideration of their needs and experiences. But by and large, those experiences were limited to trauma and combat and their impact on a student veteran's mental health and disposition. As in research outside of Rhetoric and Composition, many of these publications emphasized the pathology of PTSD and the ways student veterans might resist fully transitioning into their "new" civilian and academic lives. I would posit that this is due, at least in part, to these being the narratives that were readily available to instructors and researchers insofar as the "troubled" veteran has been the subject of innumerable pop culture representations in literature, film, and television, especially since the Vietnam War, and together those iterations have helped form a series of assumptions about what to anticipate from veterans in our classes and our communities (for more on representations of veterans in popular culture, see: Bender; Stahl; Suid). These culturally inscribed narratives are often the first thing we draw on when we have little else to use as a frame of reference. Thus, in spite of good intentions and an increasing focus on writing classrooms as a crucial site of learning for student veterans, few of the student veteran's early appearances in Rhetoric and Composition research did much to advance our understanding of their literacy practices. Up to this point, as Angie 
Mallory and Doug Downs (2014) would later argue, "the majority of research on veterans in college actually overlooks the very point: student learning" (53, emphasis in original).

\section{Recent Trends in Post-9/11 Veterans Studies Research}

There have been three major collections since the 2009 special issue of TETYC

that have contained most of the recent research in Veterans Studies: A 2013 special issue of Composition Forum, a 2014 collection titled Generation Vet: Composition, Student Veterans, and The Post-9/11 University, and a 2016 special issue of Reflections: a Journal of Public Rhetoric, Civic Writing, and Service Learning. Eileen E. Schell and Ivy Kleinbart write in their introduction to the special issue of Reflections that the submissions they received tended to focus on three central "domains":

1) “veterans' writing in extracurricular settings"

2) “veterans' writing in the composition classroom on university campuses or at military bases"

3) "faculty development initiatives the help prepare university faculty, instructors, and TAs for their work with veterans in the classroom." (8).

These categories could also easily be used to describe much of the published research on student veterans in Rhetoric and Composition, including the two other collections, as they have all featured

1) some discussion of creative, therapeutic, or community-based writing with veterans (Mapes and Hartley; Paquette, et. al.; Schell; Schell 
and Kleinbart "I Have to Speak Out"; Springsteen "Closer to Home; Springsteen, “Veterans' Writing”; Whitworth);

2) analyses of student veterans' military and academic literacies (Doe and Doe; Cleary and Wozniak; Hadlock and Doe; Handley; Hinton, "Front and Center"; Hinton "The Military Taught Me"; McGregor and Fernandez; Mallory and Downs; Morrow and Hart; Thompson, "Recognizing Silence") and

3) examples of programmatic approaches to supporting student veterans (Doe and Langstraat, "Faculty Development"; Hart and Thompson, "Veterans in the Classroom"; Keast; Shivers-McNair; Selting; Sura).

To better frame this dissertation, this literature review focuses primarily on a few central findings within the second category—student veterans' writing in military and academic settings, More specifically, I discuss current analyses of the ways in which student veterans draw on, add to, and/or move away from their existing literacies in the process of adapting to academic modes of inquiry and communication. This is followed by a more in-depth discussion of how the concepts of situated literacies and literacy sponsorship can help frame productive investigations into student veterans' literacy practices and learning. 


\section{Student Veterans Engaging Multiple Literacies}

It is clear that the overarching message of much Veterans Studies research is for educators to do more to honor and value the experiences of student veterans. As Erin Hadlock and Sue Doe (2014) conclude, "To make the initial bridge, student-veterans may need to see both the importance and the applicability of their prior experience and the relevance of their current education to the significant civilian challenges that lie ahead" (93). For some, as mentioned above, building this bridge involves allowing or encouraging student veterans to write about military and war experiences, sometimes in deeply emotional ways, as part of composition coursework (Braswell; Corley; Martin). For others, this includes learning more about student veterans' strengths in the classroom (as conscientious small-group leaders, for instance) and allowing them to put those skills to use (Dalton; Morrow and Hart; Mallory and Downs; Doe and Langstraat "Faculty Development").

In addition to relying on scholarship in New Literacy Studies (which I address later in this literature review) such research draws on two other bodies of research in Composition and Rhetoric and higher education more broadly; the first is scholarship which investigates what happens as students "transition" from one writing situation or context into another. I use terms like transition and immersion somewhat tentatively, as research on identity, particularly within the field of Rhetoric and Composition, suggests that there is no direct transition from one identity to another (Lu, "Redefining the Literate,"; Webb-Sunderhaus). Rather, student veterans often find themselves oscillating between military and academic identities and literacy practices, compartmentalizing one or the other when it seems necessary, or enacting both (or other) identities and literacy 
practices simultaneously. Although much of this research focuses on the transition from high school to college or from college to the workplace, an important underlying assumption is that students engage in a complex set of negotiations between practices they may be accustomed to and the practices that they believe are being demanded of them in their new surroundings (Michaud; Rogers and Rymer). A second and related body of research is focused on the concept of "transfer," which suggests that when entering into new writing situations, students will make connections to previous experiences to make sense of what might in many ways be an unfamiliar task (Anson and Moore; Devitt; Lettner-Rust et. al.; Robertson, Taczak, and Yancey).

Redirecting the conversation about student veterans away from a deficit model or a focus on their affective experiences in writing classes and with instructors or classmates means engaging in thorough examinations of their literacy experiences and practices. After all, even though they may be "first-year students" in our classes, military students and student veterans (like many of our students) are not necessarily "novices," and to consider them as such is, according to Corinne Hinton (2013), "asking a lot from firstyear student veteran writers who bring a pre-existing expertise into the composition classroom that complicates embracing a novice position: a wealth of educational and professional experiences, ingrained cultural values, and a strong collectivist identity" (n. pag.).

Several researchers have since taken up a similar line of inquiry and argued for and/or worked toward more nuanced investigations of the complicated literacies that student veterans bring with them into the college classroom. Some have focused student veterans as "adult learners" with a unique "workplace literacy" (Cleary and Wozniak; 
Doe and Doe). Similarly, in "Uniform Meets Rhetoric: Excellence through Interaction," Mallory and Downs argue that using discourse theory as a lens, we can better understand veterans" experiences "not as transitional but as accretional; veterans are not replacing a Discourse but adding one" (55, emphasis in original). Their study is significant in that they outline some of the key tensions between military discourses and academic discourses, including contradictory approaches to concepts like independent inquiry and hierarchies of authority which ultimately reflect specific differences in the larger institutional contexts of those discourses. More specifically, they explain how military discourse essentially serves as a "script," a set of "universal procedures delineated by nearly nonmisuderstandable texts in rigidly hierarchical culture of unwavering deference to those texts" (59). Embedded in those scripts are expectations for everything from uniforms to personal hygiene to written communication and student veterans often carry those deeply-entrenched sets of values with them into civilian life and into the classroom.

In a complementary study published in the same collection, Hadlock and Doe echo some of Mallory and Downs' claims about student veterans and their intensive experiences with particular forms of written communication in the military ("Not Just 'Yes Sir, No Sir"'). However, they aim to disrupt the assumption that all of that writing was done in lock-step fashion and delineate several ways that military discourse is rhetorically complicated, including its underlying motivations (e.g., advocacy and assertion) and built-in procedures for giving and receiving feedback. They reach a relatively common conclusion in this vein of research, which is that student veterans may be best served by "direct explanation of the ideological differences between [the] two worlds" (89; see also: Morrow and Hart; Mallory and Downs). That is, in order to help 
student veterans pivot the literacies they acquired in the military toward new academic contexts, instructors should encourage explicit conversations about the similarities and differences of the two discourses and their associated institutional and ideological structures in order to identify key points of potential transfer.

The emphasis of this line of research is not necessarily to point out the "gaps" that FYC instruction could or should fill, but rather to highlight the fact that student veterans bring a host of literacies with them that can connect with and transfer into the literacy events they will encounter in higher education. Moreover, student veterans are employing complex literacy practices as they navigate higher education that are 1) closely tied to notions of identity and 2) not inherently oppositional to traditional understandings of academic literacy practices (Morrow and Hart; Mallory and Downs; Hadlock and Doe). Although this assertion has long been made in regards to adult learners more broadly (Beaufort; Gere; Lytle; Michaud), "student-veterans' former military workplace is generally less well understood by faculty and traditional students alike," which makes it harder for faculty to see the connections between military and academic experiences (Doe and Langstraat "Introduction").

Although closer analyses of the literacy practices of student veterans are beginning to take precedence, the cumulative body of research remains rather small and what we do have suggests that we do not know as much as we could or should about the literacies of student veterans. Therefore, I add to this body of research by further illuminating 1) the literacy practices that characterize military discourses and 2) the points of tension and connection that can shape student veterans' experiences as they learn to write in academic settings. More than looking for "gaps" in military student and 
student veterans' knowledge, however, I call attention to points of connection or transfer between these two sets of literacy practices and to consider what skills these students draw on to successfully navigate new varieties of literacy events.

As a theoretical background for this line of inquiry, I draw on two central concepts from Literacy Studies: Situated Literacies and Literacy Sponsorship. Below are brief overviews of these areas of research and explanations of the key terms borrowed from them to frame this project.

\section{$\underline{\text { Literacy Studies }}$}

\section{Situated Literacies: Literacy Practices and Literacy Events}

One of the central principles of this study is that investigations of local, everyday language-based activities can reveal a great deal about larger webs of discursive practices and cultural values. As such, I am adopting a stance similar to Eli Goldblatt's in Because We Live Here: Sponsoring Literacy Beyond the College Curriculum (2007), in which he claims that

all literacy learning is local in much the same way that, as former Speaker of the House Tip O'Neill famously put it, "All politics is local." Even when the subject matter or audience is national or international, the acquisition and exercise of language is always mediated by and reflective of conditions that can be traced to the geographical, social, and economic locations of the speaker, writer, listener, or reader. (9).

Barton, Hamilton and Ivanič's Situated Literacies: Reading and Writing in Context (2000) furthers this argument for localized investigations of literacy and emphasizes the power of exploring literacy learning in context rather than in abstractions. They define "literacy practices" as "the general cultural ways of utilizing written language which people draw upon in their lives" and add that "practices are not 
observable units of behavior since they also involve values, attitudes, feelings and social relationships. This includes people's awareness of literacy, constructions of literacy and discourses of literacy, [and] how people talk about and make sense of literacy" (7; see also: Street "Recent Applications"). Brandt takes a similar stance, noting that "individual literacy exists only as part of larger material systems, systems that on the one hand enable acts of reading or writing and on the other hand confer their value" (1). Ultimately, literacy practices are larger cultural patterns of discourse that can give us a fuller picture of the social attitudes and relationships among the users of that discourse.

"Literacy events," on the other hand, are what Shirley Brice Heath (1982) describes as "any occasion in which a piece of writing is integral to the nature of the participants' interactions and their interpretative processes" ("Protean Shapes in Literacy Events" 50). Later, Barton, Hamilton and Ivanič expanded that definition to all "activities where literacy has a role. [...] Events are observable episodes which arise from practices and are shaped by them," effectively including virtually all forms of communication (8). Similarly, Valerie Kinloch (2009) argues that we should see events as discrete "engagements" or "collaborations people have across learning spaces that can lead to the creation of individually and group authored texts" (161). These collaborations "involve the negotiation of meanings, idea exchanges, and writing choices" ("Suspicious Spatial Distinctions" 161). Effectively, literacy events are the singular encounters with language that over time come to form the boundaries of available literacy practices.

This approach to literacy studies has often been used to frame studies of peoples' daily literacy practices at home, at work, and in their communities. Examples of this type of research in literacies studies includes Gregory and Williams' City Literacies (2000), 
which explores literacy practices in religious and educational spaces; Knobel's Everyday Literacies (1998), which describes the literacy practices of teenagers outside of school; Sheridan and Roswell's Design Literacies (2010), which examines the literacy practices used in digital contexts in the workplace; and Rosenberg's The Desire for Literacy (2015) which investigates the literacy practices of "marginalized adult learners" in a variety of community settings. By using the specific literacy events that participants are able to recall to characterize literacy practices more broadly, this research tries to resist focusing solely on what abilities participants have or lack. Instead, I consider patterns of literacy events over time and across contexts—including patterns of how specific literacies are taught—and the values and attitudes about literacy that are embedded in those patterns. Moreover, like Barton and Hamilton, I consider the impact of history, institutional power, and social goals on the acquisition and employment of those literacies across multiple contexts.

\section{Communities of Practice}

This study uses the concept of communities of practice to explore the particular social spaces where participants describe literacy events taking place. The value of using communities of practice as a basic framework is that

it takes learning out of the classroom and addresses the variety of groups and locations where learning takes place, including adults learning, learning in the workplace and learning in everyday life. It helps identify commonalities across these settings and contributes to understanding differences between formal and informal education. (Barton and Tusting $3)$.

In other words, the concept of the communities of practice allows us to examine literacy learning that happens across multiple settings and among individuals who are related to 
one another in a variety of ways, not just formal literacy instruction in traditional classrooms. Originally stemming from theorists Scribner and Cole in 1981 and Jean Leve and Etienne Wegner in 1998, employments of "communities of practice" has evolved over time into a broader social framework for understanding literacy. Communities of practice are useful ways of understanding how people come together in their everyday lives and learn to participate in a wide variety of often highly specialized discourses (Barton and Tusting 4-5).

Building on Wegner's early theories, which did not explicitly focus on the uptake or features of specific discourses, Karin Tusting (2005) explains how including literacy in examinations of communities of practice can lead to useful insights:

Practice involves engaging with other people in the pursuit of some joint enterprise. Where this engagement is sustained over time, the people involved develop a repertoire of ways of engaging in practice, which includes ways of thinking, speaking, discourses, tools, understandings and memories which are to a greater or lesser extent shared amongst most members of the community. (39).

Barton and Hamilton similarly argue that considering communities of practice through the lens of literacy studies helps "demonstrat[e] the centrality of literacy practices and $\operatorname{argu}[\mathrm{e}]$ that a textually mediated social world is revealed" (14-15). That is, looking at the literacy practices that define a particular community can help us better understand the role of language (written and verbal) in that community. Moreover, considering the role of discourse in specific communities of practice allows researchers to "emphasiz[e] the grounded, routinized, multiple, and socially sanctioned ways in which reading and writing occur" (Brandt, Literacy, 5). The literacy practices at work in the community can also illuminate other important features of the group, such as social attitudes, shared values, and the roles of agency and authority (Barton and Hamilton, "Literacy," 18-22). 
Together, then, literacy studies and communities of practice are useful concepts for articulating

1) Singular literacy events that form patterns of literacy practices over time.

2) The types of social spaces, formal and informal, where literacy events take place.

3) The multitude of ways, formal and informal, that literacy practices can develop within and define a particular community.

4) The multitude of potential power dynamics that can exist between individuals in the same communities of practice.

5) The ways those power dynamics can be reflected in the literacy practices of the community.

This approach is particularly useful in studying military and academic literacies because literacy acquisition does not happen exclusively in formal classroom settings but rather across a wide variety of settings and through both remarkable and mundane encounters. Additionally, borrowing these frameworks from literacy studies and communities of practice also makes it possible to distinguish the different relationships individuals have to one another and to the institutions in which they are operating (i.e., the military and the academic) and to account for the role that unequal distributions of social power can play in shaping those relationships. 


\section{Literacy Studies and Actor Network Theory}

This study also draws on Actor-Network Theory (ANT) in order to highlight the ways that issues of political power and authority can be embedded in the "objects" that circulate in particular communities of practice. Fenwick and Edwards (2010) argue that ANT can be a useful tool in education research because, through its lens

we can study how, in educational contexts, things of particular significance and apparent force, whether a standardized test or a key to the storeroom, come to emerge, how value becomes attached to them, what traces they leave, what energies they provoke in different spaces, and how and when they fade out of significance. (9).

According to Barton and Hamilton (2005), because "Wegner defines reification as 'the process of giving form to our experience by producing objects that congeal this experience into 'thingness,"” explorations of literacy practices in communities are particularly keen opportunities to make connections with ANT (26). For example, Fenwick and Edwards argue that over time, networks of actors (like communities of practice) and their "dynamic events and negotiations" become sedimented into "durable" sets of expected and accepted behaviors (what they call black boxes) (12). This process also includes the "sedimentation of power relations in educational spaces and their continuing effects" (13). Including ANT in this theoretical framework is thus a way to conceptualize the power dynamics that exist between individual actors in a given community of practice.

Using ANT to analyze the literacy practices in a particular community, we can observe how objects both grant power by association and ac as independent agents. For instance, access to a particular form or genre can grant an individual a certain amount or type of power or influence over other participants in that community of practice who do 
not have access to the same forms or genres. As I discuss in Chapter Three, as military writers move up the ranks they gain access to (and eventually mastery over) new genres of military writing that can signify their power relative to one another. In this instance, the ability to write performance reviews and recommendations for awards on behalf of one's subordinates grants a military writer significant social power. More broadly, ANT also offers a way to look across communities of practice; as Brandt and Clinton (2002) suggest, researchers can use ANT to consider the agentive roles of objects that connect even the most situated literacies to larger constellations of literacy practices, offering opportunities to reimagine how people and objects alike transgress discursive boundaries. Using ANT in this capacity presents opportunities for making more nuanced connections between military and academic settings and literacies.

\section{$\underline{\text { Literacy Sponsorship }}$}

Also central to the framework of this project is Deborah Brandt's notion of literacy sponsors, which she defines as "any agents, local or distant, concrete or abstract, who enable, support, teach, model, as well as recruit, regulate, suppress, or withhold literacy-and gain advantage by it in some way" ("Sponsors of Literacy," 166). Sponsors are ultimately responsible not only for the ways an individual is introduced to new literacy practices, but also how they employ them and the values they ascribe to them. As Brandt explains, the relationship between sponsor and sponsored is a complicated one even in the most straightforward of situations:

Usually richer, more knowledgeable, and more entrenched than the sponsored, sponsors nevertheless enter a reciprocal relationship with those they underwrite. They lend their resources or credibility to the sponsored 
but also stand to gain benefits from their success, whether by direct repayment or, indirectly, by credit of association. (Literacy 19).

Thus, literacy sponsorship is not as simple as a "more educated" individual "teaching" a "less educated" individual something new. The sponsor is inherently in a position of power, the sponsor is contributing resources of some kind (time, money, reputation), and the sponsored individual is typically expected to do something with their new skill that will, at the very least, reflect well on the sponsor, or potentially even result in financial gains for the sponsor. Embedded in these relationships are nuanced and evolving distributions of social power and authority which are not always balanced or even advantageous to the sponsored individual.

Brandt's work has focused heavily on the economic aspects of sponsorship, such as individuals choosing to join the military in order to gain access to specific types of literacy learning. As Goldblatt, who also draws heavily on the sponsorship metaphor explains, her work is important in that

She widens the concept from a function we might commonly associate only with schools and patriotic essay contests in order to factor in the economic nature of literacy, the active role that businesses and government can play in shaping reading and writing abilities and experiences people choose to pursue. (112).

However, Goldblatt posits that there is also value in considering the impacts of understandings of sponsorship on instructional practices and an individual's understanding of issues like authority and authorship (113). Throughout Because We Live Here, Goldblatt demonstrates how different approaches to sponsorship might account for the different skills his university and its nearby community colleges privilege in their first-year writing curricula. In this sense, sponsorship becomes a particular way of understanding highly localized instantiations of literacy practices while also affording 
new perspectives on programmatic, university-wide, and even regional approaches to literacy learning.

In the context of this study, I also look at sponsorship on both the macro and micro levels. The military and the university are sponsors of literacy writ large, but individuals working within both of those institutions also serve as sponsors everyday situations. These exchanges are deceptively simple on the surface; civilians enlist in the military and receive specialized instruction (including in reading and writing) that may have be of use to them after the end of their service, and in return the military is staffed by highly trained individuals who may go on to bring any number of honors onto the institution itself. But, there are other forms of sponsorship at work, too, because according to a 2011 Pew Research Center survey, 75\% of people who enlisted in the military after $9 / 11$ claim to have done so for the chance to access education benefits (33).

Thus, the military is not only offering specialized literacy training that suits its own endeavors as an institution, but also the apparent promise of continued literacy training in a specialty of the student's own choosing after the completion of their enlistment. There are also potential gains at the individual level; superiors who train their recruits well may be able to ask them to share in certain types of labor or have their own reputation enhanced by the success of a subordinate. Sponsorship relationships in university settings can be equally complicated. As Brandt notes, "although the interests of the sponsor and the sponsored do not have to converge (and, in fact, may conflict), sponsors nevertheless set the terms for access to literacy and wield powerful incentives for compliance and loyalty" (19). Sponsors, then, have significant control over literacy learning environments and the nature of sponsorship relationships can give us a unique 
perspective on the literacy practices and the modes of instruction that a particular institution values (Goldblatt 161).

\section{Converging Theories and Project Goals}

As the review of literature above suggests, scholars in Literacy Studies have long advocated for research that focuses on 1) local sites of literacy acquisition and 2) the role of institutions, ideologies, and power dynamics in literacy sponsorship and literacy acquisition. I take up both of these avenues for research by using Situated Literacies and Literacy Sponsorship as frameworks for analyzing the way participants describe 1) writing and learning to write in the military and 2) writing and learning to write in college.

This approach has been adopted as a way to better understand the multiple, highly valuable literacies that student veterans bring to bear in college writing situations and to move beyond research in Rhetoric and Composition that focuses on student veterans' deficits and the reasons educators should "worry about" them. More specifically, this study contributes to the discussion of how student veterans' are accustomed to experiencing literacy instruction in military communities in order to bring into focus the issues they may face in academic communities.

This dissertation complicates commonly held assumptions about student veterans and their experiences in higher education. The results of this study demonstrate the faultiness of relying on dualistic thinking about student veterans' learning (e.g., that they struggle to move from a highly-structured writing environment to one with no structure). Instead, I argue that evolving embodiments of sponsorship (including issues of authority 
and autonomy) and shifts in community values (especially as they are reflected in accepted literacy practices) impact student veterans' learning and opportunities for success in higher education.

\section{$\underline{\text { Preview of Upcoming Chapters }}$}

In Chapter Two I articulate the methodology that was used to collect and analyze the data presented in this study. I describe my reasoning for using individual interviews as the primary mode of data collection and the complicated process by which participants were recruited for said interviews. I also provide a rationale for the process of data analysis, which relied heavily on interview transcriptions and the grouping of emergent themes. Finally, I reflect on some of the limitations of these methods as well as the impact my own experiences and predispositions had on the research process.

In Chapter Three I share the common narrative my participants relied on when explaining how they learned to write in and for the military. Almost without exception, these participants described having worked in close proximity with a direct superior, often for an extended period of time, to master specific forms and genres critical to their positions in the military. Drawing heavily on scholarship about collaborative learning, I argue for a re-framing of that common narrative as a "collaborative apprenticeship model" of literacy learning. Additionally, I demonstrate the roles that authority, shared labor, and collective responsibility can have on relationships between literacy sponsors and the sponsored.

In Chapter Four I focus on my participants' descriptions of learning to write in college and outline several key themes, including anxieties about authority, unfamiliar institutional structures, and disabilities. In this chapter, I use the participants' reflections 
to demonstrate how they navigate the shift from an explicitly hierarchical institutional structure to an institutional structure that is similarly rigid but far less explicit.

In Chapter Five I discuss the implications of this study for student veterans at the University of Louisville as well as the contributions I am making to Veterans Studies research and the field of Rhetoric and Composition. 


\section{CHAPTER TWO: METHODS}

This study involved student veterans at the University of Louisville and relied on in-depth phenomenological interviews as its primary method of data collection. In this chapter, I will describe the site at which this study took place, with a particular focus on the features that are most relevant to the student veteran population on this campus. I will describe the processes used to recruit participants and provide a brief biography of each participant. Next I will describe the theoretical frameworks for qualitative research and conducting interviews that informed this study, including the steps I took in analyzing the data those interviews produced. Finally, this chapter will close with a discussion of the limitations of this approach and the salient ethical concerns.

\section{Description of Research Site}

The University of Louisville is a public, four-year institution with a total enrollment of 22,640 (16,033 undergraduate/5,963 graduate and post-doctoral) in Fall 2016. The student body is comprised primarily of in-state students $(16,723)$ and is $72.3 \%$ White, 10.2\% African American, and 12.7\% “other minorities." The university's mission is to become "a premier, nationally-recognized metropolitan research university" ("Profile"). As of 2017, approximately 930 student veterans attend U of L ${ }^{5}$ (Military Times n. pag.). The primary point of contact for student veterans is the Office of Military and Veteran Student Services (OMVSS), which is staffed by a VA Certifying Official

\footnotetext{
${ }^{5}$ As mentioned in the previous chapter, this number does not include student veterans who are not using the GI Bill to attend college or students in the Air Force and Army ROTC programs.
} 
(Carissa Gentry) and an Academic Counselor (Kris Roy). According to their page on U of L's website, the office's stated mission is to

to smooth the transition from military life to student life by devoting individualized support to veteran students and their families in providing a broad range of services, coordinating with VA, university departments, and other community organizations. ("Welcome.")

Together, they help student veterans navigate the process of applying for a variety of education benefits, transferring credits from other institutions, withdrawing from or being re-admitted to the university due to deployments or calls to active duty, and making connections with other veteran-related services and student groups on campus. However, with only two full-time staff, the office's resources are inevitably limited ${ }^{6}$.

According to College Factual, $\mathrm{U}$ of $\mathrm{L}$ is considered "military-friendly" because it offers student veterans career and vocational support, benefits support, counseling support, and opportunities to transfer in credits from previous institutions and (in certain cases) grants equivalencies for military experience. The majority of those advantages are embedded in the services offered by the OMVSS, however student veterans are also able to use the services offered by the Disability Resource Center and the university's Counseling Center. Outside of the OMVSS, U of L offers an optional veteran-specific orientation that introduces student veterans to the key offices and services they may want to connect with during their studies. U of L's Resources for Academic Achievement (REACH) program also coordinates an optional mentorship program specifically for student veterans in which student veteran mentors try to establish connections with incoming student veterans and provide additional support, especially during their first semester. Finally, there is an active chapter of the Student Veterans Association on

\footnotetext{
${ }^{6}$ Their low staffing likely factors into $U$ of L's previously mentioned low rating for "staff support" from The Military Times, which they have earned once again in the 2017 survey.
} 
campus; although the group had dissolved for a number of years, it has been reconstituted over the last four years under the direction of a new faculty member and has begun holding regular meetings and occasionally hosting social events.

The university is also invested in veterans and the military more broadly and participates in or sponsors numerous education initiatives on campus and in the local area. For instance, the College of Business hosts a program called VETSART, which provides ten weeks of intensive training in entrepreneurship for interested veterans and even provides limited reimbursement for start-up expenses when participants launch a new business. U of $\mathrm{L}$ also hosts the McConnell Center Strategic Broadening Seminar, a thirty-day residential program co-designed by the university, the Pentagon, and the U.S. Army Human Resources Command "to create broader educated and more flexible Army leaders to face new and dynamic challenges in the $21^{\text {st }}$ century" (Gregg). The university also has relationships with nearby Ft. Knox that involve numerous forms of outreach, including offering college-level, for-credit classes at Ft. Knox High School. All of this (which is by no means an exhaustive list), in combination with U of L's thriving ROTC programs in Military and Aerospace Science, creates to a sense that the university is sincerely interested in leveraging its resources to support veterans (enrolled students or not) and contributes to the university's appeal to student veterans.

\section{$\underline{\text { Research Narrative }}$}

\section{Identifying Participants}

I began the process of recruiting participants in July 2015. Because my initial aim was to exclusively recruit student veterans who were in their first semester at the 
University of Louisville, I met with Carissa Gentry, the VA Certifying Official in U of L's Office of Military and Veteran Student Services. Insofar as her role is to process and approve or deny every request to draw on VA benefits at $\mathrm{U}$ of $\mathrm{L}^{7}$, she had unparalleled exposure to the student veterans on our campus and access to records of enrollment. At her request, I also met with Joe Dablow, Director of Operations and Planning in the Office of Enrollment Management to discuss the aims and methods of this project and get his approval ${ }^{8}$.

Once both Carissa and Joe were on board, Joe prepared a list of $149^{9}$ students who had self-identified as student veterans and who had been tagged as being in their first semester of study. This designation primarily included students who were in their first semester at $\mathrm{U}$ of $\mathrm{L}$, only 25 of which were true freshmen; 122 others were coming into $\mathrm{U}$ of $\mathrm{L}$ with credits from other institutions and two others had incoming credit designations listed as "unknown." This list of students provided the initial subject pool for participant recruitment.

\section{Recruiting Participants}

E-mail Recruitment: The first round of recruitment e-mails (See Appendix A) were sent to the 25 students on the aforementioned list who were marked as being freshmen at $\mathrm{U}$ of $\mathrm{L}$ who were not transferring in credits from another institution and who were therefore

\footnotetext{
${ }^{7}$ Carissa works in tandem with Kris Roy, the Academic Counselor in the Office of Military and Veteran Student Services. Together they enroll

8 Joe worked closely with the Office of Military and Veteran Services before taking a position in the Office of Enrollment Management and had participated in the English Department's pre-semester training seminars for faculty and instructors by offering advice for working with student veterans.

${ }^{9}$ Additional breakdown: 118 male/31 female, 100 White/29 Black/13 Hispanic/2 Asian/2 American Indian or Alaskan Native/2 Unspecified.
} 
the original target of this study. The e-mail included an invitation to complete a survey, the purpose of which was to gather some background information about potential interview participants before we met. When this process only led to a single potential interview participant, I proceeded to send the same recruitment e-mail to the 19 additional freshmen, 34 sophomores, and 32 juniors on the list who had transferred in that semester with credits from other institutions. This decision meant moving away from the original trajectory of the study, which was to focus exclusively on student veterans in their first year of college coursework. As a result, I was unable to capture the "real time" experience of my participants' first college-level writing courses in the interviews and was instead asking them to reflect back on that experience to the best of their abilities. However, I believe the impact of that shift on the study to be minimal as all of the participants were enrolled in a writing course at $U$ of $L$ at the time of their interview and were able to ground their responses in those ongoing experiences.

In-Class Recruitment: At the end of the Fall 2015 semester, recruiting via e-mail had led to only five study participants. During conversations with those participants and with other student veterans, it was suggested to me that very few student veterans would be likely to respond to an e-mail like mine for a number of reasons, including reluctance to identify publicly as a student veteran (as opposed to on seemingly confidential university application materials), already having received a deluge of veteran-related e-mails (e.g. social events, on campus-speakers, and mentoring services), and simply having no reason to trust me. In an effort to curtail these impediments, I thus began a second round of 
recruitment by reaching out more personally to student veterans who were enrolled in Composition classes in the Spring 2016 semester. This process took two forms:

1) I asked Composition instructors who felt comfortable doing so to mention this study in their classes and distribute my contact information to any interested students.

2) I visited several sections of Composition I and II myself to give a brief overview of the study and distribute my contact information.

The hope was that having an instructor endorse the study and/or seeing me in person and getting a clearer sense of the motives behind the study would lead to increased participation. This round of recruitment led to five new participants, for a total of nine in the study.

\section{Description of Participants}

In the course of this study, I interviewed nine student veterans. All of them were men, and all but one of them was white (the other was Hispanic). All of them were enlisted; 6 in the Army, one in the Navy, and one in both the Marines and the Army. Below is a brief description of each participant based on what I was able to glean from 1) the data provided to me by the OVMSS and Office of Enrollment Management, 2) participants' response to a request for a brief biography via e-mail, and 3) our discussions during the interviews. 


\begin{tabular}{|c|c|}
\hline Participant & Brief Biography \\
\hline Chris, age 31 & $\begin{array}{l}\text { Chris started attending U of L in Fall } 2015 \text { with the hopes of } \\
\text { eventually becoming a social worker. Before coming to U of L he } \\
\text { had only completed a single semester of courses at a school in } \\
\text { Tennessee (after his first deployment a decade earlier). Chris was } \\
\text { struggling to keep up with his coursework due to issues with PTSD } \\
\text { and physical disabilities and was considering transferring to a local } \\
\text { community college where he could take courses on a schedule that } \\
\text { worked better for him. }\end{array}$ \\
\hline Mark, age 40 & $\begin{array}{l}\text { Mark served in the Navy for } 21 \text { years and worked as an Intelligence } \\
\text { Specialist for } 18 \text { of those years. During that time he was stationed } \\
\text { many places, but talked the most about his time in Hawaii where he } \\
\text { was part of the Pacific Area of Responsibility (AOR) under the } \\
\text { United States Pacific Command (USPACOM). Mark earned an } \\
\text { online Associate's degree before transferring to U of L in Fall } 2015 \\
\text { to work toward his Bachelor's in Criminal Justice. }\end{array}$ \\
\hline
\end{tabular}




\begin{tabular}{|c|c|}
\hline $\mathrm{Brac}$ & $\begin{array}{l}\text { Before attending U of L in Fall } 2015 \text { Braden had only taken a few } \\
\text { online classes with the American Military University. He came to U } \\
\text { of L specifically to attend the Speed School of Engineering. Although } \\
\text { he was technically majoring in English, his time as a diver convinced } \\
\text { him that Civil Engineering was the right path to take. After finishing } \\
\text { all the pre-requisite courses Braden intended to officially apply to the } \\
\text { Speed School and change his major. }\end{array}$ \\
\hline Johr & $\begin{array}{l}\text { John joined the Army in } 1993 \text { and retired after } 21 \text { years of service. } \\
\text { During that time, he was stationed at eight different bases and } \\
\text { deployed a total of five times to Macedonia (1), Bosnia (2), and Iraq } \\
\text { (2) where he primarily served as a mechanic and oversaw motor } \\
\text { pools. }\end{array}$ \\
\hline
\end{tabular}




\begin{tabular}{|c|c|}
\hline & $\begin{array}{l}\text { Bachelor's degree in Mathematics. He started attending U of L part- } \\
\text { time in January } 2014 \text { and became a full-time student there after he } \\
\text { retired in } 2014 \text {. }\end{array}$ \\
\hline Ryan, age 44 & $\begin{array}{l}\text { Ryan served in the Marines from 1990-1996. When he left the } \\
\text { Marines, he struggled to find a job and considered re-enlisting in the } \\
\text { Marines. Upon learning he would have lost ranks and had to work his } \\
\text { way back up, he decided to join the Army instead and served in that } \\
\text { branch for another } 18.5 \text { years. For much of his career he was a } \\
\text { Weapons Specialist, but later in his career he was an Anti- } \\
\text { Discrimination Counselor and the head of the Sexual } \\
\text { Assault/Harassment Response and Prevention (SHARP) Program. }\end{array}$ \\
\hline Derek, age 28 & $\begin{array}{l}\text { Derek joined the Army in August } 2010 \text { and after } 3.5 \text { years of active } \\
\text { duty he moved from Ft. Knox to Indiana and joined the local } \\
\text { National Guard. At the time of our interview (March 2016), Derek } \\
\text { was in the process of changing his specialty from Cavalry Scout to } \\
\text { Intelligence. He was anticipating that a required training would cause }\end{array}$ \\
\hline
\end{tabular}




\begin{tabular}{|l|l|}
\hline & $\begin{array}{l}\text { him to miss the Fall 2016 semester. } \\
\text { Derek took a year off between high school and his first semester of } \\
\text { college (2006-2007). He attended Frostburg State University in } \\
\text { Maryland for five semesters (2007-2009) before enlisting and taking } \\
\text { one semester of coursework at College of Southern Maryland while } \\
\text { he waited to leave for Basic Training (Fall 2010). He began attending } \\
\text { U of L full time in Fall 2015 and is taking a wide variety of classes } \\
\text { with the hope of eventually becoming a novelist. }\end{array}$ \\
\hline Alex, age 28 & $\begin{array}{l}\text { Alex joined the Army in 2009; in that same year he attended } \\
\text { Advanced Infantry Training (AIT) to become a combat medic and } \\
\text { was stationed at Ft. Knox where he served as a medic and Emergency } \\
\text { Care Non-Commissioned Officer (NCO). In 2011 he deployed to } \\
\text { Afghanistan where he served as a medic on supply convoys and as } \\
\text { the NCO in charge of a battalion-level aid station. }\end{array}$ \\
$\begin{array}{l}\text { Jackson, age 21 } \\
\text { Jackson attended East Carolina University in the 2013-2014 } \\
\text { In 2014 he joined the U of L ROTC program and was assigned to the } \\
\text { Grayson Community College (2007-2009). }\end{array}$ & $\begin{array}{l}\text { Jackson joined the Army National Guard in 2013. He began his } \\
\text { onlistment as Infantry, but became a Blackhawk Mechanic in } 2015 .\end{array}$ \\
\hline
\end{tabular}




\begin{tabular}{|l|l|}
\hline & $\begin{array}{l}\text { academic year, but missed the 2014-2015 academic year due to a } \\
\text { deployment. He then attended Jefferson Community and Technical } \\
\text { College (Kentucky) for 2015-2016 before transferring to U of L } \\
\text { where he now majors in Business. }\end{array}$ \\
\hline George, age 23 & $\begin{array}{l}\text { George joined the Army National Guard in 2012. He became a } \\
\text { student at U of L in Spring 2015 and majors in Biology and } \\
\text { International Business. Before U of L, George attended Union } \\
\text { County Community College (New Jersey) and Elizabethtown } \\
\text { Community and Technical College (Kentucky) where he earned an } \\
\text { Associate's degree in Science. }\end{array}$ \\
\hline
\end{tabular}

\section{Conducting Interviews}

Overview of Data Collection Process: The original research plan was to conduct a series of focus groups; however, because so few participants volunteered and at such a slow pace, I opted instead for an individual interview protocol. Individual interviews took place in the Fall 2015 and Spring 2016 semesters. After initial interviews, four participants agreed to take part in a follow-up interview (Chris, Mark, Braden, and Derek). In an attempt to garner some of the advantages of the previously-planned focus group protocol, I attempted to gather those four participants for a focus group. Once again, scheduling conflicts arose and only two participants (Mark and Braden) were able to meet at the same time.

Initial interviews and follow-up interviews were one hour long, semi-structured, and based on a series of primarily open-ended questions (see Appendices B and C). The 
follow-up interview questions were shaped by emergent themes from initial interviews and attempted to garner more detailed responses to my own lingering questions. The questions I posed were a combination of general questions about the participants' experiences with writing and more specific questions targeted at the major themes of the study, specifically different styles of literacy sponsorship and perceived tensions or connections between military and academic literacy practices. Beginning with general questions about their experiences allowed participants to contribute information that they were more familiar with and likely did not see as particularly ideologically-based, thus allowing me to gradually work them toward more nuanced discussions of those literacy practices. I audio-recorded each interview for transcription purposes.

Theoretical Underpinnings: The interview process in this study is based on what Irving Seidman, in his book Interviewing as Qualitative Research (2005), terms "in-depth, phenomenological interviewing," in which the data gathered is used to create profiles of individual participants and to identify themes across a range of participants (9). Thus, the methodological positioning of this study is qualitative, phenomenological, and social constructivist. This approach is undergirded by a phenomenological philosophy as I "seek to elucidate the meaning, structure, and essence of the lived experience of a phenomenon for a person or group of people" (Patton 482). In this case, the "phenomenon" is the relationship between literacy, identity, and access/support for military students and student veterans. Through the method of conducting interviews, I hoped to gather detailed information about the lived experiences of student veterans as they encountered new literacy events. 
Of course, that is not to say that information about lived experiences cannot be gained through other means; Elliott, Gonzalez, and Larsen's 2011 study of student veterans as they transitioned from combat deployments into higher education, for example, was based on data gathered through questionnaires that primarily featured closed-ended questions and from the 104 responses they received they were able to make some valuable connections between factors like alcohol use or PTSD symptoms and feelings of alienation in college. Much more rich, however, were the responses that they received to two open-ended questions that asked participants to describe examples of their experiences. Given this opportunity, many of their participants revealed, in detail, the ways that instructors and fellow classmates behaved during the times they felt most alienated and even made suggestions about ways that instructors and peers could be more sensitive to the presence of student veterans on campus (287-88).

As such, this study used individual interviews as the primary mode of data collection in order to foster opportunities whereby student veterans could be as descriptive as possible and provide context to explain not only what happened in and around that experience, but also how they felt about it and what kind of impact it may have had on them and their studies. Although a major drawback of an interview protocol is that it requires time (and therefore funding) that is hard to find in a graduate program and a field that often demands the quick production of results, I share Julie Lindquist's (2012) belief that this kind of "slow research" is important for our field, particularly when it comes to generating questions for future research ("Time to Grow Them: Practicing Slow Research in a Fast Field"). Because relatively little research has been done on the literacy practices that military students and student veterans engage in when 
they enter the university, I this project is an important step in starting to build that body of research by gathering rich data that will lead us toward even more targeted research in the future.

In taking up this approach, I am responding to calls from scholars like Marjorie Faulstich Orellana in her essay "Moving Words and Worlds: Reflections from 'the Middle" (2007) when she argues that literacy research has the potential to investigate the bodies, personas of our participants as potential sites for research. We can move with our participants in and through the contexts of their daily lives, and read the signs inscribed on the bodies (as teachers and parents do) to understand how these worlds move in and through them. (134).

Juan Guerra makes a related claim in his contribution to the same volume, "Out of the Valley: Transcultural Repositioning as a Rhetorical Practice in Ethnographic Research and Other Aspects of Everyday Life," when he calls for literacy researchers to engage with methods that will "capture how people engage in rhetorical practices that allow them to reposition themselves across cultures and to enact more productive and meaningful identities within" (138). Although Guerra writes primarily of his own cultural repositioning as a Hispanic, educated man moving across the nation into drastically different socio-cultural environments, I see his argument applying to military students and student veterans in that in many ways, the military is a unique culture unto itself with a whole host of accepted cultural and literacy practices, ideological assumptions, and related identities. Indeed, as Kelley, Smith, and Fox contend in their book Preparing Your Campus for Veterans' Success: An Integrated Approach to Facilitating the Transition and Persistence of our Military Students (2013), the military boot camp process "effectively and efficiently breaks down individuals in order to rebuild them into a specific military mold. It is a process of changing one's mind-set and lifestyle" (20). 
Of course, the extent to which any one participant truly ascribed to the supposed "military mind-set" or retained or displayed his military identity after leaving the military varied, but the individuals in this study nevertheless bore some (or many) of those identity markers with them into the university and felt some of the tensions, even if only internally, that Guerra describes as they navigated between those seemingly discrete discourse communities. While Guerra is primarily advocating for an ethnographic approach that he plans to adopt in his own future research, I would contend that rich interview data, especially that gathered over an extended period of time (at least a few months, but ideally multiple semesters) could accomplish similar goals when it comes to understanding what kind of literacy practices the student has been engaging in and how those practices relate to the student's identity(ies) and ideological positioning in a range of social spheres. Thus, a key advantage of in-depth interviews is having the opportunity to ask specific, detailed questions and pointed follow-up questions to paint a more expansive picture of the relationships between literacy learning, identity, and ideological positioning as student veterans navigated their evolving relationships with military and academic literacy practices.

Deborah Brandt adopts a similar approach in her initial study of literacy sponsorship in Literacy in American Lives (2001), one that Sara Webb-Sunderhaus later adopted for the case study portion of her article "A Family Affair: Competing Sponsors of Literacy in Appalachian Students' Lives" (2007). Brandt argues that literacy learning is an inherently social endeavor that can best be "understood in relationship to the particular social aims and habits associated with [each literacy practice's] contexts of use" and that "life-story" or autobiographical accounts of literacy learning are one of the 
best ways to uncover those relationships and the values associated with them (9-10). Thus, another advantage of an interview-based, phenomenological method is that it allowed me to better understand the social networks that these students engaged with during both moments of literacy learning and transitions between the military and the academy. Brandt goes on to add that "direct accounts about how ordinary people have acquired reading and writing and their motivations for doing so are largely missing from the record of mass literacy development," (10) and this study aims to use similar methods to fill that gap in research about student veterans specifically. However, unlike Brandt I did not seek entire literacy histories from my participants; while I did ask them to tell me a little about their experiences with reading and writing growing up, our interviews focused primarily on their experiences with military and academic literacies. While this may not provide the same level of expansive contextual information as Brandt's study, I still had ample opportunities to inquire about the "people, institutions, materials, and motivations that contributed to literacy learning" that her research emphasizes (9).

My study also has similar methodological aims as those described by Rumann and Hamrick in their 2010 study "Student Veterans in Transition: Re-Enrolling after War Zone Deployments," in which they argue that an interview protocol is ideal because it allows for interaction with participants and the opportunity to solici[t] descriptions of relevant experiences and ascribed meanings" (436). Unlike Rumann and Hamrick, I was unable to view or collect related documents (forms, assignment prompts, examples of student writing, etc.) due to a lack of time and resources. However, as I mentioned in the Introduction and will return to in Chapter Three, I was still able to identify certain objects that were significant as the participants acquired new literacies (e.g. manuals, specific 
forms/genres). By paying attention to the objects that circulate through these networks, I am able to counter one of the greatest weaknesses of a case study research approach, which is that it has limited generalizability. While I did not want documents or objects to become the primary focus of my analysis, keeping them in the picture (even if only through detailed descriptions from research participants) will help me connect the participants' experiences to larger literacy systems beyond the highly situated literacies they are currently participating in or choose to share with me. To this end, this study aims to take up Barton and Clinton's (2002) suggestion that literacy research allow for indepth discussions of situated literacies alongside discussions of the agency that these objects exert within a given literacy ecology. Including objects in the scope of this research project will, as Brandt and Clinton suggest, help the field "begin to expose the ways that 'local literates' are recruited into distant campaigns through reading and writing" (347).

In taking up this approach, I am relying on Brandt's argument that literacy learning is an inherently social endeavor that can best be "understood in relationship to the particular social aims and habits associated with [each literacy practice's] contexts of use" and that "life-story" or autobiographical accounts of literacy learning are one of the best ways to uncover those relationships and the values associated with them (9-10). This approach also allows me to align myself with Feminist research methods as embodied by scholars such as Chiseri-Strater (Academic Literacies: The Public and Private Discourse of University Students) and Kirsch and Richie ("Beyond the Personal"), because although the interviews were semi-structured so as "to ensure that the same basic lines of inquiry 
are pursued with each person interviewed" (Patton 343), I treated the interviews as openended discussions rather than a series of pre-determined questions with limited answers.

\section{Analyzing Interview Data}

Interview data was be analyzed using Irving Siedman's suggestions for “in-depth, phenomenological interviewing." Siedman recommends that researchers review interview transcripts multiple times looking for passages of particular interest, identifying themes within the interview transcripts, and using passages of interest to create a condensed narrative of the interviewee's experiences. This process allows for both crafting an indepth profile of the interviewee and connecting themes in their interviews to themes identified in focus group discussions and in other individual interviews. As such, I was able to aim for the depth and rich contextual work that Brandt advocates while also making connections across participants and thus enhancing the generalizability of my findings. In reviewing the interview recordings, I looked for the narrative that each participant constructed about his or her experiences with literacy broadly, but also the role that specific sponsors like the military and the academy have played in their literacy learning. By adopting this approach to analysis, for instance, I was able to identify a clear pattern in the narratives participants shared about learning to write in the military and then to reconstruct that narrative using significant passages from multiple participants (see Chapter Three for more on this common narrative). Similarly, noting and compiling emergent themes from participants' descriptions of their academic writing experiences allowed me to identify an underlying concern about authority. Although those responses did not yield as cohesive of a narrative as their descriptions of military writing, they 
nevertheless revealed that they had a great deal in common even across multiple educational contexts.

\section{Methodological Limitations and Ethical Considerations}

One of the biggest limitations of interviews is that they require a great deal of time to schedule, conduct, and transcribe. Because relatively little research has been done on the literacy practices that student veterans draw on and engage in when they enter the university, I see gathering rich data like this as essential. However, the constraints of a dissertation project (especially time and resources) do limit the effectiveness of this methodology. As I mentioned above, I had a relatively low number of participants and I believe this to be partly due to the time required to participate. I was also only able to schedule follow-up interviews with fewer than half of my participants. Thus, the profile I was able to build for these participants was not as rich as it might have been had I been able to meet with them multiple times over the course of multiple semesters.

Additionally, relying on interviews alone (and not collecting related artifacts) means my findings are based entirely on participants' recollections and ideological stances without contextualization in or corroboration from more concrete data sources.

Additionally, being an outsider to the military community almost certainly affected student veterans' willingness to participate and to openly share their experiences with me. Although I tried to learn as much about the military as I could before beginning interviews, there were still points at which participants had to stop to explain an acronym or genre of military writing with me and I suspect that this further bolstered my position as an outsider. It is very likely that participants left out details of their experiences that 
they thought would be too complicated to explain or that they worried might be too shocking or controversial ${ }^{10}$. My civilian status also affects the way I perceive and ultimately represent the information that they do offer in my writing. Although it is impossible to stand outside my own ideological positioning, I have been conscious of that positioning during the research and writing process and disclosed that position to my research participants. As such, I aimed to adopt the stance described by Kirsch and Richie in "Beyond the Personal: Theorizing a Politics of Location in Composition Research" (1995) when they argue that being self-conscious of our positionality at researchers can help avoid the "risk [of] creating another set of 'master narratives,' risk [of] speaking for and essentializing others, and risk [of] being blinded by our own culturally determined worldviews" (8). To further combat this limitation, I have also talked frequently with members of the military and fellow Veterans Studies researchers about my research and the assertions I am making in this dissertation in an effort to lessen the impact of my own assumptions on the data analysis process.

Another major concern in qualitative approaches like this, which demand a great deal of personal disclosure from participants, is how participants will and should be portrayed in the final research product and how best to ensure that participants are fully informed of the possible pitfalls of those representations before they are made public. I agree with Newkirk (1992) when he suggests that 1) the ethics surrounding the representation of participants in our research are sometimes murky when held up against the goals of our research and 2) that "informed consent" is often hardly that (4-5). Indeed, sometimes researchers feel the need to withhold part(s) of their research objectives,

\footnotetext{
${ }^{10}$ Chris remarked, for instance, that he typically had to sanitize his writing in English classes to make sure it was not too graphic for his civilian peers.
} 
perhaps to minimize the possibility that the research subject will alter aspects of his or her behavior because they know those practices are being scrutinized. I did not withhold any information about the aims of this study from participants; in addition to the informed consent letter that each participant signed, I also began initial interviews with a brief overview of why I had designed this study, the types of information I hoped to cover, and the project's overall goal to help instructor and administrators better serve student veterans.

While I do not believe participants altered their behavior in terms of specific literacy practices because of the purview of my research, I am aware of the possibility that they may have tailor their descriptions of those literacy practices (both military and academic) to suit what they think I want to hear or to maintain a sense of loyalty to sponsoring agencies. For example, it is possible that participants may have been wary to share negative experiences from either the military or their time in the academy for fear of casting the former in a negative light or offending me as a representative of the latter. Toward this end, I have strived to make it abundantly clear in my writing, when applicable, that the critique being made against a particular person or agency is coming from me and based on the larger scope of my research, not emanating directly from the participant. Also, in order to further support my encouragement to be forthcoming about their experiences, I offered participants the usual rights to anonymity both for themselves and the other persons, locations, and institutions they included in their responses. 


\section{Conclusion}

In Chapter Three I describe the common narrative my participants relied on when explaining how they learned to write in and for the military. Drawing heavily on scholarship about collaborative learning, I argue for a re-framing of that common narrative as a "collaborative apprenticeship model" of literacy learning. Additionally, I demonstrate the roles that authority and the potential for shared labor can have on relationships between literacy sponsors and the sponsored. 


\section{CHAPTER THREE: LITERACY SPONSORSHIP AS COLLABORATIVE}

\section{APPRENTICESHIP IN THE MILITARY}

"You kinda just like, you'd have one of the older guys just sit down with you and like, teach you and then just... I mean you don't really get to do stuff like that for a while, so you just watch them. Like, you'll constantly sit down with them and do it. And then eventually they'll let you start doing that kind of stuff once they feel that you're confident and ready." - Jackson

In the chapter that follows, I examine the ways literacy sponsorship is enacted in a very specific type of military setting. As I explained in Chapter Two, all of my participants were enlisted; as a result, the vast majority of the writing instruction they recalled from their time in the military happened in informal workplace settings (i.e., not in a formal classroom space) and through interactions with their supervisors. In some ways, the writing instruction process my participants described appears to be a consistent and structural enactment of fairly standard understandings of literacy sponsorship: Superiors initiate new military writers through direct instruction on specific documents ${ }^{11}$, thereby preparing them to write in ways that will be understood by their community and that will be beneficial to their careers. In that sense, the military serves as a powerful sponsor of literacy according Brandt's definition — which stays fairly consistent through Literacy in American Lives (2001), "Limits of the Local" (2002), and Literacy and

\footnotetext{
${ }^{11}$ The two forms of military writing most frequently referenced by participants were 1) the Noncommissioned Officer Evaluation Report (NCOER), which is a yearly performance review completed by one's direct superior and 2) the Recommendation for Award form, which is used to recommend servicemembers for honors like Commendation or Meritorious Service Medals. Individual participants also made note of other genres more specific to their own specialties, like maintenance logs, Intelligence Summaries, and Area Studies, which are explained in more detail later in the chapter.
} 
Learning (2009)—in which she claims that sponsors are "agents, local or distant, abstract or concrete, who enable, support, teach, model, recruit, regulate, suppress, or withhold literacy and gain advantage by it in some way" (Literacy and Learning xiii). The exchange appears to be straightforward at this stage; civilians join the military and receive specialized instruction (including in reading and writing) that may have be of use to them after the end of their service, and in return the military is staffed by highly trained individuals who may go on to bring any number of honors onto the institution itself.

As I explained in Chapter 1, sponsorship in the military context certainly includes actors working on an individual scale, like instructors in classroom settings or mentors. Literacy sponsorship can also help us understand the relationship between individual sevicemembers and the military on an institutional level; for instance, the metaphor of sponsorship makes apparent the ways in which military membership grants individuals access to specific educational and vocational training and resources that they may not otherwise have had access to. Moreover, the military continues to financially sponsor many servicemembers beyond the terms of their contracts by providing them with GI Bill funding which makes it easier for servicemembers to access institutions of higher education. However, the metaphor of literacy sponsorship also has limitations, one of which is that it does not provide much insight into the exact nature of the individual relationships that are formed or the means through which writing instruction is enacted and essential literacies are transmitted from teachers to learners.

Using the participants' reflections on their experiences learning to write in a military context, this chapter will move beyond the metaphor of sponsorship to more 
specifically characterize the teacher-learner relationships in specific military contexts ${ }^{12}$ and to articulate the instructional methods that shape those relationships. Despite marked differences in their branches, ranks, lengths of enlistment, and ages, the participants of this study shared strikingly similar narratives of their experiences learning to write in and for the military. The style of literacy sponsorship these participants describe is an intimate one in which novice writers work closely with and learn from experienced writers over an extended period of time. Even mundane writing tasks become highly collaborative as participants share in the stakes of those endeavors and higher-ranking individuals also stand to benefit in multiple ways from the success of their subordinates. In what follows, I will use excerpts from participants' interviews to demonstrate the ways in which their sponsorship relationships can be characterized as collaborative apprenticeship and how that process reflects and supports both the military's hierarchical structure and its value system. The stories my participants told me about learning to write in the military illustrate how different literacy sponsorship can look in the military compared to the university, which in turn might account for some of the difficulties student veterans face or some of the tensions that emerge between what we might consider "best practices" and what student veterans are accustomed to or desiring from us in the writing classroom.

This chapter will use theories of collaborative learning and apprenticeship to frame those experiences and to explain 1) how military writers engage in multiple forms of collaboration during the writing process, especially while in the role of an “apprentice," but also while in other roles, and 2) how a collaborative apprenticeship

\footnotetext{
12 In this case, all participants were enlisted and writing instruction happened almost exclusively in informal contexts (i.e., outside of formal classroom spaces).
} 
model of military writing instruction is both a means of instilling military values and preparation for sharing in the labor and stakes of military communication.

\section{$\underline{\text { Sponsorship as Collaborative Apprenticeship }}$}

The following passages will work toward a more nuanced understanding of military literacy sponsorship by explaining the connection between literacy sponsorship as it is broadly understood and the specific interpersonal relationships that the participants described. Using their own descriptions of the writing instruction processes they encountered, I will demonstrate how sponsorship occurs through collaboration within an apprenticeship (master-apprentice) model. Additionally, I will explain how collaboration in this model takes place interpersonally and between military writers and the forms and genres with which they work.

\section{Defining and Complicating Collaborative Learning}

My participants' stories about writing sponsorship suggest is that military writing culture more or less follows a model of collaboration like that described by Kenneth Bruffee in his seminal works "Collaborative Learning and the 'Conversation of Mankind"" (1984) and Collaborative Learning: Higher Education, Interdependence, and the Authority of Knowledge (1999). Together these texts elucidate three key tenets of Bruffee's theory of collaborative learning: 1) that language, conversation, and knowledge are all socially constructed and interdependent; 2) that education is a process of "reacculturation" in which students, through conversation (written, verbal, and internalized) transition into new communities of knowledgeable peers, 3) that each 
community of knowledgeable peers has an accepted mode of conversing and establishing and maintaining knowledge that is their "normal discourse." What my participants' reflections reveal is the means by which that "reacculturation" is achieved and why it is so important that the military culture of writing follows these principles.

Calling specifically on the work of Richard Rorty in Philosophy and the Mirror of Nature, Bruffee claims that "any effort to understand conversation requires us to understand the nature of community life that generates and maintains conversation" and these communities, he goes on to explain, rely on certain epistemological and discursive means for establishing and maintaining knowledge, which Rorty terms "normal discourse" (551). This "community of knowledgeable peers," Bruffee continues," is a group of people who accept, and whose work is guided by, the same paradigms and the same code of values and assumptions," (552). In the case of military writers, the knowledgeable peers are one's superiors and they are responsible for initiating new recruits into the military discourse community ${ }^{13}$.

Although I find Bruffee's theory of collaborative learning to be a helpful framework for the writing instruction my participants described, it is important to note that it was met with resistance in university settings. Critical responses to Bruffee's theory of collaborative learning in the field of Rhetoric and Composition often take issue with these basic premises: Bruffee's emphasis on "normal discourse" and his claim that communities are built around consensuses in regards to values and assumptions. Joseph Harris' seminal work on this subject, "The Idea of Community in the Study of Writing,"

\footnotetext{
${ }^{13}$ Within the context of this study, it is impossible to know whether the superiors my participants mention received other forms of writing instruction (e.g., formal training at academies or military schools) during their own careers.
} 
for example, takes umbrage with popular notions of community and consensus by arguing that:

Recent theories have tended to invoke the idea of community in ways at once sweeping and vague: positing discursive utopias that direct and determine the writings of their members, yet failing to state the operating rules or boundaries of these communities. One result of this has been a view of "normal discourse" in the university that is oddly lacking in conflict or change. (12).

Even more pointedly, Harris invokes Bartholomae's discussions of community and discourse in "Inventing the University," criticizing the extent to which "the view of discourse at the university shifts subtly from the dynamic to the fixed" and is "quickly rephrased in more familiar terms of us and them, insiders and outsiders" (13).

Harris' article works against the implication in early work on collaborative learning that communities are easily-defined, easily-joined, or easily-abandoned. According to Bruffee, collaborative learning came to be of interest in the 1960s and 1970s among teachers and scholars "committed to democratizing education and to eliminating what were perceived then as socially destructive authoritarian social forms" ("Collaborative Learning and the "Conversation of Mankind,"” 546). Despite these democratic goals, Bruffee's collaborative learning theory seems to do more to uphold conservative stances on knowledge-making than to undo them. "Community," for Bruffee, is defined by the shared "language, values, knowledge, mores and so on" as well as the ways those features "are constructed, established, and maintained" (Collaborative Learning 298).

Bruffee illustrates his understanding of the ties that bind these groups from a personal perspective in his article "The Art of Collaborative Learning" when he describes how he and a colleague helped one another revise various pieces of scholarship for 
publication through a process of collaborative critique and response. He writes, “...We played the game, so to speak, by a set of rules we held in common with many other such groups" (46). The game and the rules were those established, he writes, by "the mores, conventions, values and goals of our professional organization," in this case the MLA, and included consultation on research agendas and editing one another's work (46). Here Bruffee reifies his position, represented often in his work, that there are definitive practices that link groups of people in the ways that they communicate and generate knowledge and that belonging to that group means to learn those practices and perform them at will.

From a first-year writing (FYW) perspective, this this element of Bruffee's work on collaborative learning is indeed disconcerting. First, this understanding of discourse, which promotes "rules" as relatively-stable and transferrable from teacher to student or from student to student brings back to life the criticisms of the "banking model" of education so famously delineated by Paulo Freire and later argued against at length by scholars in our field. When Bruffee depicts the teaching of "normal discourse" as the imparting of "tools" that students can use or "set aside," or when he describes "abnormal discourse" as something that students can "turn to" in specific instances, he posits them as concrete, unchanging, and readily accepted habits of mind and language that can simply be picked up or put down at will. Despite Bruffee's obvious investment in social constructivist conceptions of discourse and knowledge creation, his use of Rorty's notions of "normal discourse" and "abnormal discourse" position discourse as a set of skills to be acquired rather than something students can actively create. 
What makes these notions of discourse and community especially problematic for some critics, and what seems to place it in opposition to arguments for opening the FYW classroom to discussions of difference and disagreement, is that it is also accompanied by an acculturation model of education. That is, Bruffee uses words like "conformity", "conventions," "acceptance," "orderly," and "assent" to describe what the student has to learn and what the student has to do in order to be welcomed into any given discourse community (552-555). These kinds of words privilege "normal discourse" and suggest that students can, should, and want to fully assimilate into new communities through the eradication of differences between themselves and the discourse communities they intend to join.

Although he sometimes refers to this process as an act of "negotiation" between a students' multiple socio-political interests and alignments (556), the impression is ultimately that the student will completely "loosen ties" with previous communities in order to become a fully-identifying member of the new. Such a depiction of discourse communities and the ways students access them leaves little room for the hope of change within those systems. Thus, as John Trimbur argues in "Consensus and Difference in Collaborative Learning," rather than "offer students a powerful critical instrument to interrogate the conversation - to interrupt it in order to investigate the forces which determine who may speak and what may be said, what inhibits communication and what makes it possible," students are instead "initiate[d] into the conversation as it is currently organized in the academy" (612-3). Bruffee himself terms this process "reacculturation," which he defines as ...switching membership from one culture to another. It is always complex, in most cases incomplete, and usually painful. Reacculturation 
involves, giving up, modifying, or renegotiating the language, values, knowledge, mores and so on that are constructed, established, and maintained by the community one is coming from, and becoming fluent instead in the language and so on of another community. (Collaborative Learning 298).

While this definition does leave room for reacculturation to happen in multiple ways with multiple ends, "switching" seems to imply complete movement from one group to another, as does the use of "instead" in the final sentence .

Thus, as John Trimbur contends, rather than being a process through which students learn to challenge the authorities operating within various socio-political systems, collaborative learning becomes a model for teaching students how to reify the discursive practices already in place. To be fair, Bruffee's discussion of "abnormal discourse" does contend that it is meant to be used as a form of resistance against "the canonical conventions and vocabulary of normal discourse" ("Collaborative Learning" 557). He also says that "Abnormal discourse sniffs out stale, unproductive knowledge and challenges its authority, that is, the authority of the community which that knowledge constitutes" (556-7). A slightly more generous reading, then, might posit that Bruffee's argument is simply that one must learn the "rules" in order to know how and when to circumvent, bend, or break them. But Trimbur and others seem unsatisfied by Bruffee's argument that this approach can in fact prepare students for subverting dominant modes of discourse and knowledge creation and suggests that Bruffee's pedagogy "risks accepting the current production and distribution of knowledge and discourse as unproblematical and given," effectively removing the potentially generative acknowledgement of conflict and difference (Trimbur 610). 
Moreover, this definition of reacculturation does not make any mention of embracing conflict or difference as part of the process of joining new knowledge communities; rather, it implies consensus (another heatedly debated term Bruffee uses, to which I will turn next) between the existing members of the community and that the joining member readily accepts that consensus. As an alternative, Harris proposes that we conceive of writing as "repositioning;" that is, rather than imagining that students can move fluidly from one discourse community to another (keeping in mind that we cannot even truly define said "communities"), or that they can be taught specific skills or tools that will help them move between and operate in discrete discourse communities, "it might prove more useful (and accurate) to view our task as adding to or complicating their uses of language" (17).

Harris goes on to acknowledge that this pedagogy, like those he is critiquing, is also laden with political implications. However, he considers it more beneficial to students to engage in a "kind of useful dissonance as [they] are confronted with ways of talking about the world with which they are not yet wholly familiar" (17). The ideal result of such a pedagogy is that students will not be feel trapped into "either/or choice[s]" when examining the discourses available to them and those they are attempting to participate in. Instead, they can aim to consistently "reposition themselves in relation to several continuous and conflicting discourses" (20).

\section{Consensus and the "Real World"}

Like Trimbur, Mark Myers (2003) has also been concerned by Bruffee's assertion that part of the imperative or grounding for this model of collaborative learning is in its close relationship to the operations of the "real world"-that self-same "real world" that 
was depicted in the story of collaborating with one of his colleagues. Myers writes, "Surely we all see the need to come to a reasoned agreement within a community, and to relate our teaching to the real world," but by "accept[ing] the reality we see now [we] accept the structure of illusion our system gives us. Worse, it is to see reality as something natural, outside our control, rather than to see it as something we make in our actions in society" (440). Trimbur agrees that the concept of consensus is at times necessary, suggesting that it "represents the potentiality of social agency inherent in group life - the capacity for self-organization, cooperation, shared decision-making, and common action" (604). Moreover, "the goal of reaching consensus gives the members of a group a stake in collective projects" (604, my emphasis). However, pedagogy that emphasizes training students to enter the "real world" defines that world by consensus, Trimbur argues, "runs the risk of limiting its focus to the internal workings of discourse communities and of overlooking the wider social forces that structure the production of knowledge" (Trimbur 603). In such a situation, "what we might think is free and progressive thought may be another way of perpetuating a system we want to change" (Myers 440).

At the core of these objections may be the depiction of consensus in Bruffee's theory of collaborative learning. As described above, in Bruffee's work discourse communities tend to be defined by what its members agree on (values, assumptions, discursive practices, etc.) and the possibility that members of a community could be in a state of dissensus does not come into play. For example, in discussing how he began thinking about collaborative learning after reading M. L. J. Abercrombie's report which argued that medical students working in groups to diagnose a patient "acquired good 
medical judgment faster than individuals working alone," Bruffee does not make the plausible suggestion that perhaps the students learned more and faster because they had to work through disagreements and defend their suggestions (546-7). Instead, we leap to the assertion that the goal of collaborative learning is to reach a consensus (either between group members or between the group and the instructor) that it is an appropriate way of preparing for "real world" where professionals constantly work together to create a consensus.

Harris' critique also demonstrates his frustration at the lack of discussion about how dissent is also a part of community and knowledge formation, maintenance, and circulation and objects to what he sees as an emphasis on the assumption of shared interests, objectives, and ways of thinking in descriptions of communities (15). By presenting conversation that leads to some kind of consensus as a common and even uncontentious process, Bruffee's pedagogy robs collaborative learning of its potential as an opportunity for students to engage productively in dissent and prepares them for a "reality" that does not actually exist. "The problem," Trimbur explains, "is that invoking the 'real world' authority of such consensual practices [i.e., Bruffee's references to the workplace or "standard" academic practices] neutralizes the critical and transformative project of collaborative learning" (612). Such a model of collaborative learning, as Trimbur argues, makes it difficult for students to "transform the productive apparatus [of knowledge], to change the social character of production" (612). Rather, Myers argues, "We need to look at the consensus within these institutions as the result of conflicts, not as a monolith" (451). Thus, another key criticism of Bruffee's work is that it does not take into account (or, at least not adequately) the tenuousness of consensus, the dissent 
that can exist within groups that are still bound together by other factors, or the necessity for dissent in order to create or advance knowledge.

Important as these discussions are in regards to college writing classroom pedagogy, the narratives my participants shared demonstrate that the writing instruction they experienced in the military is nevertheless very closely modeled after Bruffee's theory of collaborative learning and their reflections make it clear that this model is in place for specific and important reasons. The following four sections will illustrate the ways that participants' experiences were collaborative and characterize military literacy sponsorship even more specifically by incorporating apprenticeship as an additional element in their instructor-student relationships.

\section{Military Literacy Sponsorship as Collaboration}

One of the only commonalities I found in my nine participants' stories was how they described learning to write for the military. According to my participants, the military values precision and concision in language across a wide range of documents and the stakes are often high as fellow servicemembers' careers or even lives might be on the line. As a result, teaching subordinates to complete mandatory writing tasks accurately_ or, in line with what Bruffee considers the military's "normal discourse"—is an important part of the higher-ranking individual's role. Almost unanimously, my participants described being taught how to write job-specific documents ${ }^{14}$ for the military

\footnotetext{
${ }^{14}$ By this I mean that my typically described moments when they were asked to take on a new level of responsibility that also required them to learn new genres of writing. For example, after a promotion, a servicemember's new duties might include writing performance evaluation reports; or, after moving to a position involving equipment maintenance, a servicemember might have to contribute to maintenance logs for the first time. It was in these kinds of situations that participants described working side-by-side with a more experienced individual to master these new genres. Although a few participants made very
} 
through individual instruction from their direct superior. Ranging from an hour or two to half a day or more, these writing sessions involved looking at examples of the higherranking person's past work, working on documents together, and discussing immediate critical feedback on the subordinate's efforts. Working side-by-side with their superior, the new writer learns not only what the military at large expects from them, but also what their direct superior demands of them.

In the participants' reflections, it is apparent that direct mentorship and individual instruction were integral parts of the learning process for new military writers; even if they were able to suss out some of the expectations by looking at examples, they were still expected to practice with their superior before attempting the process on their own. This collaborative process, then, is also in many ways an apprenticeship process. Kory Lawson Ching (2011) explains the benefits of this model in the article "Apprenticeship in the Instructor-Led Peer Conference," in which he argues that student learning is enhanced by having the opportunity to work side-by-side with someone more experienced with the skills required by the task at hand. Ching, falling more or less in line with Bruffee's theory, writes that "Typically, an apprentice learns how to perform tasks, or modified versions of them, with assistance from (or in close proximity to) a more experienced practitioner" (102). Ching bases his understanding of apprenticeship on Vygotsky's theory of the zone of proximal development, claiming that in order to grow beyond their current skill level, "learners must participate in collaborative problem solving alongside someone who is 'more 'capable' in some relevant way" (107). In the context of military writing, less experienced individuals "gain access to the meanings and values teachers 
ascribe to various features of student writing" and are positioned as "novice readers and writers working in close proximity to their... expert instructors" (102-3). In combination with Bruffee's theory of collaborative learning, an apprenticeship metaphor helps elucidate the ways in which new military writers are expected to inherit or internalize accepted writing practices by observing the "master" while also working with the "master" to craft messages and create meaning in appropriate ways.

For example, when I asked Jackson how he learned to write in the military, he said:

You kinda just like, you'd have one of the older guys just sit down with you and like, teach you and then just... I mean you don't really get to do stuff like that for a while, so you just watch them. Like, you'll constantly sit down with them and do it. And then eventually they'll let you start doing that kind of stuff once they feel that you're confident and ready.

Jackson's explanation suggests that instruction was direct and individualized and that taking on writing tasks independently came only after a significant period of both observing and being observed. John described the way he learned to write performance evaluation reports very similarly:

[My superior] sat me down one time for like, I think like a half a day. We sat in his office and I went through them with him and he would tell me what he looked for and he would - 'cause you know you'd have a regulation too to kind of help you out — and he did that for about a half a day and after that I was like, "Okay, I know what he wants."

Although here John only refers to one instructional session, he does make it clear that a significant amount of time was invested in his learning and that it involved both models and a clear articulation of his superior's expectations. 
Later, John described his own teaching style as "baptism by fire," but when he actually explained his approach it seemed to be anything but:

You know, I mean, and I'd get those ones that'd say "Look, well look, I've never wrote this before' okay?" And I would say "Well come in here, I have examples." and I'd be like "Well this is how it should structure, you know, you're, you'd have your"... We used to call it cause and effect. He did this cause, you know, supervised some kind of cause, something... and this is what happened. Your result of it. "He watched five people to this, it made him do everything faster," just for a simple example.

Indeed, rather than asking the junior servicemember to take a leap and attempt a writing task without much guidance the first time, which is suggested by the "baptism by fire" metaphor, John took the time to work through examples of particular documents and discuss specific requirements for language and formatting, much like his superiors had done for him.

Each of these reflections depicts a collaborative learning environment where junior servicemembers look to a "community of knowledgeable peers," e.g., their superiors, and work side-by-side with them until they understand and can emulate the "normal discourse" of their military community (Bruffee 551-2). That is, through an intensive collaborative apprenticeship process with their direct superiors, new military writers not only learn the ins and outs of military discourse — that is, not only specific forms and genres, but also accepted language and modes of communication more broadly — as well as the value systems and cultural norms of their military environment.

\section{Collaborative Apprenticeship as Reacculturation}

The process of initiation into the military "code of values and assumptions" begins the moment an enlisted recruit begins basic training. Exposure to military 
discourse also begins at this time, as recruits start reading military doctrine and manuals as part of their training ${ }^{15}$. As explained above, Bruffee describes this process as "reacculturation," and while his definition does leave room for reacculturation to happen in multiple ways with multiple ends, he ultimately implies that learners will move completely from one community to another. And, again, while criticisms of the acculturation model in higher education are certainly valid, the acculturation model actually suits the military quite well; individuals are in fact expected to learn and align themselves fully with the ways of thinking and communicating that are valued by the military. Military doctrine, manuals, and educational materials outline virtually all aspects of a serviceperson's life and duties and their superiors serve as models of acceptable behaviors and ensure strict compliance with military protocol. While writing instructors are working to de-center authority in the classroom, the military continues to hold the authority of one's superiors as a central piece of institutional philosophy. While we encourage students to explore topics of interest and negotiate meaning from a variety of sources, many writing tasks in the military have much narrower parameters and do in fact have a "right answer." As a result, as my participants learned to write in the military, they had an instructional experience that was very unlike what we might be aiming for in our classrooms but one that was nevertheless an important part of how they came to understand military values and expectations.

Pushing back at (or even pushing beyond) the suppositions at play in Bruffee's early work on collaborative learning, FYW pedagogy today is, generally speaking,

\footnotetext{
${ }^{15}$ However, it should be noted that none of my participants seemed to consider their initiation into military writing as happening during this time; rather, when asked how they learned to write for the military, they pointed toward more specialized training and personal interactions later in their military careers.
} 
trending toward more inclusive approaches to discourse-including, for example, incorporating and valuing students' home dialects and encouraging digital compositionand more student-centered learning that disrupts expectations that the instructor be the "authority" in the classroom. However, the military is a distinct type of institution that, unlike a FYW classroom, very much relies on hierarchies of authority and mandated sets of behaviors (including appropriate discursive practices) to function. Therefore, a pedagogical approach that privileges the direct transmission of accepted knowledge and discrete sets of practices is desirable and even necessary in a military instructional context. As the participants revealed, there are in fact clearly delineated protocols that they are expected to uphold and a collaborative apprenticeship model in which a more experienced individual provides highly directive guidance to a trainee as they reacculturate into the military, or even into a new position within the military, ultimately suits the demands of the environment well.

\section{Internal Review as Collaborative Apprenticeship}

The instructional process that participants described was not collaborative only in

the sense that trainees learned how to complete specific writing tasks by working closely with a knowledgeable superior. The process is also collaborative in the more commonly understood sense, which is that all parties involved work together (to varying degrees) to compose the text and shape its meaning. One way this collaborative process is enacted is when participants have to pass documents up the chain of command for editing and revision. How far up the document had to go in order to be approved depended on the significance of the document; recommendations for a significant award, for instance, 
needed to be signed off by superiors farther up the chain than a typical end-of-job report, for instance. Passing something up the chain meant more than seeking approval for the document wholesale; rather, each reader physically marked up the document, often with red ink and/or more fully-fledged notes. Participants used words like "check" to describe the reviewer's job and one participant claimed that it was very different from the type of response one might get from a writing professor. Different, that is, because as the use of red ink might suggest, review of these documents was sometimes harsh and documents might come back down the chain to their author filled with marks and suggestions; the worse a writer the author was perceived to be, the more ink he found on returned his draft. One participant explained, "I had ones where it'd look like... like you took a red highlighter and just did this [scribbling gesture]," suggesting it was not uncommon to have a document returned with significant changes or suggestions.

Of course, not all documents needed so much revision and not all reviewers would be so fierce as editors, but participants' descriptions of this process made it clear that there was always something to be picked at:

There's kind of like a... I don't know if you'd say a culture or a stigma, that no matter what you send up to like the battalion level staff for awards and evaluations, you're never gonna get perfect. Ya know, it's like, 'Ya need to switch this period.' And ya know, it's different than having an English teacher critique a paper. [...] You typically send it up two or three times to get reviewed before it makes its way through.

In other words, military writers learned to expect that editorial changes were made any time a document was reviewed by their superiors and that the process could turn out to be a lengthy one.

Overwhelmingly, the concerns participants described finding marked on their work (and marking on others' work) were related to surface-correctness-spelling, 
punctuation, formatting corrections, syntax, and so on. And yet, the number and kinds of changes suggested both have the potential to significantly alter the document and its message, underscoring how the writing process was almost never an individual effort. As Mark explained:

Over time, as you would submit your paragraphs and your summaries, they would make certain changes to it. So you'd have usually one or two people in your chain - from where I was sitting — one or two people above me that would look at 'em and bless off or no and make corrections and add to.

Mark's description of what happens when a document is passed up a chain of command is significant in that he goes beyond approval/rejection and surface corrections to include additions (and presumably subtractions) from a text. Although there is not much opportunity for creativity in organization or structure, there is certainly still room for personal choices of expression and it is in that sense that demands for editing and revision open the door for a re-negotiation of meaning with one's superiors. Mark's statement highlights the collaborative nature of military writing even well beyond the apprenticeship phase and highlights the extent to which the collaborative apprenticeship model of instruction may serve to prepare military writers for the review process that will continue throughout their career.

\section{Military Forms and Genres as Collaborative Agents}

Given the apparent simplicity of the documents these participants were working on, this intensive apprenticeship model might seem a bit unnecessary. Indeed, one participant described Noncommissioned Officer Evaluation Reports (NCOERs) as akin to completing a tax form. Others described military writing as "fill in the blank," or 
"dumbed down." Jackson claimed that for him, military writing was "almost like filling out a tax form. [...] It's block by block. Like, literal blocks." However, participants actually described the demands of working within the regulations of these forms and genres in complicated ways. Participants' reflections revealed that opportunities for meaning-making are sometimes limited by the forms and genres with which a writer is working. On the one hand, there is significant variance in form design and organization.

For example, John described NCOER forms this way: "Everything we had to do is action-driven. [...] And it has to be concise because we don't write in sentences. Everything is bullet comments." Each box only has so much space, so the writer has to convey as much as possible in a limited number of words. But, he says, in an Award form, it allows for more elaboration on the person's skills and performance. And yet, as he goes on, his description reveals how rigid an Award form can be:

Award's completely opposite [from NCOERs]. They're wrote in more formal paragraphs. More formal paragraphs but they have to be, you know, I think you're only allowed... [...] It was four paragraphs and then a summary. Summary's cut and dry. That's actually regulation, how it writes. But you have four paragraphs to make your argument for whatever this guy, you're putting him in for. You have four paragraphs to sum it up. So we don't... Our writing was very short. You know, we had to make everything very to the point.

Notably, John says "That's regulation, how it writes," implying that the expectations are so formulaic that the form essentially completes itself or that even at the paragraph level the writer likely knows the required sequence of moves to make. John's description suggests that despite the appearance of more freedom, perhaps because the writer has entire paragraphs to work with, the Award Recommendation Form still demands a specific structure and concision as a matter of "regulation." 
Virtually all of the participants who described completing NCOERs and award recommendations remarked on their rigidity, their purpose-driven design, and the regimented expectations of anyone filling one out. In other words, regardless of branch, military forms tended to manifest a particular style of response to their design. In this sense, the forms themselves are actors in the writing process as they prompt military writers to respond in specific ways and limit opportunities to deviate from what is considered "normal discourse." Moreover, the direct instruction received during the initial period of apprenticeship is reinforced because the form itself mandates such a specific response. That is, even long after direct apprenticeship may have ended, the form itself, because of its institutionalized and rigid nature, serves to continuously remind the military writer of the document's purpose and the parameters of an appropriate response. Thus, in working with or within the discursive demands of a particular genre or form, the military writers is effectively collaborating with that genre or form, responding to its expectations and demands and allowing it to shape available avenues for meaningmaking.

Additionally, forms and genres of military writing also carry power in these writing situations. According to Fenwick and Edwards in Actor Network Theory in Education, the value of ANT is that

we can study how, in educational contexts, things of particular significance and apparent force, whether a standardized test or a key to the storeroom, come to emerge, how value becomes attached to them, what traces they leave, what energies they provoke in different spaces, and how and when they fade out of significance. (9).

Their assertion is that in institutional settings, objects can carry symbolic power that evolves over time and can impact the institutional culture. Moreover, a person's 
possession of or interaction with those objects can shape their experiences and others' perceptions of them. Similarly, in their co-authored article "Limits of Local: Explaining Perspectives on Literacy as a Social Practice," Deborah Brandt and Kate Clinton suggest using ANT to pay more attention to and grant at least limited agency to the objects that shape situated literacies. With that aim in mind, I argue military forms and genres (like military writing instruction itself) clearly shape the writing process and the possibilities for knowledge creation by eliciting highly specific responses from writers. The same could be said of specific forms of writing in any context. But, using ANT as a lens, I also argue that the forms (or genres) servicemembers are working with have also come to hold a "particular significance and apparent force" in military contexts.

Access to various forms or genres and the skill and authority to complete them grants power to military writers; reviewing a fellow serviceperson's performance or recommending that person for an award, for just two examples, grants the higher-ranking individual power over his subordinates. Military writers effectively exercise authority through the forms and use them to actively shape fellow servicemembers' careers. Being able to complete these writing tasks accurately and persuasively depends on this collaborative apprenticeship process and signals to readers that the author has earned a certain level of authority. Successful execution of generic conventions signifies power; certain genres of military writing are themselves powerful.

If we imagine military writers and their various instructors (or sponsors) as existing in a network whose interactions are mediated by literacy practices, Fenwick and Edwards argue that over time, those networks and their "dynamic events and negotiations" become settled into "durable" sets of expected and accepted behaviors, 
what they call black boxes (12). This process also includes the "sedimentation of power relations in educational spaces and their continuing effects" (13). In other words, understanding military genres as a means through which both discursive rules and power relations are defined and repeatedly re-inscribed once again draws attention to a possible difference between academic and military writing environments; stability is expected and fiercely maintained in the former and often purposely disrupted in the latter. The collaborative apprenticeship model is a process of sharing and transferring power and the forms and genres themselves are agents in this collaborative process.

\section{Collaborative Apprenticeship: Shared Labor and}

\section{Collective Responsibility}

Collaboration between masters and apprentices and between writers and genres/forms in the military is a reflection of both the hierarchical structure of the military and the value of consistency in protocol in that environment. In the following sections, I will describe how the collaborative apprenticeship model my participants described also serves two additional purposes: to train personnel for shared labor and to prepare them for shared responsibilities. Ultimately, in yet another divergence from the relationships and stakes common to FYW classrooms, the culture my participants described also featured a shared investment in the everyday operations of their units and shared responsibility for the outcome of their writing tasks. 


\section{Collaborative Apprenticeship as an Investment in Personnel}

The extended collaborative relationship between junior and senior

servicemembers could be seen as an extension of the initial apprenticeship or sponsorship period. In that sense, the higher-ranking individuals are working in service of their subordinate, checking her or his work in order that s/he may successfully reproduce the military's "normal discourse" and have the desired impact on the document's readers. The benefits of the hierarchical review structure, then, could be intended primarily for the writer. However, in his theory of collaborative learning Bruffee also contends that the process is meant to "imitate the 'real world' interdependence and consultation that goes on in much business and professional work" ("The Art" 45-6). Likewise, Ching also posited that in the context of the instructor-led peer conference, the instructor's role is to model how to give helpful feedback so that the students can eventually mimic those feedback strategies themselves. As he puts it, by working alongside the instructor, students will "participate to learn, and they learn to participate" (104). In other words, collaborative and apprenticeship models are not just ways to pass content from expert to novice, they are also ways to model skills and behaviors that will later become valuable to the novice. In this light, collaborative apprenticeship can have additional, sometimes hidden, benefits for the expert.

If we consider both initial instruction and the continued review of the servicemember's work as extensions of the same apprenticeship goals, we see that through these processes military writers learn the values that the superior/expert places on certain aspects of writing and the writing process (in this case, as a representative of the servicemember's particular military branch) and they also learn how to become reviewers 
of others' writing in the future. These results are significant benefits to the higher-ranking individual that must be taken into consideration. For example, the more proficient one's subordinates are at completing these writing tasks, the less work it is when their writing lands on one's desk for review. As any instructor can tell you, responding to writing can be a time-consuming activity, especially if you are marking every error or matter of personal preference in a document. In that sense, personalized response to a subordinate's writing early on in his time in a new position had significant advantages to the higherranking mentor. Investing time up front into training your subordinates to do the job correctly (or at least the way you want it to be done) can therefore pay big dividends down the line.

The payoff is even more significant when the ranking individual finds a pupil they can trust to share in the reviewing duties - two of my participants described just such an arrangement. In one case, the participant's supervisor spent half a day working with him on NCOERs not only so he could be more proficient at composing them, but also so he could eventually help his supervisor review documents coming up the chain from individuals below them. Sharing the labor with my participant meant only having to review half of the documents coming up from the ranks below, a significant time-savings when you consider that he had over 200 soldiers working for him. This approach complicates the seemingly simple relationship between a supervisor and his subordinate, between sponsor and sponsored. Whether the result is shared labor or simply less labor for the "master," the culture of writing apprenticeship in the military reflects a collaborative approach to producing and policing texts. Military writers — both master and apprentice-work together to create meaning and, eventually, to serve as gatekeepers 
for others' writing. Intensive and continuous oversight, as supported by the collaborative apprenticeship model, is ultimately a means of investing in personnel with shared labor as a potential reward

\section{Collaborative Apprenticeship and Collective Responsibility in High-Stakes Writing}

The culture of ongoing collaborative writing apprenticeship in the military also has a great deal to do with the wide and significant audiences for military texts and the high stakes of the writing some members of the military do. In other words, the importance of even some of the most "mundane" military genres necessitates an infrastructure for consistent instruction and oversight. The stakes are more obviously considered "high" as military personnel climb higher in the ranks or move into more specialized military occupations; however, all of my subjects brought up concerns that suggest a keen sense of both audience awareness and the stakes of their work that frequently goes beyond whether they might be perceived as "good" or "bad" writers. Calling again on Bruffee's theory of collaborative learning, one of the premises is that it is an opportunity to learn certain practices in a low-stakes context (i.e., working side-byside with a superior) before being asked to perform those practices in more high-stakes contexts (i.e., writing more independently with oversight coming later in the writing process). Thus, the collaborative apprenticeship model is a structured way to prepare military writers for gravity of the writing tasks they will be responsible for in the future.

For example, in the later part of his career as an Anti-Terrorism Intelligence Specialist, Mark wrote reports in which he prioritized and summarized large amounts of 
large raw intelligence and made recommendations to Army commanders about possible courses of action. He explained:

We would take a certain subject, do a lot of research on a certain subject, and then write a detailed analysis of a subject... an entity... that we want to either develop more information on - so we would recommend to our command, and ultimately going up the chain of command, what resources we would like to see put against a certain target or entity to gather more information —or if it it's something we think ultimately should be taken out.

In other words, Mark regularly had to complete several high-order tasks: Distinguishing significant data from irrelevant data, distilling and synthesizing raw global intelligence, making inferences about potential threats, and arguing for a course of action based on his understanding of the intelligence. Mark explained that "[Intelligence Summaries] would get then published in a daily report command-wide up and out. So anybody can read it if they just log onto the website," making the quality of his work of paramount importance as he was open to significant scrutiny. Long-standing collaborative apprenticeship with his superiors not only prepared Mark to fulfill the significant demands of this kind of writing, but also meant a structure was in place for internal review and quality checking before a text was circulated widely.

Chris had a similar experience writing Area Studies for a Civil Affairs Unit in the Army. During his tours in Afghanistan, Chris and his team were responsible for gathering as much knowledge about the local culture as possible in order to guide the American military through interactions with civilians and leaders in Afghani communities. Chris explained that

Basically [Army Commanders] come to [Civil Affairs] like, "Hey, I've got a meeting with a local warlord, what can I do not to offend him?" So you go over stuff like don't use your left hand, don't show the bottom of your 
feet, engage in small talk for three hours while you sit there before you get... you're not going to get down to business directly.

To some extent, then, part of Chris' work was to create Area Studies that could help fellow servicemen and women navigate day-to-day encounters. But Area Studies are also used for training domestically ahead of deployments to the area and eventually Chris went on to re-write the Army's entire training program for troops preparing to deploy to southern Afghanistan based on his experiences there.

The formal reports and training documents that circulated necessarily had a particular style to suit a wide audience:

I learned to be really analytical with writing reports for that. [How so?] Umm... You tend to leave out a bunch of fluff. So you get straight to the point, you learn what's important, how to structure a good paragraph or good report. Your reports aren't just being read by some lieutenant, they're being read by colonels and generals and congressmen and etcetera.

Like other participants, Chris' description of his military writing underscores the expectations of concision, directness, and structure and an acute awareness of a wide and powerful audience. The quality of the intelligence Chris and his team gathered and the clarity with which they conveyed it to their fellow soldiers influenced everything from policy decisions to negotiations with local leaders to resolving conflicts with civilians. Because the military relies so heavily on cooperation with local populations, improper or offensive interactions could have dire consequences, making the stakes for Chris' work very high and reinforcing the importance of strong writing apprenticeship as part of his military training.

Even participants who did more "mundane" or "everyday" writing in the military remarked that they felt pressure to do that work well- pressure that was accentuated both by the training they received from their superiors and the institutionalized hierarchical 
review process for their writing. Thus, however simple the "form" might appear to be for an NCOER, award recommendation, or end-of-job report, the review process was intensive and demanded conscientious work. Participants described the importance of sending quality work up the chain because it reflected not only on oneself, but also one's immediate superiors and the individual being written about. For participants whose primary writing responsibilities were, for example, NCOERs or Counseling Reports, the writing that they produced had tangible effects on the people around them. Braden, for instance, talked about how he spent more time than was expected on Counseling Reports for the soldiers under him:

I tried to make them longer just because the more in-depth it is the better it looks for the soldier and their progression. If you don't put enough time into it and you just kinda, like, half-ass it, then they're not gonna look very good and they're not gonna look good for progression. That doesn't like make you look very good either 'cause you obviously don't care about their progression so you as a leader look pretty bad. But I'd always try to put a little bit into it so they could get something out of it. Because it's something you had to do and so if we're gonna have to do it we might as well make it worth it.

Thus, although he was only in the Army for four years and only wrote evaluations for other soldiers for about six months, Braden knew that NCOERs could have a direct impact on a soldier's career and reflect back on his own performance as a superior and mentor. Similarly, John explained that attention to detail in end-of-job reports and NCOERs included word choice: "We wouldn't put 'fail.' that's very bad. You know, that's very... If you tell someone they failed you know that'd be a red flag. You'd be like 'continue to work on,' you know, or 'needs improvement."' Indeed, despite specific expectations from superiors and significant constraints on space and organization, 
participants also found creative ways to convey messages, sometimes with multiple layers of meaning.

Other participants primarily wrote in more technical capacities but nevertheless recognized and remarked on the importance of their audiences and what was at stake in their performance as writers. For instance, although mechanical logs might involve less direct instruction and oversight than more formal writing, the demand for detail and accuracy was still high because the stakes were high as well. According to Jackson, the importance of those logs looms large in the mechanic's mind as every hour a helicopter is put into use and every bit of mechanical work completed on the helicopter must be logged in detail. Thorough logging can be essential to diagnosing problems with a piece of equipment and holding military personnel accountable in the event of a problem. In such a situation, specificity, clarity, and accuracy are all skills the military writer must bring to bear on his work in order to be successful because the audience for that writing could eventually be much larger than just the mechanic and the serviceperson operating the equipment. these participants' reflections on the writing they did for the military suggest not only that they knew who read their writing but also what they would be reading for, which demanded conscientiousness at every step of the writing process and underscored the importance of the mentoring and reviewing processes.

The participants' understanding of the varied yet significant stakes of their writing not only highlights the role of strong and continuous collaborative writing apprenticeship, they also point toward another reason why such an infrastructure is in place. The hierarchical structure of the military is such that no member is accountable solely to him or herself; rather, all members are responsible for one another in some way and higher- 
ranking officials are responsible for the actions of all those working below them. This is not to say that an individual will not face consequences for an error, but that individual's direct superiors will also share in that responsibility. The same premise holds, then, for the consequences of the writing done in the military. Thus, to ensure that you are represented well by your subordinates and that their writing both has a desirable impact and does not reflect poorly on you as a leader and instructor, you must invest the time into training them well. Through both direct (synchronous, specific instructions about how to complete a writing task) and indirect (asynchronous response to/collaboration on a particular writing task) means, the military writing "experts" instill the principles of military discourse in their subordinates so that inadvertent errors in meaning do not bring unwanted consequences on the parties involved.

\section{Conclusion}

Although labeling the military as a "literacy sponsor" is accurate, on its own the term occludes the exact nature of the relationship between new and experienced military writers. Looking specifically at the relationships described by these participants, who were all enlisted soldiers learning to write in relatively informal contexts, incorporating the concepts of collaboration and apprenticeship helps specify the nature of those relationships and illuminate the writing pedagogy being enacted. The collaborative apprenticeship model serves to prepare military writers for a process of creating, reviewing, and revising texts that will continue for their entire careers. That ongoing collaborative process also reinforces hierarchical structures and ensures that writing tasks are completed accurately, that the messages are rhetorically appropriate, and that 
undesired outcomes are avoided. Additionally, despite how the majority of the participants described their military writing as "easy" or "dumbed down," the thought process going into that work was actually quite rhetorically complicated. Moreover, the ability to complete that work in rhetorically sensitive ways is an important outcome of the military's collaborative apprenticeship model of writing instruction.

Despite being necessary in this learning environment, the time invested in providing one-on-one/side-by-side instruction and the rigidity of the expectations my participants described are unlikely to be found in college classrooms (perhaps even less so in FYW than in other subjects) and that can lead to frustration for student veterans.

In Chapter Four I discuss my participants' descriptions of learning to write in college and outline several key themes, including anxieties about authority, unfamiliar institutional structures, and disabilities. In this chapter I use the participants' reflections to demonstrate how they navigate the shift from an explicitly hierarchical institutional structure to an institutional structure that is similarly rigid but far less explicit. 


\section{CHAPTER FOUR: ANXIETIES OVER AUTHORITY AND SUPPORT}

\section{IN THE TRANSITION FROM MILITARY TO COLLEGE WRITING}

"Like they [college instructors] ask... Like, most of the writing I've done for my classes here are like, 'What do you feel about this? How do you feel about this?' And you don't have to write about anything like that in the military. It doesn't matter at all." - Braden

There are several apparent differences between the way my participants describe learning to write for the military and what the field of Rhetoric and Composition tends to regard as "best practices" in the writing classroom. The core of the contrast between the two seems to revolve around the issue of authority. Although the participants describe having increasing rhetorical skill and freedom the more they wrote in the military (making more conscious choices about word choice to achieve particular goals, for instance), my participants' narratives about military writing nevertheless tend to feature authority at their center: Superiors giving direct instruction and constant feedback, seeming certainty about the right and wrong ways to complete each form or report, and military doctrine and protocol determining virtually all decisions. The scene in many composition classes is quite different: Instructors abnegating authority and encouraging students to control the class' discourse, co-creation of knowledge and resistance of accepted "truths," open-ended writing assignments and formatting options. Admittedly, these descriptions are somewhat reductive, yet they strike at the heart of many of the tensions my participants described when they talked about writing in college.

Indeed, my participants are not the first to reflect on differences in authority and 
power-relations in college and the military. In Mallory and Downs' chapter in Generation Vet, "Uniform Meets Rhetoric: Excellence through Interaction," they discuss how offputting a slouching, unkempt, two-minutes-late, and disorganized English professor can be on the first day of classes. For students used to sharp creases, rigid posture, and always being early, the relaxed atmosphere of many college classrooms - not just in English— can make student veterans question their instructors' authority and preparedness (62). Other researchers discuss a similar concern from a pedagogical angle; for student veterans who are accustomed to instructors providing strict guidelines, closed-ended assignments, direct application of each lesson into practice, and somewhat firm boundaries around "correct" and "incorrect" answers, the exploration and negotiation of meaning that writing instructors try to cultivate can seem aimless and sometimes even useless (Cleary and Wozniak; Dalton; Hadlock and Doe; Mallory and Downs; Selting). Issues of authority and the practicality of course content are only two among many that student veterans describe when they reflect on their experiences in not only writing classes, but college classes in general. Frustrating though it may be the, reality is that there is no single source of tension between student veterans and academic learning environments in higher education. The experience of transitioning into college is different for every veteran based on their age, gender, race, educational background, military occupation, length of service, attitude toward academia, and so on. This is part of why educators tend to see such dichotomous depictions of student veterans in the media and in educational scholarship; two ends of an imaginary spectrum - the highly successful and well-prepared type-A veteran and the PTSD-ridden or war-wounded veteran-have come to represent common notions of what to expect from veterans in college classrooms. 
Missing from these representations is the nuanced reality of student veteran populations, a reality in which a veteran may fit both or neither of those stereotypes and where each student veteran possesses her own set of strengths and weaknesses that may have nothing or everything to do with her military service. That is, in the push to "prepare" for student veterans in college classrooms, educators have often essentialized them into a handful of tropes that are easily conveyed and understood by the masses (thanks, in part, to corresponding representations of veterans in film, television, news reports, etc.).

Preparing for student veterans is not so simple, however, because they are in fact individuals with individual needs. While they are united by their service to our country, they are diverse in their educational pursuits and proclivities. This realization highlights a paradoxical aspect of this research, which is that while one of the goals of this study is to help writing instructors and writing program administrators to better serve student veterans, there is no set of fool-proof recommendations that will be appropriate for all student veterans. However, woven through my participants' discussions of their experiences writing in college are anxieties about expectations (theirs and their instructors), their relationships with instructors and classmates, and avenues for accessing various means of support. To that end, this chapter teases apart some of the seemingly idiosyncratic tensions described by my participants in order to argue that 1) representations of student veterans as either highly successful or academically incapable are so essentializing as to be a disservice to students and instructors and 2) links can be drawn between the military learning environment participants described and their responses to learning in college classrooms that can help instructors understand student veterans in more nuanced and pedagogically effective ways. 
In this chapter, I share some of the common experiences my participants described in regards to writing classrooms and assignments, access to campus resources, and the impact of physical and cognitive disabilities on their studies. What binds these observations together are concerns — or even confusion—about hierarchies and demonstrations of authority and mechanisms for support in higher education settings. This chapter ultimately argues that transitioning from an explicit, rigid social structure marked by clear delineations of authority to an implicit and less rigid social structure in which authority is at times absolute but more often fluid or shared generates uncertainty about how to proceed in a variety of academic situations. I conclude that in many cases, there is a need for more explicit discussions of academic authority and values with student veterans and/or a more conscientious approach to course design and student support resource systems in order to ease the strain on student veterans as they acclimate to higher education.

\section{Authority, Structure, and Stakes}

As I explained in Chapter Three, the participants in this study provided almost identical narratives of how they learned to write in the military; one of the most resounding similarities was their description of being guided step-by-step through each new writing task until they learned to tackle it independently. Again, those narratives underscored the importance of correctness and compliance with both their immediate superior's expectations and military protocol in virtually all military writing tasks. Conversely, participants generally described their college writing experiences as allowing more room for imagination and creativity and as less concerned with correctness or 
compliance with overly-specific guidelines. For some participants, the lack of rigidity suggested to them that the stakes of their academic writing were relatively low. That is, while they readily talked about the importance of rhetorical choices in their military writing (word choice impacting the future of a subordinate's career, for instance), their reflections on academic writing revealed very little sense of "real life" impact.

This is not much of a surprise, though, considering the artificiality of much of the writing students in first-year composition are asked to do. And, despite increased interest in and demand for service-learning and otherwise "engaged" writing in first-year classrooms, ${ }^{16}$ the vast majority still rely on more insular genres for most of their assignments. ${ }^{17}$ Indeed, in a recent two-year CCCC Research Initiative Grant study, D. Alexis Hart and Roger Thompson found that $71.3 \%$ of the 205 institutions surveyed still require personal narratives as part of their first-year writing curriculum (“An Ethical Obligation" 9). Of the nine participants in this study, none of them had taken a writing course with a service-learning or community engagement component, suggesting that all of them had probably been engaged with genres that could only imply theoretical stakes in a hypothetical rhetorical situation. The language of such prompts is probably familiar: "Imagine that you've been hired for a local non-profit," "Compose a research essay

\footnotetext{
${ }^{16}$ Skimming through recent issues of major journals and publications from university presses, it is clear that involving students in "real world" writing with actual stakes is becoming increasingly popular. The National Council of Teachers of English website (which houses both College Composition and Communication and College English) for example, returns 136 hits for the search term "community engagement" in their print and digital publications. The Conference on College Composition and Communication also published its "Statement on Community-Engaged Projects in Rhetoric and Composition" in response to growing interest in such project across the field.

${ }^{17}$ This is likely due to two key limitations: 1) Developing community partnerships is difficult work, especially for instructors wanting to involve their first-year writing students, many of whom see first-year writing as a means to an end, not an opportunity to become truly invested in a long-term commitment with a local organization. 2) University expectations for promotion and tenure often place too little value on collaborative and community-based research for it to feel worthwhile to junior faculty who are already facing tight timelines for promotion.
} 
related to the field of study you hope to join as your major," "Choose a job advertisement that represents the kind of job you hope to apply to over the summer and compose your cover letter." All of these scenarios present helpful opportunities for students to rehearse rhetorical moves for their imagined futures and all of them can be valuable in their own ways. But their artificiality is not lost on the students engaging with them and that can impact not only the seriousness of their response, but also the way students perceive their usefulness. Personal narratives, rhetorical analyses, annotated bibliographies and even traditional research essays can feel fabricated and futile even for so-called traditional students, but may seem even more so to adult learners who enter the writing classroom with high-stakes, professional writing experience.

This tension these student veterans described over the value of imagined writing scenarios was not exclusive to first-year writing courses. One participant was currently enrolled in Technical and Science Writing when he completed his interview. When I asked how the class was going in general, he immediately shrugged and gave me a look that said "Do you really want to know?" I pressed him to explain what this gesture meant and he went on to say that although the course was required for his major, he felt like a lot of the writing he was doing was useless to him. His primary example was the résumé assignment. Not only had he completed a résumé during a course he had already taken in the Army, making the "practice" with a class assignment seem unnecessary, he also recognized that his military experience did not translate well into the more "traditional" style of résumé he was being asked to produce.

On one hand, some work with student veterans has already dealt with concerns over how to represent military experience on a résumé in meaningful ways (Rumann and 
Hamrick) and the Writing with Future, Current, and Past Members of the Military

Standing Group at CCCC 2016 even held a pre-conference workshop with veterans from the Houston area on résumé-writing. Resources for this kind of translation of skills and experiences can also be found easily on the web, especially from organizations dedicated to helping veterans find post-military employment. Thus, it is clear that transitioning into the civilian workforce is a major priority for many veterans and therefore the task Alex undertook in this course assignment was not necessarily without merit or completely "unnecessary" practice. And yet, it felt frustrating and useless to him, not in small part because of his plans to continue his military career for the foreseeable future.

Alex's experience highlights two key concerns about authority in the classroom. First, the instructor seems to be making assumptions about the value of their assignment and relying (perhaps too heavily) on an implicit authority_-both in their position as instructor and in the assignment itself. This can be particularly frustrating for student veterans who have significant training and experience; thus, as Leonhardy warns, "composition instructors must first recognize that we have much to learn from veterans, just as we have much more to do for them" (338). In this case, by taking for granted the usefulness of the assignment, the instructor also signals to students like Alex that s/he knows what is most valuable for students without much input from the students themselves. As I have suggested elsewhere, there is no "easy fix" here. Entire course curricula cannot be subject to the needs and demands of each different student. However, the context of courses like this one that effectively work in the same vein as a Writing in the Disciplines approach, students' previous experiences and future plans do seem particularly relevant, perhaps far more so than in the first-year writing sequence. Alex's 
experiences in this class epitomize the kinds of opportunities that are lost when student veterans' military experiences are misunderstood or undervalued; the student is taught that military experience does not carry authority in academic contexts and the instructor loses the chance not only to help the student import those skills productively into new settings but also to learn from the student veteran.

Second, Alex was reluctant to question the instructor's authority outright by asking for either a more explicit discussion of the value of the assignment or for an alternative assignment that might better suit his professional needs. Although he was allowed to make his final product slightly different from what his classmates had done, he more or less completed the assignment as designed and his attitude made it apparent he did not find much practical value in rehearsing for a scenario that seemed unrealistic or far-off for him. Instead, his tone suggested he was just going through the motions in order to get the grade that would get him into his major coursework. And Alex was not the only participant to describe college writing assignments that way; others expressed a similar understanding of what they had to do to "get through" a writing course, the implication being that in spite of their instructor's best attempts to expand students' horizons, they resisted by feigning interest and growth (or, at least thinking they were feigning it). As Jackson put it, "I realized that you've gotta kinda like, figure out what your teacher likes and then write like, to their standards" in order to earn a high grade. Considering the only real "stakes" as their grade on the writing assignment and in the course overall was a theme among these participants, and several of them unabashedly admitted writing however and whatever they believed their instructor wanted so they could achieve the best possible grade regardless of their personal goals or desires. 
Veterans are certainly not the only students prone to these kinds of performances; therefore, being more aware of these attitudes can be useful for any instructor as they reconsider their pedagogical approaches — even if they are not aware of any student veterans in their classrooms. Moreover, I contend that the reasons these participants chose to "fall in line" rather than push back or dig deeper might be more complicated than what traditional students in similar situations experience. More specifically, it is possible that student veterans draw on past military experiences with rigid hierarchies and processes for advancement and do not recognize opportunities to (or feel it is appropriate to) question the usefulness of classroom activities or assignments. Moreover, several participants also indicated a general frustration with the fact that much of what they covered in college courses was not directly applicable to something in their careers or daily lives. Compared to information covered in military training settings, most of which had a concrete and immediate purpose, college learning seemed vague and inconsequential to them. I would argue that even if this sentiment is common among most students (particularly during general education course sequences), it may be especially troublesome for student veterans whose previous experiences seem to stand in stark contrast to what they see as impractical or unhelpful coursework.

\section{Redistributing Authority: Cause for Concern or Celebration?}

For some participants, the freedom to design their own response to assignment prompts (which occurred in a range of degrees for the participants in this study, from nearly "free form" digital assignments to more nuanced conceptions of freedom like argument structure and citation style), worked in tandem with expectations that the 
students work through the research and writing process increasingly independently. Only a few participants welcomed this change. Braden, for instance, enjoyed the Concept in 60 assignment ${ }^{18}$ in his English 102 course $^{19}$. His instructor provided basic requirements for the project's length and the number of types of media the final product should include, but beyond that Braden was free to respond to the prompt however he saw fit. The result was a video about veteran homelessness in Louisville, a subject Braden felt passionately about, due in part, no doubt, to his military service. When I asked Braden if he preferred the open-ended style of the Concept in 60 assignment or the more structured response papers he was required to write for his Theatre Appreciation course ${ }^{20}$, he surprisingly answered that he much preferred the freedom of the Concept in 60 assignment. Under more strict guidelines, he explained, "I have a tough time trying to fit my line of thought into what they want it to be." In other words, Braden seemed to recognize that more restrictive assignments limited his freedom to think and explore and he struggled to make his perspective "fit" within his instructor's.

Rather than causing him anxiety, being given authority over his work made Braden feel more at ease and more capable of expressing himself. It is of interest to note that much of Braden's time in the Army he was working as a diver, which is an elite specialty that highly values independence. In his first interview, Braden described his time as a diver this way:

\footnotetext{
${ }^{18}$ This assignment asks students to create a 60 -second multimodal video about a concept or concern of their choice (often within the context of the course's larger theme).

${ }^{19}$ This course, Intermediate College Writing, is the second course in our two-semester composition sequence and it focuses on developing research-based arguments.

${ }^{20}$ In this course, students were required to write brief response papers each time they attended a play on campus. The assignment dictated the expected word count as well as a set of specific questions that had to be answered in a specific order. In essence, the Theatre Appreciation course assignments sounded a lot like how participants described the genres they worked with most in the military.
} 
It kind of feels like an odd part of the military because in the military like, you're... People think everybody's... Every step you take, you know, somebody's looking over you and you're gonna be told exactly what to do. But the dive field's not really like that because when you're underwater you're probably the only guy there, and probably whoever you're with isn't going to be able to see what you're doing and they're trusting you to figure out the situation. Like, there's going to be a different, or like, a million different ways to solve this type of problem and you've gotta figure out the best way for you to solve this problem. It's a lot of independent critical thinking skills involved with that.

Braden clearly recognized that the way he functioned as part of his dive team was different from the way soldiers in other specialties routinely operated and even how he had to operate at different points in his military career. On the dive team, rather than feeling like a cog in the machine, Braden felt great personal responsibility and a corresponding sense of independence. In his second interview, Braden re-articulated the same contrast and concluded by saying that because of his time working in a specialty that allowed him some measure of intellectual freedom, he "didn't lose all of that""that" being his ability to think for himself and act independently — and his transition into college was probably easier as a result.

I recount Braden's experience at length to highlight two important observations, one of which is the direct impact of his military experience on how he saw himself as a student and how he learned in college. Braden explicitly drew the connection between his specialty and his understanding of independence and authority in college coursework, suggesting the salience of the connection between the two contexts. Many other student veterans likely experience a similar level of influence, underscoring the importance of taking military experience into account when working with and assessing student veterans in higher education settings. The second observation is that of my participants, Braden was one of only two to suggest their specialties allowed or encouraged the kind of 
independence he described and he was, not surprisingly, in the minority when it came to enjoying open-ended, independent writing projects. Thus, his experience points again to the importance of resisting the urge to generalize about student veterans, their experiences, and their expectations in the classroom. Minority or not, his unique perspective is nevertheless valid and worth considering in discussions about veterans in higher education.

For students unlike Braden, the freedom to pursue unique lines of inquiry independently caused varying degrees of concern. For some, room for exploration and flexibility in presentation expectations sometimes negatively impacted participants' sense of the stakes of their writing - making them feel as if their instructors did not "care." While it is possible that participants who made this remark about a course were sensing some actual apathy from their instructors - perhaps instructors in the midst of a particularly busy semester or dealing with an unusual amount of personal stress - there is a more interesting possibility, which is that the participants perceived a lack of interest from instructors who were in fact purposely sharing authority over writing projects with students. An unexpected redistribution of authority could seem particularly strange or even frustrating for a student veteran accustomed to a system with rigid hierarchies where one's superiors not only take an active role but also have a vested interest in project outcomes. What these students may struggle to see is that while overt embodiments of authority like direct orders and hands-on instruction sometimes characterized "support" in the military, writing instructors may often diminish their own authority as their own strategy for supporting students. If made more explicit, this rationale for allowing students more freedom could be less likely to be perceived as a lack of instructor 
investment and less likely to meet with resistance — which would be beneficial not only to student veterans, but to students in general.

Similarly, several participants remarked during their interviews that they sometimes wished their instructors would tell them exactly what they wanted in response to assignment prompts. Jackson, for example, said "I like to just know what the teacher wants so I can just do that.” For these students, a successful writing assignment was often one where they "gave the teacher what she wanted" or "told him what he wanted to hear," suggesting that what these students valued most was getting the "right" answer and the "good" grade, not learning to think in new ways or exploring a new topic of interest in an open-ended way. This response is due, in part, to the conditions under which these students wrote in the military. In Braden's words, "Like they [college instructors] ask... Like, most of the writing I've done for my classes here are like, 'What do you feel about this? How do you feel about this?' And you don't have to write about anything like that in the military. It doesn't matter at all." Instead, military writing privileged factual information, conveyed succinctly and written correctly. More open-ended assignments in writing courses, on the other hand, can become a source of anxiety when the student veteran is unsure where to draw their own boundaries.

As Mark explained,

I enjoy the strict structure of a paper that says "You will write about these certain subjects." "Cause my mind, if I'm given the chance on a free form project, like in 102, I find that I'm wandering a lot in my paper. And, like, I was telling my professor, I feel like I'm babbling a lot as I write 'cause I have a lot of thoughts that need sometimes focused. So, I try to focus as I write as well, but I always explain to her every time I submit a project, "Please let me know where I'm starting to wander in my writing because I feel like I'm babbling at certain points when it comes to my ideas that I'm trying to convey." 
Without strict military guidelines, students like Mark are—in addition to the expected goals of the course-also learning how to self-regulate and to refine their lines of inquiry and sense of focus. For student veterans, this is a specific challenge that could be addressed more explicitly in order to deepen their understanding of academic discourse and to help them develop concrete strategies for addressing it in the future.

Additionally, several participants implied or stated that being asked (or forced) to be more independent in college writing situations than they had had to be in the past caused them some anxiety even before beginning the "official" writing process. When asked what his English 102 instructor could do to better support him in the research and writing process for an assignment later in the semester, Jackson's answer crystalized the impression I got from many of these participants in regards to what they wish college writing assignments and instructors could be like. He said:

I know like with research like, if you like, well... Like a lot of teachers that I've had in the past, when we do research papers they'll take you to the library and help you out. 'Cause I know like, me personally, and other people like me, are kinda shy when it comes to going to the library and actually trying to dig into stuff. [...] Providing class time for actually going and maybe not even researching, but just like, being there if people need help to find sources, kind of guide them, teach them, I find that helpful.

What Jackson was asking for should sound familiar because it echoes the writing and instruction process my participants described from their learning experiences in the military. He is essentially saying he feels more comfortable doing something new or difficult if the instructor is by his side guiding him or is available immediately if he has any questions about what he is supposed to be doing. Certainly student veterans are not the only ones who sometimes feel this way when approaching new academic tasks, but 
these participants' reflections on how they learned to write in the military seem to be directly tied to their expectations (or at least hopes) for how complicated skills will be dealt with college. Walking students through complicated research projects or digital projects is only sometimes an instructor's priority, and often once the classroom session devoted to a topic has happened and the instructor's office hours have passed, students can feel unsure about where to seek further support. This might be a stark difference for student veterans who have been accustomed to much easier access to the resources they need on a base or command post, first instance.

Luckily for Jackson and other students at the University of Louisville, there are tutors and consultants available at various locations across campus who specialize in research and digital media in addition to the tutors at the University Writing Center who work with students on the rhetorical side of all types of projects, digital and otherwise. In Jackson's case, when I asked if he was aware of any of these resources, he said he was not. Of course, it is entirely possible his instructor may have had an introduction to those resources planned for the very next class meeting and I want to be clear that I am also not suggesting his instructor is responsible for him being unaware of their existence. There is a great deal of content to cover in any class and it cannot all be previewed in the first few weeks or alluded to on the course syllabus. (Plus, there is also the possibility that these resources were alluded to in a class early in the semester or on the course syllabus and Jackson just had not noticed or remembered.) However, it is nevertheless true that these resources cannot be helpful if students are not aware of them and, perhaps more importantly, if it is not clear to students exactly what kind of guidance they provide. 
What Jackson also did not know is that a class visit to the library to learn about how to use its resources is a common practice in our department. He seemed relieved when I told him as much as his lack of awareness had already led to anxiety about how to he would proceed with the project without sufficient instructor support. Here again, we see how the opaque nature of the university system can occlude the numerous means of support in place not only for student veterans, but for all students. On one hand, one might argue that it is the student's responsibility to reach out and ask about available resources. On the other hand, in the case of student veterans, the act of asking for help can be particularly fraught with concerns about who the appropriate point of contact might be and what apparatuses for assistance they ought to engage with. That is, in a military setting where the chain of command is explicit as are the procedures for essentially any type of inquiry. In contrast, understanding the "chain of command" in a higher education setting is a particular kind of literacy that is not necessarily intuitive, perhaps particularly for students who are accustomed to more straightforward systems. While a given university might publish an organizational chart somewhere on its website, that is still nowhere near as easy to find or understand as a ranking system that participants physically wear on their bodies, literally announcing their relationships relative to one another and their unique operational specialties or areas of expertise via visible symbols. In a military setting, then, physical markers can not only denote an individual's place in the hierarchy, but also the kinds of information they might be able to provide. This is important not because all student veterans will necessarily need to use support services, appeal a grade, or withdraw from a class, but because when they do need to take those kinds of steps, navigating the system can be exceptionally difficult. 
And, while the university power structure might in some ways resemble military hierarchies, student veterans cannot simply map one onto the other and find solutions. Some issues, for instance, can easily be addressed by an instructor, others by an academic advisor, others by the GI Bill benefits Certifying Official, and so on. In the case of student veterans like Jackson, then, it is particularly important to find more effective ways to make explicit what services are available, what kind of assistance they provide, and what procedures to follow for a wide variety of typical student issues.

\section{Authority and the Mastery of Grammar and Genre Conventions}

Another trend in my participants' responses was a persistent preoccupation with superficial concerns like spelling and grammar. Their overwhelming focus on sentencelevel errors in college writing hearkened back to the kinds of concerns they mentioned when describing the review processes they experienced in the military, and I would argue that the concerns of their military writing mentors lead these participants to continue to value (or even privilege) those aspects of writing when they entered the academy. I asked all of my participants, "How would you describe yourself as a writer?" and more than half of them responded immediately, as if it were a trained response, "horrible" or "terrible" or "awful." When I pressed them to explain why they thought they were poor writers, they consistently said it was because they were bad at grammar, spelling, punctuation, or sentence structure. Not one participant who described himself as a poor writer initially mentioned a higher-order skill they struggled with.

For one participant, anxiety about spelling and grammar kept him from seeking feedback on his writing from anyone but his instructors. Interestingly, Mark was a high 
ranking member of the Army who worked largely in Intelligence for the last 10 years of his 20-year career. At his post in Hawaii, Mark worked independently to draft countless intelligence reports and was apparently highly successful. Not only was he trusted with the important task of gathering raw intelligence and distilling it into a report in which he made recommendations about military action, his reports also had a wide and highranking audience. As such, the Army must have had a great deal of confidence in his ability to think critically and to write. Like Braden, he was one of very few soldiers he knew who held a position where he was encouraged to think and write independently: "It was always one of our jokes that in our profession you were one of the only professions to get paid to provide your opinion. And most other ones you tell the young'uns, the other people, you tell them 'You're not paid to give your opinion, you're paid to do."”

Nevertheless, Mark was the participant who was most preoccupied with concerns about spelling and grammar to the extent that he would not let his own wife read his work because he did not want her to see how poor his writing was. While I would consider the types of errors he described as indicative of poor editing and proofreading, he dismissed his own writing abilities entirely. He explained that he worries his wife-and his classmates - would "look down" on him if she saw the superficial errors he makes in his writing. Speaking of his wife, he jokes, "I say, 'You'll divorce me if you read my papers." Early in our interview he asserted, "I hate to write. I hate it. With a passion. I even told my English teacher that in an interview." Certainly Mark's concern about the superficial elements of his writing might be to some extent idiosyncratic; after all, we all have our own insecurities. It seems, though, that his insecurity could very well have been reinforced by writing feedback that focused on spelling and grammar. 
Similarly, another participant swiftly reduced the efficacy of his English 102 course down to his ability to master the different styles of citation. John complained,

It was easy. I didn't really do much. [...] They wrote like, two papers. [...] I was like, "Let me take it so I can learn how to write how you all write." 'Cause I didn't understand the styles and everything you know... MPA? I don't even know what they are. [...] She didn't... she didn't require none of "em. She goes, "Well this is for this, this is for that, this is for this." So it's like what style do we...? I'm looking for a style. A style. I'm looking for a template. But there is none. So, I mean I just went back to... I reverted back to high school. You know, the paragraph that's your topic, you add a couple paragraphs in the middle, then you have your conclusion. And that's what I did.

In this discussion, John's concern about writing styles is directly linked to his desire for a "template" for writing, which suggests that he mistakenly assumed that academic styles like MLA and APA would offer that kind of clearly delineated structure for writing projects. John thought that mastering MLA guidelines would be the key to how "you all"-a.k.a. academics in the humanities—write, when in fact those guidelines may only determine features like document formatting and citation practices. In the absence of such templates, John essentially reverted back to the only other academic template he was familiar with: the five paragraph essay. His tone suggested he was confident in his ability to mimic that structure and felt comfortable employing it in the context of his 102 class.

John's comments highlight two key observations; the first is that he came into the course expecting to acquire the "key" to unlocking academic writing and expected that "key" to come in the form of some kind of template. Although John does say that he thinks the instructor did help him with his writing to some extent, this part of our conversation ended with John concluding, "So, all these ‘styles?' Still no clue. None," with a dismissive shrug, as if that were nevertheless his ultimate metric for the usefulness of the course. Both Mark and John point toward a key set of underlying assumptions 
about college writing instruction and writing in general. Their comments reveal that they value the features of writing that are easily observable, can be characterized as correct or incorrect, and/or can be likened to a kind of "formula" for academic writing. In both cases, the participants made direct comparisons to what they had become accustomed to in military writing (e.g., frequent and intensive commentary on issues of spelling and grammar and the availability of templates) and indicated that they had carried those expectations with them into their college writing. These sentiments were common among most of my participants. They explicitly stated at times, and implied at others, that the way they had written in the military shaped their expectations for writing in college and even at times made it difficult to adapt to college writing.

It is important to note that neither the desire for an academic writing template nor reducing the effectiveness of one's writing to its surface correctness are unique to student veterans. Surely many "traditional" college students and non-veteran adult learners have similar impulses. I argue, however, that these assumptions might be particularly difficult for student veterans to overcome due to the highly-immersive nature of military experience, the intensive nature of the collaborative apprenticeship model of writing instruction participants described, and the high stakes associated with the modes of writing they are accustomed to. Moreover, as I discussed in Chapter Three, one way that authority is conveyed in the military writing my participants described is through access to and mastery of specific forms/genres. With that in mind, both John and Mark's comments might be less indicative of a desire for formulaic writing assignments or for instructors to actually focus on spelling and grammar in their assessment and might be more indicative of a belief that similar academic or professional gains—-such as high 
grades, high GPAs, or even making positive impressions on a faculty member in their field — could be at stake through similar demonstrations of mastery.

Thus, another factor that sets student veterans apart on this aspect of college writing instruction is that in many cases, their previous experiences with generic conventions and correctness have been tied directly to assessments of their professional accomplishment and opportunities for advancement. From this perspective, we can begin to think of the tension some student veterans describe not just as a tension between different styles or genres of writing (i.e., the assumption that it is difficult to transition from military to academic writing because one is formulaic and the other is open-ended) and more as a contrast in what is valued in different writing contexts. This can open the door to more explicit discussions about how, for example, mastery of the technicalities of specific citation formats is less important than the quality of sources being cited and the strength of the argument being constructed. This is not to say that the details of MLA formatting, like issues with spelling and grammar, are insignificant; rather, they can be dealt with secondarily in consultation with a friend, tutor, or handbook and need not be memorized or mastered in order to be considered a "good" writer. Ultimately, these observations suggest yet another way in which explicit discussions of how authority is earned and demonstrated in the context of the college writing classroom could be beneficial to student veterans and no doubt other students as well.

\section{Un/Disclosed: Authority and Disabilities both Perceived and Invisible}

Unlike some of the preceding themes that emerged from my interviews, which have not historically been addressed significantly in research about student veterans in 
writing studies, issues that student veterans might encounter if they are affected by PostTraumatic Stress Disorder (PTSD) or Traumatic Brain Injury (TBI) are probably some of the most common topics of discussion in veteran-studies-related research across the disciplines. PTSD, a collection of symptoms developed in response to high-stress, traumatic encounters like those soldiers are likely to have in combat, is perhaps the more well-known of the two conditions. Meanwhile, TBI is becoming more common in discussions of post-9/11 veterans because of the prevalence of weapons like bombs, also known as improvised explosive devices (IEDs), and their ability to cause major head injuries that can significantly disrupt cognitive functioning. The emphasis on these conditions in educational research on student veterans is not altogether unwarranted; in 2010 researchers estimated that "soldiers have about a 40 percent chance of cognitive injury during their times of service" and that number may be higher as research continues to show the diagnostic strategies for both conditions are still developing and are not always equitably applied (Wood 158). Obtaining accurate estimates of PTSD and TBI is further complicated by the number of soldiers who are unlikely to reveal symptoms for fear of negative professional or social consequences.

While the majority of these injuries are mild, they "can impact all aspects of life, including the development and maintenance of interpersonal relationships and the ability to function in social settings" (the Defense and Veterans Brain Injury Center, qtd. in Wood 159). From an educational perspective, it is also significant that both TBI and PTSD can impact cognitive functioning, including issues with concentration, attention span, and "so-called executive functions, such as planning, organizing, abstract reasoning, problem solving, and making judgments" (National Institute of Neurological 
Disorders and Stroke). Moreover, the NINDS adds, student veterans with TBI may also experience "difficulty with understanding and producing spoken and written language." The prevalence of both conditions is also such that it is likely that many student veterans can suffer from both, each compounding the impact of the others' symptoms.

From psychology to student services to educational leadership, it seems like representatives from all facets of university culture are interested in how a student veteran's potential PTSD or TBI will affect not only that student's experience and performance in college, but also the university community as a whole. A keen example of university-wide interest in issues like PTSD among student veterans is described in Linda S. De La Ysla's chapter "Faculty as First Responders" (2014) when she describes her experience with a student veteran who wrote a troubling and violent personal narrative in response to an assignment in her composition course. I want to set aside for now the oftasked question "What do I do when a student veteran writes or says something troubling or violent in my class?" as such occurrences were neither within the purview of this study nor mentioned at any point in the study's interviews. Rather, more relevant to this discussion is the complex system of responses that was triggered by this student's essay being published in the school newspaper. Before 48 hours had passed, De La Ysla had been called in to meet with her Dean and she was asked to appear before the school's "Behavior Intervention Team (BIT)" (103). Having perceived the student's essay as an indicator that he had the potential to become violent or otherwise be a threat to his fellow students, the BIT interviewed the student and almost immediately suspended him until he could provide documentation that he was being treated by a VA psychologist. 
I recount De La Ysla's experience here to highlight two key points: 1) The most common narrative that civilians (both in and out of higher education) hear about veterans seems to be tied to their status "wounded warriors" with the potential to explode at any given moment and 2) as a result, one of the most highly efficient processes for "dealing with" student veterans on campuses like De La Ysla's is geared toward neutralizing the threat of the veteran, not supporting the veteran. Because of media representations of veterans as "ticking time-bombs" and, in fact, a trend in educational research (including within writing studies) to focus on experiences with student veterans who obviously suffered from either PTSD and/or TBI, those stereotypical "warning signs" like anger, aggression, hyper-vigilance, etc., are some of the only features college instructors know to look for in their students. In reality, both PTSD and TBI are significantly more complicated, especially within an educational context. Our misunderstanding is due, in part, to a reliance on medical models of disability which limit our ability to recognize or address conditions like PTSD and TBI in a classroom setting. Traditional medical views of PTSD and TBI not only provide fodder for fears of the unpredictable and caustic student veteran, they also serve as a means to cast student veterans afflicted with either condition into a position of "lacking" particular skills or abilities necessary for success in college. In many cases, the knee-jerk reaction is to assume that if a student veteran is not one he is likely the other; if not a potentially explosive presence in the classroom, then possibly struggling with concentration, higher-order processing, or short-term memory loss.

Ultimately, this narrow perception of the prevalence and effects of PTSD and TBI — born out of the medical model of disability — is limiting for both the student 
veteran and the instructor in several ways. First, even in situations where a student veteran willingly discloses that she has been diagnosed with PTSD or TBI, it encourages the instructor to make assumptions about the impact the condition may have on her work. Second, very few instructors are aware of what they can or should do to accommodate a student who discloses such information. As Elizabeth O'Herrin explains in "Enhancing Veteran Success in Higher Education," (2011) "fewer than half of all schools with military and/or veterans programs offer opportunities for faculty and administrators to acquire information about the unique needs of military student populations" (qtd. in De La Ysla, 108). This finding is reinforced by Hart and Thompson's 2014 survey which revealed that very few instructors and administrators in English or Composition programs had received any training on issues related to student veterans or knew what services were available for student veterans - including for academic or psychological support (“An Ethical Obligation,” 4, 8).

In cases where the student's condition has been documented and their concerns are primarily academic, a common response is to fall back on the typical protocol for learning disabilities, which is to refer the student to the campus disability resource center and await further guidance from them (assuming the student is willing and able to reach out to and work with them (Wood). As Tara Wood explains in "Signature Wounds: Marking and Medicalizing Post-9/11 Veterans," reliance on the medical model of disability is what leads instructors down this path of "no accommodation without documentation" and it makes it all too easy for them to remain entrenched in narrow conceptions of conditions like PTSD and TBI and how to deal with them in the classroom (161). Instead, she argues, movement toward a social model of disability can "offer 
promising alternatives to the medical models and cognitive rhetorics that inhibit access and exacerbate the stigmas associated with disability" (157). That is, rather than focusing on the "cognitive, functional, and skill-based literacies" that PTSD and TBI might affect, instructors and administrators should be considering the "political, social, and cultural challenges" facing student veterans with these conditions (164). Like many of the recommendations offered earlier in this chapter, a social model of disability would be beneficial for all students with disabilities, not just student veterans.

In trying to understand the myriad ways that PTSD or TBI could affect a student veteran in the classroom - including among our considerations, for example, strains on interactions with peers, lack of sleep, or fears of being cast as damaged or deviant by classmates and instructors alike - a social model of disability asks us to look beyond assumptions of skill deficiency toward "an incredibly complex set of challenges, experiences, and expectations" (164). For Wood, this is an opportunity not only to better understand and accommodate the needs of student veterans, but also to "increase access and promote inclusivity...for all students in the class" (165). In other words, challenging ourselves to re-conceptualize conditions like PTSD and TBI is an opportunity to reconsider disability more broadly and to resist casting students with disabilities as inherently lacking or in need of adjustment.

Such an approach is complemented by the principles of Universal Design for Learning (UDL), which "stress[es] multiplicity and inclusivity for the representation of information, for how students express what they know, and how students can be active learners" (Grohowski 2). By using UDL, instructors can "focus on inclusive design in order to reduce barriers student veterans report facing, as well as the stigma attached to 
needing accommodations and assistance" (2). UDL thus offers a framework for creating assignments that allow students to respond in ways that utilize their strengths and minimize their weaknesses and for re-thinking assessment in similarly open-minded ways. As a result, disability is no longer inherently signals a deficit that requires accommodation; instead, courses and assignments are designed to be accessible to all students regardless of disability status. The two narratives that follow offer examples of how the adoption of UDL and the associated social model of disability could benefit not only student veterans, but all students.

\section{Chris' Story}

In the course of my interviews, only two participants revealed any history of PTSD or TBI and together they represent two strikingly different cases of how these conditions can impact a student veteran's performance in college. The first student is Chris, an Army veteran who was medically discharged from the military after sustaining serious injuries when he was struck by a drunk driver while out for a run on a domestic base. The accident led to his spending two years in Walter Reed before he was officially discharged in 2013, but before that he had also been on two tours of duty - one to Iraq and one to Afghanistan. When Chris and I first met at a busy café on campus, I spotted him immediately because he seemed to epitomize — at least visually — the "wounded warrior" with a cane and a service dog sporting a vest emblazoned with several militaryaffiliated patches. Unlike some student veterans who aim to "pass" as "regular" nontraditional students, Chris seemed to announce his veteran status with several aspects of his appearance. Chris immediately spoke openly about his injuries in the accident, the 
time he spent in Walter Reed, and his subsequent and ongoing battles with PTSD-related depression and suicide attempts even though my questions did not directly ask for that information. Throughout the initial interview, Chris also mentioned spending time at the Office of Military and Veteran Services and the Disability Resource Center, making it clear he was not only aware of the services available to him on campus but also taking advantage of them. I got the impression that Chris was probably just as forthcoming about his various physical and psychological conditions with his instructors.

Chris's physical and psychological injuries had impacted his education in many ways by the time we met; he had moved back to Louisville so he could live with family members after being given an ultimatum by his VA psychologist: either reside with family who could help care for and support him or be hospitalized indefinitely. As a result, he was limited in his options for universities to attend and chose the University of Louisville because it is the best in the area for his field of choice, Social Work. Additionally, Chris learned early in the semester that a full courseload was beyond his capabilities and he had already been forced to drop two courses by the time we met at midterm, again at the demand of his VA psychologist, because he had been so overwhelmed he was not able to regularly attend his appointments. Given the choice between lightening his courseload or being hospitalized — which would effectively mean "failing" the entire semester-Chris called dropping the second course "the lesser of two evils." He also remarked that he had scheduled his classes so he had an hour or two to "decompress" in the Office of Military and Veteran Services between classes rather than going directly from one to the next. Chris also talked about spending considerable time in the university's Disability Resource Center and was working with them to set up regular 
“puppy play times" for DRC students where they could come in and play with puppies as a strategy for relieving stress and anxiety.

On the one hand, Chris's seems to fit some of the stereotypes of the student veteran "afflicted" with PTSD and TBI; he has issues managing his courseload, visibly walks with a limp and has a service dog, talks openly about both physical and psychological conditions, and occasionally has to miss class for VA appointments. Chris also struggles with managing his temper, something he did not reveal until the second time we met. Sitting down again in the same café as before, Chris told me how he had just "yelled" at a man outside for having an unofficial service dog on campus. Perhaps unknowingly, Chris was talking loudly and aggressively compared to the relatively quiet crowd at the café - probably a combination of adrenaline from the recent confrontation and the hearing loss he suffered as a result of "being blown up one too many times." Chris remarked that his therapist was going to be "berate" him for confronting the man outside: "He prefers me just to walk away. But sometimes it, especially with PTSD, I tend to get angry. I can get angry just like that [snapping noise]. It doesn't present as anxiety as a lot of people have, it actually tends toward anger-rage." As he explained the impact of PTSD on his temper, I wondered if any of Chris's peers or instructors had ever noticed those aspects of his condition or perhaps even felt uncomfortable or threatened because of changes in his mood or the tone of his voice. In other words, I wondered if in spite of how candidly he talked about currently being treated for PTSD and anger management, how well he was doing in his classes, or how involved he was on campus and in the larger veteran community, Chris might also be the kind of student who could end up being referred to something like De La Ysla's "Behavior Intervention Team." 
While Chris might struggle in many of the "expected" ways with PTSD and TBI - a struggle that has been in some ways mitigated by his ability to take initiative in seeking psychological and academic support—many student veterans are neither so visibly marked by their military service nor open about their conditions. Indeed, "students' connections to war may be largely invisible to us as instructors" (Thompson 201). Chris was the only one of my participants who seemed to announce his status as a veteran on campus; the rest of the participants told me that they tried to blend in with other students on campus and, if anything, would only disclose their status if it came up naturally in the course of a class discussion or they encountered someone they could easily tell was also a veteran. Resisting disclosure is a choice student veterans make for any number of reasons, but many times it is a decision imbued with social and political implications. That is, these veterans often want to avoid being marked as such so as not to impact their interactions with instructors and classmates for better or for worse.

Disclosure of service-related injuries works similarly in that many student veterans do not want to be cast into the typically accepted post-service narratives like the wounded warrior, the ticking time-bomb, or the wartime hero (Wood 162). Or, in other situations, student veterans who face service-related challenges in the classroom do not disclose those issues to their instructors because they do not want "special treatment" or an "unfair advantage" over their non-military peers, a sentiment that was echoed by several participants speaking about themselves or other student veterans they knew.

Invisible and undisclosed, PTSD and TBI can become critical barriers to student veteran success and "create significant institutional problems" for faculty and administrators. In 2008, the Americans with Disabilities Act was amended to include 
"concentrating" and "thinking" as part of its list of "major life activities" that, when disrupted by some kind of medical or psychological condition, could qualify a person for a documented disability (Wood 159). As a result, it became easier for student veterans whose PTSD or TBI interrupted certain cognitive functions to seek documentation from a medical professional and, ultimately, accommodations and support from campus Disability Resource Centers and individual instructors. This is particularly important for students like Chris, for instance, whose conditions were well-documented long before attending the University of Louisville. But what about student veterans whose conditions are not diagnosed or documented? Or student veterans who have been diagnosed but do not want to disclose their diagnoses to either the DRC or their instructors? In an institutional environment where there can be "no accommodation without documentation," options for student veterans and their instructions can quickly become limited (Wood 161).

\section{Ryan's Story}

Such was the case for the second participant in my study who, despite never explicitly mentioning TBI, struggled with short-term memory loss and did not disclose that information to his instructors. Ryan joined my study after I made a visit to his English 102 class to introduce myself and describe the types of students I was interested in interviewing. I found out several weeks after that visit, when I met Ryan for his interview, that my presence in his class that day inadvertently had a larger impact on his experience in the course. Because this particular instructor taught two sections of 102 in the same room back-to-back, I dropped in for the last five minutes of Ryan's class and 
then waited in the back of the room while they filed out and the second set of students got settled in. As a result, I was there to hear the instructors parting message to Ryan's class, which was one of disappointment and frustration because so few students had come to class with their homework done in preparation for the activities that day. While we waited for the second section of students to arrive, the instructor-who was very young and only in her second semester of teaching — asked if I had any advice for encouraging students to come to class with their reading assignments completed and textbooks in hand. I suggested she take a few minutes at the beginning of each class for a short, lowstakes reading quiz that she could count as part of the students' participation grade for the day. She agreed, thinking that it would probably only take a few instances of losing points for the unprepared students to start feeling more motivated.

A few weeks later when Ryan and I met, I asked how the class was going and like many of my study participants he expressed a certain level of frustration at having to "review" concepts that he felt like he had already been trained on during his time in the military. He also explained that he was annoyed by his peers who very clearly had no interest in participating in the class activities and therefore made class difficult and frustrating for both their instructor and their more prepared peers (like himself). "I'm not enjoying being with traditional students whatsoever" he said. "They're unprepared, they complain. Then I feel like, 'You obviously didn't do the reading.' [...] There's uh... the only discourse is between maybe two other students and myself and the professor in the classroom." Then Ryan spontaneously added that there was one part of the class that had been particularly difficult for him recently—the reading quizzes his instructor had instituted in response to his classmates regularly coming to class unprepared. "I have a 
horrible short term memory," he said, "so I'm not committing the Everyday Writer journal to memory, so I'm failing her little quizzes that she does. So you know, it's very frustrating." Although Ryan seemed to understand the reasoning behind the quizzes, his inability to retain detailed information like a specific definition of plagiarism from daily course readings was affecting both his grade and his attitude toward the class.

In our discussion, Ryan never stated that he had TBI or mentioned any specific events that would necessarily reinforce my suspicions (unlike, for instance, Chris's comment about having been "blown up a one too many times"). Moreover, it is important to note, as Wood does, that "By no means does a symptom list equip instructors of composition with the means of diagnosing student veterans in their classrooms with either TBI or PTSD” (160). However, knowing that Ryan has a military background, that he was deployed overseas several times, and that he struggles with short-term memory does make a TBI seem possible or even probable. But the situation is complicated by several factors: First, as far as I know, Ryan did not disclose his short-term memory problems to his instructor. Second, even if he had, she may not have been willing or able to make any accommodations his behalf without some kind of documentation from the campus DRC. Third, if Ryan had proper documentation of a TBI that listed short-term memory loss as one of his symptoms and presented it to his instructor, it would then pose an interesting challenge to the instructor to find alternatives for Ryan that would also be fair to his classmates. Such accommodations can be and are often made, but they nevertheless pose pedagogical challenges to instructors.

Chris and Ryan's stories highlight some of the myriad difficulties student veterans face as well as some of the challenges instructors face in trying to accommodate their 
needs. Chris's seemingly "stereotypical" presentation of PTSD and TBI symptoms is much less "stereotypical" when you consider how well he is managing his conditions and maintaining high standards of academic performance. By being open with his instructors about his conditions, making immediate connections with both the DRC and the Office of Military and Veteran Services, and reducing his courseload so he could keep up with his work and his medical and psychological needs, Chris set himself up for success in spite of his potential setbacks. In doing so, he also embraces the social and political implications ascribed to his veteran status and his conditions. Meanwhile, Ryan, who effectively shows no obvious signs of any combat-related physical or psychological injuries, has chosen to go through his coursework - or, at least his English 102 coursewithout disclosing a personal difficulty that is directly affecting his performance on graded class assignments. Ryan's decision may be indicative not only of his concerns about being labeled with a combat-related injury, but also an attitude fostered by a long career in the military, one that would not allow him to receive any special considerations that might give him an "unfair" advantage over his peers. In both cases, these student veterans are making choices that involve dimensions of authority - their authority over when and to whom to disclose sensitive information, the DRC's authority in determining the validity of specific medical and psychological conditions, and the instructor's authority over course assignments and reasonable accommodations. Moreover, both students seem to epitomize and push back against some of the routine expectations instructors might have of their student veterans.

Their stories can also "create an awareness that might inform institutional policy, curriculum design, and classroom practice" (Wood 160). That is, they demonstrate how 
varied the symptoms of conditions like PTSD and TBI can be as well as how unique every student veteran's approach to dealing with those conditions might be. Such variability expectedly makes developing a uniform approach—especially one based on the medical model of disability — to PTSD and TBI not only difficult, but ill-advised and unhelpful. Of course, instructors cannot read students' minds and ultimately there may be little to be done to assist student veterans like Ryan who choose not to disclose their veteran status or any injuries that might affect their performance in a class. Indeed, this is precisely why administrators and instructors should move away from the medical model of disability toward a social model based in UD. Both students are making decisions that have social, political, and cultural consequences in addition to the obvious impacts on their education. A medical model of disability "inhibit[s] access and exacerbate[s] the stigmas associated with disability" (Wood 158), which might explain why some students like Ryan choose not to disclose anything that could cast them into one of the limited available narratives for student veterans.

Movement toward a social approach to disability and UDL can, in time, lessen the power of those reductive narratives and instead lead educators to an understanding of their students' disabilities that accounts for their socio-political contexts and, perhaps more importantly, gives them the power to resist pedagogical approaches that perpetuate the deficit model or the erasure of students' disabilities via standardized accommodations. Such an approach "requires critical analysis of a pedagogy based on lack as well as an affirmation of the composition instructor's expertise regarding pedagogical pathways for particular students with disabilities rather than simply leaving it to Veterans Affairs, disability resource centers, or medical professionals" (168). In 
other words, embracing a social model of disability would mean lessening the stigmas associated with all disabilities, making it less socially or politically risky for students to disclose their status and giving instructors more flexibility to develop individualized responses to students' needs.

\section{Conclusion}

My participants' statements about their experiences in college-level writing courses are so diverse it can be difficult to take a central message or "lesson" from them. As researchers-and as writing instructors reading the results of that research-it can be frustrating not to walk away with a concrete list of dos and don'ts, a "how-to" guide for teaching student veterans. Their statements are nevertheless telling as they not only point toward some key differences between academic and military approaches to writing and learning but also to several specific and sometimes divergent ways those differences might manifest in a student veteran's writing or in classroom interactions.

These students' reflections on their experiences writing for college after writing for the military highlight the significant and complicated role authority can play in a student veteran's transition from one context to the other. Their stories complicate assumptions that might be easy for educators to make; for instance, that the problem student veterans encounter is that they are moving from a rigidly hierarchical system to one without structure. In reality, colleges and universities are highly structured enterprises, but their organization and their means of distributing authority are less explicit and their nuances might be imperceptible to the unfamiliar student. For some student veterans, then, frustration may result from recognizing that there are hierarchies 
of authority at work but not intuitively understanding how they work or how they compare to military structures. Similarly, some of their remarks further underscore my conclusion in the previous chapter that differences in the style of instruction can be as influential as differences in styles of writing. When an instructor's goals for an assignment or the class as a whole were left unstated that tended to elicit more anxiety and resistance than situations where participants described explicit course expectations and clear understandings of an instructor's approach.

Concerns about authority and autonomy also permeate Chris and Ryan's stories and suggest that narrow definitions of PTSD and TBI and unifocal approaches to addressing student veterans' needs are simply not adequate. Rather, student veterans' presence in writing classrooms of all levels presents instructors and administrators with an opportunity to reconsider, as Ann Shivers-McNair asks, what more can be done to turn "tur[n] academic checkpoints into points of access" (234). Put another way, their experiences demonstrate the myriad potential advantages to moving toward an educational model of access rather than accommodation. Designing both courses and physical spaces that are more inclusive could ease students' anxieties about disclosing difference and encountering associated stigmas, granting them more authority over when and how they identify in particular ways and opening new avenues for educational achievement.

Moreover, the commonalities between student veterans and other student populations like non-traditional students and those with disabilities can 1) foster connections to other bodies of scholarship that might usefully inform pedagogical practice and 2) further incentivize pedagogical evolution that makes writing classrooms 
more accessible for all students, not just student veterans. These students' narratives suggest that rather than looking for a concrete set of pedagogical guidelines, the aim should be to provide a new framework for evaluating both course design and classroom attitudes to the benefit of all students — not just student veterans. 


\section{CHAPTER FIVE: CONCLUSION}

This dissertation makes several key contributions to our understanding of particular military literacies and forms of military literacy sponsorship as well as to an already growing body of research about student veterans' experiences when they enter into higher education settings. This chapter will offer a discussion of the local implications of this study, its contributions to both Veterans Studies and Literacy Studies, and its limitations. The chapter concludes with recommended avenues for future research.

\section{Veterans at the University of Louisville}

As discussed in Chapter Four, this study reinforced some common findings from other studies with student veterans (e.g., that they are often frustrated by their young, civilian classmates; that they may struggle to see the "real world value" of activities/assignments; and that they face complicated decisions when it comes to disclosing or concealing their veteran or disability status). My participants' concerns about authority and navigating opaque academic social systems are also reflected in some of the existing research (Bonar and Domenici; Mallory and Downs; Hadlock and Doe). Considered within the context of this specific institution, however, this study also sheds light on a few key issues regarding veterans at $U$ of $L$. 
First, my participants' descriptions of their academic and social experiences suggest low rates of interest in veteran-specific activities and services on campus. ${ }^{21}$ Of the nine participants, only Chris was actively involved with veteran-related initiatives on campus and vocal about his veteran status. ${ }^{22}$ The other participants' reasons for not being more involved varied; Mark said that he tried to attend things when he had time because he knew events would not continue to be offered if no one attended them, but he had too many family obligations to do so often. Braden, on the other hand, cited his lack of interest in being associated with the military any longer. Not having seen combat, he did not consider himself a "veteran" and although he spent four years in the Army, he felt he had his "own core identity and beliefs and [they were] not affected by being a student or being a veteran necessarily." Additionally, none of my participants were taking part in the REACH mentoring program designed for student veterans (mentioned in Chapter Two). When I asked about it, few of them even knew it existed. Braden specifically remarked that he tended to delete any e-mails that appeared to be sent campus wide or to all veterans on campus, essentially considering them "spam."

Generally speaking, my participants also refrained from engaging with most academic support services on campus. Three participants (Jackson, Alex, and Braden) reported using REACH tutoring occasionally and Chris had visited the University Writing Center, but by and large they did not seek additional support. To some extent, I think this is due to the fact that they were all generally faring well in their coursework (or so they told me) and did not feel like they "needed help.” However, Jackson's admission

\footnotetext{
${ }^{21}$ This lack of interest was confirmed anecdotally in conversations with university staff and faculty who remarked on low attendance at veteran-focused events.

${ }^{22}$ Right about the time of our interviews, for instance, he had a letter to the editor published in the campus newspaper about his frustration with seeing "fake" service dogs on campus.
} 
that he was concerned about the research paper coming up in his writing class because he did not know enough about how to access the library's resources suggests that even when the need does arise, student veterans on this campus may not be sure where to look for assistance. While this does not necessarily make student veterans different from other students on campus, it does indicate that outreach targeted at them is not as effective as it could be.

I contend that together, the lack of interest in veteran-related events and programs and their infrequent engagement with academic support services point toward two key implications I see for student veterans at U of L specifically, and perhaps student veterans more broadly:

1) Social groups, campus initiatives, and support programs designed for student veterans may not be effective because many student veterans no longer want to be affiliated with a military identity once they become students.

2) The types of programs or services being offered simply may not appeal to large portions of student veterans on campus and/or may not be adequately addressing their unique needs. Put another way, educators/administrators and student veterans may be defining "support" differently.

3) The methods commonly used to reach out to student veterans to make them aware of campus resources may be ineffective (e.g., e-mail blasts). Combined with uncertainty about navigating university structures and services independently, this could account for low uptake of available resources. 
These findings make it clear that student veteran support services on campus would benefit from an intensive review of their offerings and their approaches to reaching out to student veterans. Moreover, in order for a revision of these programs to be effective it would need to be based on an updated, more thorough understanding of the perspectives of student veterans on campus. Therefore, I contend that significant research is still needed regarding the needs and desires of student veterans at $\mathrm{U}$ of $\mathrm{L}$.

\section{Implications for Veterans Studies Research and Rhetoric and Composition}

Military Literacy Sponsorship as Collaborative Apprenticeship: One of the most significant implications of this project is that the particular style of literacy sponsorship my participants described is collaborative apprenticeship relationship. By looking closely at the social and instructional relationships formed between participants and their superiors in the process of learning new forms of writing, this project contributes to the body of research that sheds light on the dynamics of literacy sponsorship in workplace settings. The unique value of this dissertation's discussion of literacy sponsorship is in its focus on the everyday interactions of members of the military and their superiors and subordinates that are also critical points of military literacy acquisition.

Additionally, I demonstrate that this collaborative apprenticeship relationship reflects the realities of shared authorship, labor, and responsibility in the military. And how, more than simply imparting a particular writing style or series of regulations onto their subordinates, sponsors frequently enact intensive pedagogical strategies and model complicated rhetorical practices. This approach to literacy instruction can have a significant impact not only on how sponsored individuals write for the military, but also 
how they will eventually teach others to write for the military and how they will expect writing instruction to happen in situations outside the military. As such, these findings also provide a useful framework for exploring how collaborative apprenticeship models of literacy sponsorship might operate in other under-researched workplace settings and for investigating their pedagogical purposes and potential long-term influence on students' literacy practices in higher education.

Reframing Existing Literacies: Offering a more detailed picture of these particular forms of military literacy sponsorship also contributes to the field's existing knowledge about the range of writing-related experiences student veterans might have had before entering a college classroom and further complicates the "novice-to-expert" narrative of student learning. My analysis provides useful information for instructors who wish to better understand the experiences student veterans may bring to bear in the classroom; however, it is even more useful insofar as it can be used as a basis for explicitly addressing some student veterans' unique expectations and needs. For instance, armed with this information, instructors might find it easier to recognize student veterans who would benefit from more one-on-one instruction or modeling and (perhaps) encourage them to visit more during office hours or to take advantage of individual tutoring resources (whether they are offered in writing centers or elsewhere).

Additionally, a more nuanced understanding of military literacy practices, like that presented in Chapter Three, can also facilitate opportunities for helping student veterans reframe their experiences and employ their skills into new academic settings. Passing documents up the chain of command for feedback and then revising them is not altogether unlike a common peer review activity. The situations are far from identical; the 
power dynamics between peers are vastly different from the power dynamics between superiors and subordinates in the military and the types of concerns that should be addressed (and to what degree) in the review of a peer's work would also have to change ${ }^{23}$. However, comparing the two types of review activities as a starting point could demonstrate to student veterans that their military experiences have value in academic contexts and that, in the case of this particular activity, they already have at least some understanding of its role in the writing process and its potential benefits and pitfalls. In this sense, through this project's examination of both literacy sponsorship in the military and participants' writing experiences in college, I also contribute to ongoing discussions about pedagogical strategies for supporting student veteran success by offering some specific connections that can be made between military and academic literacy practices.

Reframing Resistance: Another way in which this study contributes to larger discussions of the influence of existing literacies on academic experiences is by exploring the roots of the participants' anxieties about issues like "correctness" and "mastery." As I explained in Chapter Four, several participants expressed a desire to master some aspect of academic writing (including grammar and APA or MLA style), some remarked that they wished instructors would lay out more explicit expectations for assignments, and one even claimed that the key to college writing is figuring out what an instructor wants to hear and saying simply that. I have already suggested that we might reconsider these comments in light of the assertion made in Chapter Three that in the military, mastery over specific forms of writing can represent one's authority in a given situation or even open doors to new forms of power. From this angle, we can see how an emphasis on

\footnotetext{
${ }^{23}$ Particularly in light of participants' comments about critiques of their writing in the military being overwhelming in number and often focused on surface-level issues.
} 
"correctness" and "mastery" in academic writing may reflect the desire for a familiar way of demonstrating authority, asserting power, or meeting certain benchmarks of success.

This is a useful perspective not only for understanding why student veterans might seem preoccupied by correctness and mastery in academic writing, but also why some student veterans might resist open-ended writing assignments or situations where they are being asked to consider an issue from multiple perspectives. Indeed, casting these behaviors simply as resistance to critical inquiry and staunch adherence to dualistic thinking (e.g., right or wrong, all or nothing) completely would mean overlooking the sophisticated kinds of thinking and writing these participants described having done in the military. Instead, I argue that we can understand this resistance as the result of a history of situations where reaching the "correct" answer involved serious material stakes - whether in terms of one's social power or in terms of loss of life or costly resources.

To that end, this study also contributes to our understanding of the potential influence of other kinds of workplace literacies on student learning, as the stakes associated with particular forms of inquiry and writing in the workplace can clearly have a lasting effect on an individual's literacy practices. One of the most direct translations of this principle across student populations would be recognizing similar resistance to openended assignments from other students and, rather than pushing back against it, having an explicit conversation about the differences in purpose, expectations, and stakes of the different epistemologies or styles of writing. This would be useful to all students and ultimately falls in line with other common goals of writing courses, such as investigating issues of purpose, audience, and genre across a variety of discourse communities. The 
key takeaway of this approach is that the full range of students' workplace and extracurricular literacies could be featured points of comparison in the writing classroom, potentially helping students develop strategies for moving between and among those literacies and facilitating greater knowledge transfer.

\section{Limitations}

Some of the most significant limitations of this study stem from the number and type of participants that I was able to recruit. Despite the fact that the student veteran population at $\mathrm{U}$ of $\mathrm{L}$ is rather large (at least 932) and at least somewhat diverse in terms of gender and race ${ }^{24}$, I was only able to interview nine men, eight of whom were white. Therefore, the demographics of my participants are not representative of either the student veteran population at $\mathrm{U}$ of $\mathrm{L}$ or the military as a whole. Ultimately, this limits the extent to which I can make broad claims about the experience of learning to write in the military, the realities of being a student veteran at $\mathrm{U}$ of $\mathrm{L}$, or the potential influence of race or gender in either context.

Moreover, because all of the participants were enlisted, this study is narrowly focused on a very specific type of military literacy sponsorship that occurred only in the professional-yet-informal situations described. While I suspect that similar forms of sponsorship take place even in more formalized settings like ROTC programs and military schools, those settings were not within the purview of this study. There are, of course, benefits to this narrow scope; by focusing on a particular type of literacy sponsorship I am able to give a much more rich description of the relationship between sponsor and sponsored, the associated power dynamics, and the teaching strategies

\footnotetext{
${ }^{24}$ See footnote in Chapter Two regarding the demographics of the first-year cohort of student veterans.
} 
espoused. This is particularly true due to the uniformity of my participants' reflections. Nevertheless, the narrow focus of this inquiry also puts constraints on any claims I could make about military literacies and military literacy sponsorship more broadly, particularly those established in formal classroom spaces and manuals, for example.

In a similar sense, this study is also limited by the fact that the participants were all $\mathrm{U}$ of $\mathrm{L}$ students. Thus, student concerns about the styles of writing being assigned in their courses, the resources available to them, and the attitudes of their classmates and instructors are in some ways all the product of this particular research site. While some of their concerns are reflected in the existing body of research (e.g., working with younger students (Elliott, Gonzalez, and Larsen), resisting open-ended writing situations (Leonhardy; Mallory and Downs; Morrow and Hart), they may be reflected to greater or lesser degrees at other institutions with, for instance, fewer student veterans; more veterans in faculty or administrative positions; more staff support in the office dedicated to student veteran needs; or more robust student veteran participation in campus clubs (e.g., SVA) or activities.

\section{Suggested Avenues for Future Research}

One avenue for future research in this area is to complete more in-depth investigations of military writing instruction and military writing styles, especially with an emphasis on the connections or tensions between those styles and what is common in college writing contexts. Although some research has been done in this area (e.g., Anson and Neely's exploration of citation practices and conceptions of intellectual property in the Army), there seems to be very little in the way of recent rhetorical examinations of 
the writing styles characteristic of each of the military branches and even less (if anything at all) about the specifics of military writing instruction in formal or informal spaces. This work could be especially useful in two ways. The first is fostering a better understanding of military writing among college writing professionals. In doing so, we can be better prepared to recognize the strengths student veterans bring into the classroom and to incorporate or be responsive to those experiences in the classroom. The second, closely-related benefit is that we would be more prepared to facilitate explicit conversations with student veterans about the differences and similarities they will encounter as they engage with new academic literacies and to offer concrete strategies for productively transferring their skills into new rhetorical contexts. Thus, the field of Rhetoric and Composition can contribute to a better understanding of student veterans and the paths and barriers to success they encounter by amassing more rich, qualitative data about

1) the literacy practices student veterans carry with them from the military into the classroom and

2) the ways student veterans learn to adapt (or not to adapt) their existing literacies to academic writing contexts.

Future research in Veterans Studies within Rhetoric and Composition would also benefit from more longitudinal observations of student veterans as they navigate their college/university experience. The previously-mentioned National Veteran Education Success Tracker (NVEST) report (2017) is one version of this type of study in that it uses nationwide data from the past nine years to illustrate the educational patterns of Post-9/11 GI Bill veterans. The scale of their data makes it possible to track factors like degree 
completion and persistence, numbers and types of degrees earned, and patterns in the types of institutions student veterans enroll in. Their study revealed promising trends more or less across the board, suggesting that student veterans are-in some ways-outpacing and out-performing their traditional counterparts. Their quantitative, data-driven approach helps make a compelling case for continuing GI Bill benefits and against the assumption that student veterans struggle in college, but it only reveals one element of the student veteran experience.

To complement big-picture approaches to research on student veterans, the field needs more in-depth investigations of the nuances of student veteran success; this could include the impact of a student veteran's: educational background prior to joining the military, specific military training/specialty, service-related physical or psychological injuries, family or workplace responsibilities, and continued affiliation with (or distancing from) the military. Similarly, there is a need for research on the impacts of existing veteran-related initiatives on college campuses. Much like NVEST, programs like the Military Times "Best for Vets" rankings only provide a numerical snapshot of a college or university's ability to support student veteran success and it is even further limited by the fact that it is based primarily on survey responses from administrators rather than feedback from student veterans themselves. In some ways, our field may be particularly well-suited for such research in settings like writing centers; however, we can also employ critical frameworks like literacy sponsorship to pursue similar lines of inquiry in a wide range of veteran-serving campus settings in order to investigate the extent to which student veterans are being granted access to the full benefits of higher education and provided adequate support in their educational pursuits. 
Moreover, because so much of our field is dedicated to understanding how human experience is mediated through language, researchers in Rhetoric and Composition are also well-positioned to investigate other aspects of student veterans' experiences through qualitative and rhetorical lenses, such as

1) the reasons some student veterans choose to readily and openly self-identify while others resist being identified as a veteran

2) the reasons a student veteran may choose to disclose or conceal a servicerelated physical or psychological injury

3) the ways student veterans make sense of and navigate academic spaces (e.g., assignment instructions, access to support services, procedures for addressing grievances)

4) the ways student veterans perceive degrees of "veteran-friendliness." 25

Finally, there is much more work to be done in training instructors, faculty, and administrators to work alongside student veterans and support them in and out of the classroom. In March 2015, the Conference on College Composition and Communication published its position statement on working with student veterans; in it, they advocate for moving toward and assets-based approach to understanding student veterans and outline some special considerations writing faculty and administrators might make on their behalf. Hart and Thompson have also covered some of this ground by making recommendations like the inclusion of a syllabus statement aimed at student veterans. Similarly, Doe and Langstraat (2016) published a detailed account of the workshops they

\footnotetext{
${ }^{25}$ This could be an especially important course of study as it could complement or challenge the factors used by publications like Military Times to determine a university's veteran-friendly designation.
} 
have designed and implemented to train instructors in the English Department at Colorado State University on working with student veterans. Together, these documents are a solid starting point for educators interested in better serving student veterans, but the current research is by no means an exhaustive discussion of the "best practices" for working with student veterans.

Continuing the push toward even more nuanced understandings of veterans' assets and needs in the writing classroom should absolutely be a primary focus in the coming years. However, I believe there is an even larger imperative that also needs to be addressed, which is finding ways to advocate for those "best practices" beyond our own disciplinary boundaries. Discussions with instructors and administrators from writing programs across the country at the $2017 \mathrm{CCCC}$ - particularly at veteran and militaryrelated panels and at the meeting of the Writing with Former, Future, and Current Members of the Military Standing Group — make it clear that the vast majority of veteranrelated research and programmatic or curricular development (especially as it pertains to supporting student veteran success pedagogically) is happening within the walls of English and Writing departments. The looming question for researchers and practitioners of writing is how we can establish sustainable interdisciplinary relationships that facilitate the transfer of our strategies for supporting student veterans into other classrooms, departments, and even campus-wide contexts.

The argument can be made that writing courses (especially first-year writing courses) can have considerable influence on student veterans' experiences due to features like their (typically) small class sizes and the personal, potentially-emotional nature of writing. In this light, the impact of our efforts to better understand and serve student 
veterans almost certainly have a tremendous impact in their own right. Nevertheless, the positive impact of this work would grow exponentially if it were augmented by the insights of other educators and transformed into a collaborative and institutional approach to fostering student veteran success in and beyond the writing classroom. 


\section{REFERENCES}

Ackerman, Robert, David DiRamio, and Regina L. Garza Mitchell. "Transitions: Combat Veterans As College Students." New Directions for Student Services 126 (2009): $5-14$

Alex. Personal Interview. 11 Feb. 2016.

Altschuler, Glenn C. and Stuart M. Blumin. The GI Bill: A New Deal for Veterans. Oxford UP, 2009.

Anson, Chris and Jessie L. Moore. Critical Transitions: Writing and the Question of Transfer. The WAC Clearinghouse, 2016, wac.colostate.edu/books/ ansonmoore. Accessed 6 April 2017.

Anson, Chris and Shawn Neely. "The Army and the Academy as Textual Communities: Exploring Mismatches in the Concepts of Attribution, Appropriation, and Shared Goals." Kairos: A Journal of Rhetoric, Technology, and Pedagogy, vol. 14, no. 3, 2010. kairos.technorhetoric.net/14.3/topoi/anson-neely.

Barton, David and Mary Hamilton. "Literacy, Reification and the Dynamics of Social Interaction." Beyond Communities of Practice: Language, Power, and Social Context, edited by David Barton and Karin Tusting, Cambridge UP, 2005, 14-35.

---. Local Literacies. Routledge Linguistics Classics, 2012.

Barton, David, Mary Hamilton, and Roz Ivanič. Eds. Situated Literacies: Reading and Writing in Context, Routledge, 2000. 
Barton, David and Karin Tusting. "Introduction." Beyond Communities of Practice:

Language, Power, and Social Context, edited by David Barton and Karin Tusting, Cambridge UP, 2005. 1-13.

Beaufort, Anne. Writing in the Real World: Making the Transition from School to Work. Teachers College P, 1999.

Bender, Ashley. A Few Good Men and Women: The Rhetorical Constitution of Military Personnel Identity. Dissertation. University of Louisville, 2015. Electronic Theses and Dissertations. Paper 2094. doi-org.echo.louisville.edu/10.18297/ etd/2094.

Bonar, Ted and Paula Domenici. "Counseling and Connecting with the Military Undergraduate: The Intersection of Military Service and University Life.”Journal of College Student Psychotherapy vol. 25, no. 3, 2011, pp. 204-219. EBSCOHost, doi: $10.1080 / 87568225.2011 .581925$.

Brandt, Deborah. "Drafting U.S. Literacy." College English vol. 65, no. 5, 2004, pp. 485502. JSTOR, www.jstor.org/stable/4140731.

---. Literacy and Learning. Jossey Bass, 2009.

---. Literacy in American Lives. Cambridge University Press, 2001.

---. "Sponsors of Literacy." College Composition and Communication, vol. 49, no. 2 , 1998, pp. 165-185. JSTOR, www.jstor.org/stable/358929.

--- and Katie Clinton. "Limits of the Local: Explaining Perspectives on Literacy as a Social Practice." Journal of Literacy Research, vol. 34, no. 3, pp. 337-356. Sage Journals, doi: 10.1207/s15548430jlr3403_4. 
Braden. Personal Interview. 16 Oct. 2015.

---. Personal Interview. 2 Dec. 2015.

Braswell, Sean M. "War Stories: 'Truth' and Particulars." War, Literature \& the Arts: An International Journal of the Humanities vol. 11, no. 2, 1999, p. 148-156. EBSCOhost, search.ebscohost.com/login.aspx?direct=true\&db=a9h\&AN= 6074243\&site=ehost-live.

Bruffee, Kenneth. "Collaborative Learning and the 'Conversation of Mankind." The Norton Book of Composition Studies, edited by Susan Miller, W. W. Norton \& Company, 2009, 545-562.

---. Collaborative Learning: Higher Education, Interdependence, and the Authority of Knowledge, 2nd ed., The Johns Hopkins UP, 1999.

---. "The Art of Collaborative Learning: Making the Most of Knowledgeable Peers." Change, vol. 19, no. 2, 1987, 42-27. EBSCOHost, issn: 0009-1383.

Burdick, Melanie. "Grading the War Story." Teaching English in a Time of War, a special issue of Teaching English in the Two-Year College, vol. 36, no. 4, 2009, 353-4. www.ncte.org.echo.louisville.edu/library/NCTEFiles/ Resources/Journals/TETYC/TE0364/TETYC0364Grading.pdf .

Cate, Chris, Jared Lyon, James Schmeling, and Barret Y. Bogue. National Veteran Education Success Tracker: A Report on the Academic Success of Student Veterans Using the Post-9/11 GI Bill. Student Veterans of America, Washington, D.C., 2017, nvest.studentveterans.org/wp-content/uploads/2017/03/NVESTReport_FINAL.pdf. 
Ching, Kory Lawson. "Apprenticeship in the Instructor-Led Peer Conference." Composition Studies, vol. 39, no. 2, 2011, pp. 101-119. JSTOR, http://www.jstor.org/stable/compstud.39.2.0101.

Chiseri-Strater, Elizabeth. Academic Literacies: The Public and Private Discourse of University Students. Heinemann, 1991.

Chris. Personal Interview. 27 Oct. 2015.

---. Personal Interview. 11 Jan. 2016.

Cleary, Michelle Navarre and Kathryn Wozniak. "Veterans as Adult Learners in Composition Courses." Veterans and Writing, a special issue of Composition Forum, vol. 28, 2013, compositionforum.com/issue/28/adult-learners.php. Conference on College Composition and Communication. "Student Veterans in the College Composition Classroom: Realizing Their Strengths and Assessing their Needs." NCTE, www.ncte.org/cccc/resources/positions/student-veterans.

Corley, Liam. "Reconsiderations: 'Brave Words': Rehabilitating the Veteran-Writer." College English vol. 74, no. 4, 2012, pp. 351-365. JSTOR, www.jstor.org/stable/23212905.

"VETSTART-Entrepreneurship Program for Veterans." University of Louisville, business.louisville.edu/eship/vetstart-entrepreneurship-program-for-veterans. Accessed 3 March 2017.

Dalton, Kelly Singleton. From Combat to Composition: Meeting the Needs of Military Veterans through Postsecondary Writing Pedagogy. Master's Thesis. Georgetown University, 2010. 
De La Ysla, Linda S. "Faculty as First Responders: Willing but Unprepared." Generation Vet: Composition, Student-Veterans, and the Post-9/11 University, edited by Sue Doe and Lisa Langstraat, Colorado State UP, 2014, 95-118.

DeMott, Benjamin. “Mina Shaughnessy: Meeting Challenges.” Nation, vol. 227, no. 20, 1978. EBSCOHost, search.ebscohost.com.echo.louisville.edu/ login.aspx direct $=$ true $\& d b=u l h \& A N=11300773$.

Derek. Personal Interview. 28 Oct. 2015.

Devitt, Amy. “Transferability and Genres.” The Locations of Composition, edited by Christopher J. Keller and Christian R. Weisser. State University of New York Press, 2007.

DiRamio, David and Kathryn Jarvis. "Veterans in Higher Education: When Johnny and Jane Come Marching to Campus.” ASHE Higher Education Report vol. 37, no. 3, 2011, pp. 1-144.

Doe, Sue and William W. Doe. "Residence Time and Military Workplace Literacies." Veterans and Writing, a special issue of Composition Forum, vol. 28, 2013. compositionforum.com/issue/28/residence-time.php.

Doe, Sue and Lisa Langstraat. "Faculty Development Workshops with Student-Vet Participants: Seizing the Induction Possibilities.” Veterans' Writing, a special issue of Reflections: a Journal of Public Rhetoric, Civic Writing, and Service Learning vol. 16, no. 2, 2016, pp. 151-184. reflectionsjournal.net.

---. "Introduction." Generation Vet: Composition, Student-Veterans, and the Post-9/11 University, edited by Sue Doe and Lisa Langstraat, Colorado State UP, 2014, 130. 
Drew, David E. and John A. Creager. "The Vietnam-era Veteran Enters College.” ACE Research Reports vol. 7, no. 4, 1972, pp. 1-58. ERIC, eric.ed.gov/?id=ED072744. Elliott, Marta, Carlene Gonzalez and Barbara Larsen. "U.S. Military Veterans Transition to College: Combat, PTSD, and Alienation on Campus.” Journal Of Student Affairs Research And Practice, vol. 48, no. 3, 2011, pp. 279-296. Taylor and Francis Online, doi:10.2202/1949-6605.6293.

"English for Ex-Service Personnel: A Survey Conducted by 'College English."” College English, vol. 6, no. 4, 1945, pp. 206-212. JSTOR, www.jstor.org/stable/370882.

"Fact Sheets." National Veteran Education Success Tracker: A Report on the Academic Success of Student Veterans Using the Post-9/11 GI Bill. Student Veterans of America, Washington, D.C., 2017, nvest.studentveterans.org/wpcontent/uploads/2017/02/NVEST_Factsheets.pdf.

Fenwick, Tara and Richard Edwards. Actor Network Theory in Education. Routledge, 2010.

Frydll, Kathleen J. The GI Bill. Cambridge UP, 2009.

George. Personal Interview. 3 March 2016.

Gere, Anne Ruggles. “Kitchen Tables and Rented Rooms: The Extracurricular of Composition." Literacy: A Critical Sourcebook, edited by Ellen Cushman et. al., Bedford/St. Martin’s, 2001.

Goldblatt, Eli. Because We Live Here: Sponsoring Literacy Beyond the College Curriculum. Hampton Press, 2007.

Gregory, Eve and Ann Williams. City Literacies: Learning to Read across Generations and Cultures. Routledge, 2000. 
Gregg, Gary. “A Letter from the SBS Director.” University of Louisville, louisville.edu/ mcconnellcenter/civics/army/letter-from-the-director. Accessed 17 March 2017.

Grohowski, Mariana. "Enacting UDL: Encouraging Inclusivity for Student Veterans."

Thomas R. Watson Conference, Oct. 2014. Conference presentation handout.

Guerra, Juan. "Out of the Valley: Transcultural Repositioning as a Rhetorical Practice in Ethnographic Research and Other Aspects of Daily Life." Reframing Sociocultural Research on Literacy, edited by Cynthia Lewis, Patricia E. Enesco, and Elizabeth B. Moje, Routledge, 2007, 137-162.

Hadley, Loren S. "Scholastic Adjustment Problems of the Returning Veterans." Educational Research Bulletin, vol. 24, no. 4, 1945, pp. 87-92. JSTOR, www.jstor.org/stable/1474186.

Hadlock, Erin and Sue Doe. 'Not Just 'Yes Sir, No Sir': How Genre and Agency Interact in Student-Veteran Writing." Generation Vet: Composition, Student-Veterans, and the Post- 9/11 University, edited by Sue Doe and Lisa Langstraat. Colorado State UP, 2014, 73-94.

Handley, Derek G. "Steal Veterans and Citizenship Pedagogy in the First Year Writing Classroom." Veterans'Writing, a special issue of Reflections: a Journal of Public Rhetoric, Civic Writing, and Service Learning, vol. 16, no. 2, 2016, pp. 106-127. reflectionsjournal.net.

Harris, Joseph. "Beyond Community: From the Social to the Material." Journal of Basic Writing, vol. 20, no. 2, 2001, pp. 3-15. JSTOR, www.jstor.org/stable/ 43443740. 
---. "Negotiating the Contact Zone." Journal of Basic Writing, vol. 14, no. 1, 1995, pp. 27-42. JSTOR, www.jstor.org/stable/43443647.

---. "The Idea of Community in the Study of Writing." College Composition and Communication, vol. 40, no. 1, 1989, pp. 11-22. JSTOR, www.jstor.org/ stable/358177.

Hamrick, Florence A., and Corey B. Rumann. Called to Serve, edited by Florence A. Hamrick, and Corey B. Rumann, John Wiley \& Sons, Incorporated, 2012. ProQuest Ebook Central, ebookcentral.proquest.com.echo.louisville.edu/ lib/louisville/detail.action?docID=889423.

Hart, Alexis and Roger Thompson. "An Ethical Obligation: Promising Practices for Student Veterans in College Writing Classrooms." National Council of Teachers of English. NCTE, June 2013, www.ncte.org/library/NCTEFiles/Groups/CCCC/ AnEthicalObligation.pdf.

---. "Responding Responsibly to Veterans in the Writing Classroom: An Interview with Marilyn Valentino." Composition Forum, vol. 28, 2013, compositionforum. com/issue/28/valentino.php.

---. "Veterans in the Writing Classroom: Three Programmatic Approaches to Facilitate the Transition from Military to Higher Education." College Composition and Communication, vol. 68, no. 2, 2016, pp. 345-371. ProQuest Literature Online, gateway.proquest.com.echo.louisville.edu/openurl?ctx_ver=Z39.88.2003\&xri:pqil :res_ver $=0.2 \&$ res_id $=x r i: l i o n \& r f t$ id $=$ xri:lion:rec:criticism:R05485831\&rft.accou ntid $=14665$. 
---. "War, Trauma, and the Writing Classroom: A Response to Travis Martin's 'Combat in the Classroom."'Writing on the Edge, vol. 23, no. 2, 2013, pp. 37-47.

Heath, Shirley Brice. "Protean Shapes in Literacy Events: Ever Shifting Oral and Literate Traditions." Literacy: A Critical Sourcebook, edited by Ellen Cushman et. al., Bedford/St. Martin's, 2001.

Hinton, Corinne. "Front and Center: Marine Student-Veterans, Collaboration, and the Writing Center." Generation Vet: Composition, Student-Veterans, and the Post9/11 University, edited by Sue Doe and Lisa Langstraat. Colorado State UP, 2014, $257-281$

---. “'The Military Taught Me Something about Writing': How Student Veterans Complicate the Novice-to-Expert Continuum in First-Year Composition." Veterans and Writing, a special issue of Composition Forum, vol. 28, 2013, compositionforum.com/issue/ 28/novice-to-expert.php.

Holliday, Sylvia A. "Gladly Teach and Gladly Learn.” Teaching Writing in a Time of War a special issue of Teaching English in the Two-Year College, vol. 36, no. 4, 2009, pp. 368-378, www.ncte.org.echo.louisville.edu/library/NCTEFiles/ Resources/Journals/TETYC/TE0364/TETYC0364Gladly.pdf.

"How Accommodating to Veterans is the University of Louisville?" College Factual, www.collegefactual.com/colleges/university-of-louisville/. Accessed 29 March 2015.

Jackson. Personal Interview. 1 March 2016.

John. Personal Interview. 8 Feb. 2016. 
Keast, Darren. “A Class for Vets, Not by a Vet: Developing a Veteran-Friendly Composition Course at City College of San Francisco." Veterans and Writing, a special issue of Composition Forum, vol. 28, 2013, compositionforum.com/issue/ 28/class-for-vets.php.

Kelley, Bruce C., Justin M. Smith, and Ernetta L. Fox. Preparing Your Campus for Veterans' Success: An Integrated Approach to Facilitating the Transition and Persistence of Our Military Students. Stylus Publishing, 2013.

Kiely, Denis O. and Lisa Swift. "Casualties of War: Combat Trauma and the Return of the Combat Veteran." Teaching English in a Time of War, a special issue of Teaching English in the Two-Year College, vol. 36, no. 4, 2009, pp. 357-364, www.ncte.org.echo.louisville.edu/library/NCTEFiles/Resources/Journals/TETYC /TE0364/TETYC0364Casualties.pdf.

Kinloch, Valerie. "Suspicious Spatial Distinctions: Literacy Research with Students across School and Community Contexts.” Written Communication, vol. 26, no. 2, 2009, 154-182. Sage Journals, doi: 10.1177/0741088309332899.

Kirsch, Gesa and Joy Ritchie. "Beyond the Personal: Theorizing a Politics of Location in Composition Research.” Cross Talk in Comp Theory $2^{\text {nd }}$ Edition. Edited by Victor Villanueva, NCTE, 2003, 523-546.

---. "Ethics and the Future of Composition.” Lynn Z. Bloom, Donald A. Daiker, Edward M. White. Composition Studies in the New Millennium: Rereading the Past, Rewriting the Future, Southern Illinois UP, 2003, 129-141.

Knobel, Michele. Everyday Literacies: Students, Discourse, and Social Practice. Peter Lang Inc., International Academic Publishers, 1998. 
Lindquist, Julie. "Time to Grow Them: Practicing Slow Research in a Fast Field.” JAC, vol. 32, no. 3/4, 2012, pp. 645-666. JSTOR, www.jstor.org/stable/41709847.

Lettner-Rust, et. al. "Writing Beyond the Curriculum: Transition, Transfer, and Transformation.” Across the Disciplines, vol. 4, 2007, wac.colostate.edu/atd/ articles/lettnerrustetal2007.cfm. Accessed 28 March 2015.

Lewis, Isaiah. "U of L Shows Support for Veterans.” The Louisville Cardinal, 17 Nov. 2014, www.louisvillecardinal.com/2014/11/u-of-1-shows-support-for-veterans. Accessed 17 Nov. 2014.

Leonhardy, Galen. "Transformations: Working with Veterans in the Composition Classroom." Teaching English in a Time of War, a special issue of Teaching English in the Two-Year College, vol. 36, no. 4, 2009, pp. 339-352, www.ncte.org.echo.louisville.edu/library/NCTEFiles/Resources/Journals/ TETYC/TE0364/TETYC0364Transformations.pdf.

Lu, Min-Zhan. "Redefining the Legacy of Mina Shaughnessy: A Critique of the Politics of Linguistic Innocence.” Journal of Basic Writing vol. 10, no. 1, 1991, pp. 26-40.

---. "Redefining the Literate Self: The Politics of Critical Affirmation." College Composition and Communication vol. 51, no. 2, 1999, pp. 172-94. JSTOR, www.jstor.org/stable/359038. Accessed 19 April 2013.

Lytle, Susan S. "Living Literacy: Rethinking Development in Adulthood." Literacy: A Critical Sourcebook, edited by Ellen Cushman et. al., Bedford/St. Martin's, 2001. Madaus, Joseph W., Wayne K. Miller II, and Mary Lee Vance. "Veterans with Disabilities in Postsecondary Education." Journal of Postsecondary Education \& Disability, vol. 22, no.1, 2009, pp. 10-17. ERIC, eric.ed.gov/?id=EJ844247. 
Mallory, Angie and Doug Downs. "Uniform Meets Rhetoric: Excellence through Interaction." Generation Vet: Composition, Student-Veterans, and the Post-9/11 University, edited by Sue Doe and Lisa Langstraat. Colorado State UP, 2014. 5172.

Mapes, Aimee C. and Michael T. Hartley. "Re-Authoring Narratives: Reflective Writing with Veterans with Spinal Cord Injury." Veterans' Writing, a special issue of Reflections: a Journal of Public Rhetoric, Civic Writing, and Service Learning vol. 16, no. 2, 2016, pp. 61-82, reflectionsjournal.net.

Mark. Personal Interview. 28 Oct. 2015.

---. Personal Interview. 2 Dec. 2015.

Martin, Travis L. "Combat in the Classroom: A Writing and Healing Approach to Teaching Student Veterans.” Writing on the Edge vol. 22, no. 2, 2012, pp. 27-35. JSTOR, www.jstor.org/stable/43157456.

McDonagh, Edward C. "Veterans Challenge Higher Education: Not Insurmountable if Recognized." The Journal of Higher Education vol. 18, no. 3, 1947, pp. 149-52 and 169-70. JSTOR, www.jstor.org/stable/1975213.

McGregor, Bree and Lourdes Fernandez. "Writing Faculty on the Marine Corps Base: Building Strong Classroom Communities through Engagement and Advocacy." Veterans' Writing, a special issue of Reflections: a Journal of Public Rhetoric, Civic Writing, and Service Learning vol. 16, no. 2, 2016, pp. 129-150, reflectionsjournal.net.

Mettler, Suzanne. The GI Bill and the Making of the Greatest Generation. Oxford UP, 2007. 
Michaud, Michael. "The Reverse Commute: Adult Students and the Transition from Professional to Academic Literacy." Teaching English in the Two-Year College, vol 38, no. 3, 2011, pp. 244.57. ProQuest Literature Online, gateway.proquest. com.echo.louisville.edu/openurl?ctx_ver=Z39.88-2003\&xri:pqil:res_ver= 0.2\&res_id=xri:lion\&rft_id=xri:lion:rec:criticism:R04397513\&rft.accountid=146 65.

Military Times. "Best for Vets: Colleges 2017.” Military Times, 2016, bestforvets. militarytimes.com/2017-11-01/colleges/4-year.

---. “Methodology.” Military Times, 2016, www.militarytimes.com/colleges2017methodology.

Miller, Richard. "Fault Lines in the Contact Zone." College English vol. 36, no. 4, 1994, pp. 389-408. JSTOR, www.jstor.org/stable/378334. Accessed 19 April 2013.

Miller, Richard F. “Some Unexpected Results of College Military Programs.” College English, vol.6, no. 8, 1945, pp. 444-8. JSTOR,http://www.jstor.org/stable/ 370325 .

Morrow, Sean and D. Alexis Hart. "Veterans in College Writing Classes: Understanding and Embracing the Mutual Benefit." Generation Vet: Composition, StudentVeterans, and the Post-9/11 University, edited by Sue Doe and Lisa Langstraat. Colorado State UP, 2014. 31-50.

Myers, Greg. "Reality, Consensus, and Reform in the Rhetoric of Composition Teaching." Cross-Talk in Comp Theory: A Reader, edited by Victor Villanueva, NCTE, 2003. 
Newkirk, Thomas. "The Narrative Roots of the Case Study." Methods and Methodology in Composition Research, edited by Gesa Kirsch and Patricia M. Sullivan, Southern Illinois UP, 1992, 130-152.

NINDS. Traumatic Brain Injury: Hope through Research. National Institute of Health, National Institute of Neurological Disorders and Stroke. www.ninds.nih.gov/ disorders/tbi/tbi_htr.pdf.

O'Herrin, Elizabeth. "Enhancing Veteran Success In Higher Education." Peer Review, vol. 13, no. 1, 2011, pp. 15-18. EBSCOHost, ISSN: 15411389.

Orellana, Marjorie Faulstich. "Moving Words and Worlds: Reflections from the Middle." Reframing Sociocultural Research on Literacy, edited by Cynthia Lewis, Patricia E. Enesco, and Elizabeth B. Moje, Routledge, 2007, 123-136.

Paquette, et. al. "A Story Worth Telling: Sharing Stories and Impacting Lives in the Veterans' Book Group Project at Fort Benning.” Veterans' Writing, a special issue of Reflections: a Journal of Public Rhetoric, Civic Writing, and Service Learning vol. 16, no. 2, 2016, pp. 83-105, reflectionsjournal.net.

Patton, Michael Quinn. Qualitative Research \& Evaluation Methods. $3^{\text {rd }}$ ed., Sage Publications, 2002.

Pew Research Center. "War and Sacrifice in the Post-9/11 Era." Pew Research Center. 5 Oct. 2011. www.pewsocialtrends.org/2011/10/05/war-and-sacrifice-in-the-post911-era/\#. Accessed 3 March 2017.

"Profile." University of Louisville, louisville.edu/about/profile. Accessed 17 March 2017. 
"Report of the Special Committee of the National Association of State Universities to Study Post-War Educational Problems." Education for Victory vol. 2, no. 24, 1944, pp. 19-22.

Robertson, Liane, Kara Taczak and Kathleen Blake Yancey. "Notes Toward a Theory of Prior Knowledge and Its Role in College Composers' Transfer of Knowledge and Practice." Composition Forum, vol. 26, 2012, compositionforum.com/ issue/26/prior-knowledge-transfer.php. Accessed 28 March 2015.

Rogers, Priscilla S. and Jone Rymer. "Analytical Tools to Facilitate Transitions into New Writing Contexts: A Communicative Perspective.” Journal of Business Communication, vol. 38, no. 2, 2001, pp. 112-152. Sage Journals, doi: 10.1177/002194360103800201.

Rosenberg, Lauren. The Desire for Literacy: Writing in the Lives of Adult Learners. NCTE, 2015.

Rumann, Corey B. and Florence A. Hamrick. "Student Veterans in Transition: ReEnrolling after War Zone Deployments.” Journal of Higher Education, vol. 81, no. 4, 2010, pp. 431-58. Project MUSE, doi:10.1353/jhe.0.0103.

---. Marisa Rivera, and Ignacio Hernandez. "Student Veterans And Community Colleges." New Directions for Community Colleges 2011.155 (2011): 51-58.

Ryan. Personal Interview. 10 Feb. 2016.

Schell, Eileen. "Writing with Veterans in a Community Writing Group." Veterans and Writing, a special issue of Composition Forum, vol. 28, 2013, compositionforum. com/issue/28/writing-with-veterans.php. 
Schell, Eileen E. and Ivy Kleinbart. "'I Have to Speak Out: Writing with Veterans in a Community Writing Group." Generation Vet: Composition, Student-Veterans, and the Post-9/11 University, edited by Sue Doe and Lisa Langstraat. Boulder: Colorado State UP, 2014. 119-139.

---. "Introduction to the Special Issue on Veterans' Writing." Veterans' Writing, a special issue of Reflections: a Journal of Public Rhetoric, Civic Writing, and Service Learning, vol. 16, no. 2, 2016, pp. 3-17, reflectionsjournal.net.

Seidman, Irving. Interviewing as Qualitative Research: A Guide for Researchers in Education and the Social Sciences. Teachers College Press, 2005.

Selting, Bonnie. "The Value of Service Learning for Student-Veterans: Transitioning to Academic Cultures through Writing and Experiential Learning." Generation Vet: Composition, Student-Veterans, and the Post-9/11 University, edited by Sue Doe and Lisa Langstraat. Colorado State UP, 2014. 240-256.

Shaughnessy, Mina P. "Diving In: An Introduction to Basic Writing.” College Composition and Communication vol. 27, no. 3, 1976, pp. 234-9. EBSCOHost. MLA International Bibliography. Accessed 10 Sept. 2011.

---. Errors and Expectations: A Guide for the Teacher of Basic Writing. Oxford UP, 1977.

Sheridan, Mary P. and Jennifer Roswell. Design Literacies: Learning and Innovation in the Digital Age. Routledge, 2010.

Shivers-McNair, Ann. “A New Mission: Veteran-Led Learning Communities in the Basic 
Writing Classroom." Generation Vet: Composition, Student-Veterans, and the Post-9/11 University, edited by Sue Doe and Lisa Langstraat. Colorado State UP, 2014. 216-239.

Springsteen, Karen. “Closer to Home: Veterans' Workshops and the Materiality of Writing." Generation Vet: Composition, Student-Veterans, and the Post-9/11 University, edited by Sue Doe and Lisa Langstraat. Colorado State UP, 2014. 140155.

---. "Veterans Writing and a Rhetoric of Witnessing." Veterans' Writing, a special issue of Reflections: a Journal of Public Rhetoric, Civic Writing, and Service Learning vol. 16, no. 2, 2016, pp. 20-34, reflectionsjournal.net.

Street, Brian V. "At Last: Recent Applications of New Literacy Studies in Educational Contexts." Research in the Teaching of English vol. 39, no. 4, 2005, pp. 417-23. JSTOR, www.jstor.org/stable/40171646.

Stahl, Roger. Militainment Inc.: War, Media, and Popular Culture. Routledge, 2010.

Suid, Lawrence. Guts \& Glory: The Making of the American Military Image in Film. UP of Kentucky, 2002.

Sura, Thomas. "Articulating Veteran-Friendly: Preparing First-Year Writing Instructors to Work with Veterans." Veterans' Writing, a special issue of Reflections: a Journal of Public Rhetoric, Civic Writing, and Service Learning, vol. 16, no. 2, 2016, pp. 187-205, reflectionsjournal.net.

Thompson, Roger. "Recognizing Silence: Composition, Writing, and the Ethical Space for War." Generation Vet:Composition, Student-Veterans, and the Post-9/11 
University, edited by Sue Doe and Lisa Langstraat. Colorado State UP, 2014. 199215.

Trimbur, John. "Consensus and Difference in Collaborative Learning." College English, vol. 51, no. 6, 1989, pp. 602-616. JSTOR, www.jstor.org/stable/377955.

Tusting, Karin. "Language and Power in Communities of Practice.” Beyond Communities of Practice: Language, Power, and Social Context, edited by David Barton and Karin Tusting, Cambridge UP, 2005, 36-54.

Valentino, Marilyn J. "Rethinking the Fourth C: Call to Action." College Composition \& Communication vol. 62, no. 2, 2010, pp. 364-378. JSTOR, www.jstor.org/ stable/27917900. Accessed 23 Feb. 2011.

Wallace, Robert M. “Twenty-Two Anti-Tanks Mines Linked Together: The Effect of Student Stories on Classroom Dynamics.” Teaching English in a Time of War, a special issue of Teaching English in the Two-Year College, vol. 36, no. 4, 2009, pp. 365-67. ncte.org.echo.louisville.edu/library/NCTEFiles/Resources/ Journals/TETYC/TE0364/TETYC0364Twenty.pdf.

Watts, Marjorie. “Three Problems for Composition Classes.” English Journal vol. 33, no. 9, 1944, pp. 491-494. JSTOR, www.jstor.org/stable/806887.

Webb-Sunderhaus, Sara. "A Family Affair: Competing Sponsors of Literacy in Appalachian Students’ Lives.” Community Literacy Journal vol. 2, no. 1, 2005, 524. ERIC. Accessed 28 March 2015.

"Welcome U of L Military and Veteran Students." University of Louisville, louisville.edu/admissions/apply/transfer/veterans. Accessed 28 April 2017. 
Whitworth, Melissa. "Writing to Bear Witness." Veterans' Writing, a special issue of Reflections: a Journal of Public Rhetoric, Civic Writing, and Service Learning vol. 16, no. 2, 2016, pp. 35-60. reflectionsjournal.net.

Wood, Tara. "Signature Wounds: Marking and Medicalizing Post-9/11 Veterans." Generation Vet: Composition, Student-Veterans, and the Post-9/11 University, edited by Sue Doe and Lisa Langstraat. Colorado State UP, 2014. 156-173. 


\section{APPENDIX A: PARTICIPANT RECRUITMENT E-MAIL}

Dear students,

I would like to invite you to participate in a research study that I am conducting for my dissertation. This study is being sponsored by the Department of English at the University of Louisville under the guidance of Dr. Brenda Brueggemann.

I am interested in understanding more about military students and student veterans at $U$ of L. I plan to examine the strategies and resources that military students and student veterans learn to draw on when writing in the military and those they draw on when writing at the university level. I am inviting students who are currently enlisted in the military or who are retired from the military to participate in this study. I would like conduct a series of four short focus group meetings during the fall semester to discuss your experiences as a writer, any instances of successes or struggles with these experiences, and whether you feel that your past writing relates to or helps you with your writing in college.

Please note that this study is designed to reflect on and discuss your educational and writing experiences, not necessarily any combat or more general military experiences. I understand that some of you may not want to identify as a veteran or as military personnel while you're in school or may not see connections between your military experience and your goals as a student. Even so, this study is just as interested that perspective as any other and I encourage you to consider participating. Through this research, I hope to better understand how military students and student veterans transition into the kinds of writing they will do at the college level and how university faculty and staff can best support ALL types of first-year military students and student veterans.

This main study will take place between October and December 2015. There are two ways you can participate in this study:

1) You can complete this brief survey about your thoughts on education and writing (it should take approximately 5-10 minutes) and/or

2) You can participate in a focus group about your experiences in the military and as a student here at $U$ of L. (If you are interested in the focus group only, please email me directly.)

Your participation in either part of this study is completely voluntary. You can reach me by phone or email to further discuss the details of this study. 
Thank you for your time. I look forward to answering any questions you may have!

Sincerely,

Ashley Ludewig

Ph.D. Candidate in Rhetoric and Composition

University of Louisville

ashley.ludewig@louisville.edu

605-366-7323 


\section{Background:}

\section{APPENDIX B: INITIAL INTERVIEW QUESTIONS ${ }^{26}$}

Family history of military?

Family history of reading/writing?

Parents' educational background?

Significant other or spouse + educational background?

Other family who may have influenced thoughts about education and/or reading/writing?

\section{Military background:}

Why did you enlist?

What age did you enlist?

JROTC or anything like that?

What can you tell me about the work you did in the military?

\section{Reading and Writing in the Military:}

Did you have much experience writing in the military? If so, explain?

What kind of reading did you do?

\section{Your Semester So Far:}

How did you end up at U of L? What's your major?

Did you have any anxiety about starting college?

Do you feel welcome at $U$ of $L$ as a student veteran?

Is this your first semester of college courses (including online)?

Are you participating in the REACH mentorship program?

What classes are you taking?

How are they going?

What kind of writing are you doing?

How has that been going?

What's your writing process like?

Have you sought any kind of assistance with any writing? (Friend, professor, family member, writing center, web resources?

What kinds of writing projects do you have coming up? Are you worried about writing?

Is there anything you wish was different?

\section{Education/Reading and Writing More Generally--}

Thinking about previous educational experiences (like HS)...

How would you describe yourself as a learner?

${ }^{26}$ Adapted from Hinton, "Front and Center." 
How would you describe your learning style or process?

How would you describe yourself as a writer?

How do you see writing factoring into your future? Professionally or otherwise. 


\section{APPENDIX C: FOLLOW-UP INTERVIEW QUESTIONS}

How would you describe writing in the military?

Is there a particulars style of writing in the military (in your branch specifically, perhaps)? If so, how might that compare to the writing style preferred in college?

Did you have experiences with other forms of writing besides in English or did you do any multimedia work? How does that compare to your own preconceived notions about college writing or what you've done in college writing this semester or in the past?

What kind of criteria - yours, your instructor's, or the course's - are important for you to be successful in a college writing course or on writing assignments in other courses?

How would you describe your writing process? Has it changed at all over the course of the semester?

Have there been any particular individuals, services, or offices who/that you feel have impacted your experiences or abilities as a writer in college? If so, describe that impact.

Have you interacted with many veteran-related services on campus? Why or why not?

Were you at all anxious about returning to school?

Have there been any obstacles or challenges for you in moving from learning in the military to learning in college? If so, how have you approached/are you approaching those challenges?

What skills, attitudes, or behaviors that you learned in the military have you been able to apply in college? Have any of these been obstacles rather than helpers for you?

Have you had the opportunity to work in groups with other college students? How would you describe those experiences?

How would you describe yourself compared to your peers in your English classes?

Based on what you know about other veterans' experiences, would you describe yourself as being typical? 


\title{
CURRICULUM VITAE
}

\author{
Ashley Ludewig
}

\section{$\underline{\text { Education }}$}

University of Louisville, expected graduation: May 2017

$\mathrm{Ph}$.D. Candidate in Rhetoric and Composition

Dissertation: "The Military Meets the University: Understanding Literacy Practices and Patterns of Sponsorship among Military Students and Student Veterans," (Committee: Dr. Bronwyn Williams [Chair], Dr. Stephen Schneider, Dr. Susan Ryan, Dr. D. Alexis Hart).

Southern Illinois University-Carbondale, December 2012

M.A. English Studies, Specialization in Rhetoric and Composition

Thesis: "Fostering Learning Communities in the First-Year Composition Classroom: An Exploration of Group Conferencing as a Response Strategy" (Dr. Ronda L. Dively, Director).

\section{South Dakota State University, May 2010}

B.A. English, B.A. Spanish; Minor Professional Writing

Magna Cum Laude

\section{Research Interests}

Composition Pedagogy

Qualitative Research Methods
Writing Across the Curriculum/In the Disciplines

Writing Program and Center Administration

\section{Administrative Experience}

Assistant Director of Business Communication, University of Louisville, July 2016Present.

- Develop tools for program-wide assessment.

- Support faculty working to incorporate effective writing pedagogy and assessment into their curricula.

- Implement and manage software to coordinate student consultation appointments.

- Proof and provide feedback on student and faculty work including course assignments, grant applications, and articles for publication. 


\section{Teaching Experience}

\section{University of Louisville}

Business 301 (Business Communication), Fall 2016, Spring 2017

English 105 (Honor's Composition), Fall 2014

English 310 (Writing About Literature), Summer 2014

English 102 (Intermediate College Writing), Spring 2014, Spring 2015

English 101 (Introduction to College Writing), Summer 2013, Fall 2013

\section{Southern Illinois University-Carbondale}

Instructor, English 101 (Composition I), Fall 2010 and Fall 2011

Instructor, English 102 (Composition II), Spring 2011, Summer 2011 and Spring 2012

\section{Writing Center Experience}

\section{University of Louisville}

Dissertation Writing Retreat Consultant, University of Louisville, May 2016, May 2015

University Writing Center Tutor, University of Louisville, August 2014-June 2015

\section{$\underline{\text { Awards }}$}

University Fellowship, University of Louisville, School of Interdisciplinary and Graduate Studies, August 2015-May 2016 (\$20,000).

University Fellowship, University of Louisville, School of Interdisciplinary and Graduate Studies, August 2012-May 2013 (\$20,000).

\section{$\underline{\text { Presentations }}$}

\section{Refereed}

"Military and Academic Literacies: Challenging Boundaries and Binaries," Thomas R. Watson Conference, Louisville, KY, October 2016.

"Student Veterans in Composition Scholarship: Why the Rhetoric of Representation Matters," Cultural Rhetorics Conference East Lansing, MI, October 2016.

"The Military Meets the University: Understanding Literacy Practices and Patterns of Sponsorship among First-Year Military Students and Student Veterans," Conference on College Composition and Communication, Houston, TX.

"Student Veterans and Composition/Rhetoric: A Historical Perspective on the Generative Possibilities of the 'Crisis' of Changing Student Demographics," Western States Rhetoric and Literacy Conference, Reno, NV, November 2014. 
“"War Writing' and the Writing Classroom: Curricular Considerations for FYC after a Decade of Combat," The Thomas R. Watson Conference, Louisville, KY, October 2014.

“(Re)Investigating Writing Apprehension as a Placement Tool: A Qualitative Exploration of Writing Apprehension with First-Year, At-Risk Writers," Conference on College Composition and Communication, Las Vegas, NV, March 2013.

\section{Roundtables}

"How WPAs Can Build Capacity for Student Learning," (with Steven Bailey, Cathrine Hoekstra, Kuhio Walters, and Jeffrey Turner), Sponsored Panel for the Writing with Current, Former, and Future Members of the Military Standing Group, Conference on College Composition and Communication, Portland, OR, March 2017.

\section{Workshops}

"Using Core Competency Rubrics for Grading and Assessment," (3 hours, with Kristen Lucas, Jenna Haugen and Jacob Rawlins), Association of Business Communication Annual Conference, Albuquerque, NM, October 2016.

"Working Alongside Student Veterans," (1.5 hours with Ashly Bender) University of Louisville Composition Program, Louisville, KY, April 2013.

\section{Non-Refereed}

"War Writing in the Composition Classroom/Student Veterans and Literacy Sponsorship," Conference on College Composition and Communication Research Network Forum, Tampa, FL, March 2015.

"Exploring Group Conferencing in the First-Year Composition Classroom," Conference on College Composition and Communication Research Network Forum, St. Louis, MO, March 2012.

"Strategies for Supporting Underprepared Students in the Mainstream Composition Classroom," SIUC Graduate Student Conference, Carbondale, IL, April 2011.

\section{Professional Service}

\section{University of Louisville}

Composition Instructor Orientation Panel on Student Services, August 2015, August 2016

- Represented the Office of Military and Veteran Services.

- Provided suggestions for accommodating student veterans to new and continuing instructors. 
General Education Assessment, March 2016, May 2015, May 2014

- Assessed artifacts from Arts and Humanities, Oral Communication, and Written Communication courses in General Education to determine student progress toward General Education program learning objectives.

English Graduate Organization (EGO), President, August 2014-July 2016

- Designed and coordinated pedagogy and professional development workshops for English Department GTAs.

- Coordinated GTA participation in department-wide events and initiatives.

- Facilitated fundraising and charity events.

English Graduate Organization (EGO), Ph.D. Student Liaison, August 2013-July 2014

- Represented Ph.D. students' needs and interests on the EGO committee.

- Assisted with pedagogy and professional development workshops for English Department GTAs.

\section{Southern Illinois University-Carbondale}

Small Group Leader, English Department Pre-Semester Workshop, August 2011

- Trained new GTAs on the English 101 common syllabus.

- Trained new GTAs on introductory writing pedagogy practices, including designing assignments and rubrics, scaffolding student learning, and providing formative and summative feedback on student writing.

\section{Research Experience}

Instructor, "Proposal for Developing a Flex Syllabus Approach to Teaching At-Risk Students in Freshman Composition at SIUC" August 2011-May 2012. Pilot study funded by the Illinois Student Assistance Commission and Directed by Dr. Michael R. Molino, English Department Chair.

- Designed curriculum for at-risk students in the English 101-102 sequence using a stretch-syllabus approach.

- Taught one section of students in the stretch-syllabus program for the academic year.

- Compiled student learning and success data.

\section{Community Service}

Animal Protection Association, Jeffersonville, IN, October 2015-Present

- Compose quarterly newsletter about the shelter's fundraising events, community outreach programs, and needs (e.g. donations, volunteer support, professional services).

- Increase social media presence to foster community engagement and support.

- Volunteer weekly to care for animals housed at the shelter. 


\section{Completed Professional Development Sessions}

Celebration of Teaching and Learning Symposium, Delphi Center for Teaching and Learning, University of Louisville, February 2017.

"Digital Writing Matters//Matters of Digital Writing" led by Dr. Dánielle DeVoss, Thomas R. Watson Visiting Professor, Department of English, University of Louisville, November 2015.

"Safe Zone Training," led by the LGBT Center, University of Louisville, November 2015.

"Writing for Publication," led by Dr. Bronwyn Williams, Department of English, University of Louisville, October 2015.

“Creating Conversations about Diversity," led by Dr. Mordean Taylor-Archer, Vice Provost for Diversity and International Affairs; Brian Buford, Assistant Provost and Director of the LGBT Center; Tierny Bates, Director of the Cultural Center; Linda Rogers, Lecturer in the Arts and Sciences; University of Louisville, September 2015.

Digital Composition Colloquium, led by Dr. Brenda Brueggemann and Dr. Cynthia Selfe, University of Louisville, August 2015. Two-day workshop regarding multimodal and digital assignment design, instruction, and assessment.

\section{Professional Memberships}

National Council of Teachers of English, August 2012-Present.

Writing with Current, Former, and Future Members of the Military Standing Group Conference on College Composition and Communication, March 2016-Present.

Association of Business Communication, July 2016-Present. 